\title{
Neighbors Helping Neighbors
}

digitalresearch.bsu.edu/immersive-learning-showcase-2021/exhibits/show/neighbors-helping-neighbors

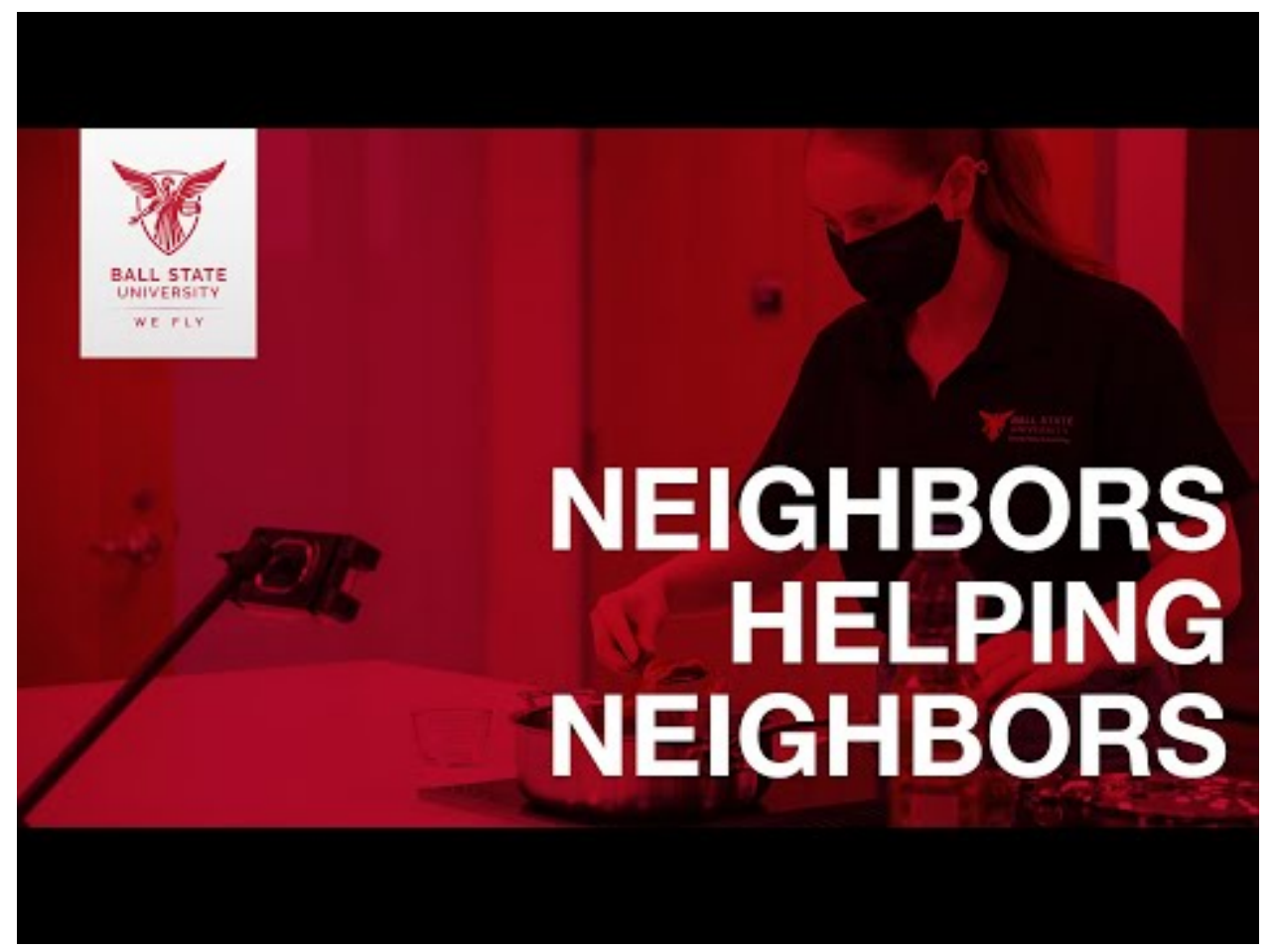

Watch Video At: https://youtu.be/-ODtXz7X 7 gg

To sensitize students to the depth and breadth of food insecurity in our community, senior dietetics students volunteered at several Tailgate events to see firsthand the 'faces of hunger' in our community. There, in the freezing cold of January and February, they helped load box after box of food into people's cares. Next, each student chose two healthy, simple recipes -one that used a frequently distributed food item from the tailgate and one that included a plant-based protein source. The students made videos that demonstrated how to prepare the recipe, created a recipe sheet that included the cost and a fun nutrition fact, and created a coloring page, word search, cross word puzzle, etc., to provide a bit of nutrition education. The materials will be placed on the Second Harvest Facebook page for easy access. Throughout the experience, the students were exposed to resources they can use as dietitians when they work with food insecure individuals and families wherever they live and work. 


\section{Project Overview with Hyperlinks to Videos and Recipes}

digitalresearch.bsu.edu/immersive-learning-showcase-2021/exhibits/show/neighbors-helping-neighbors/projectoverview-with-hyperlin

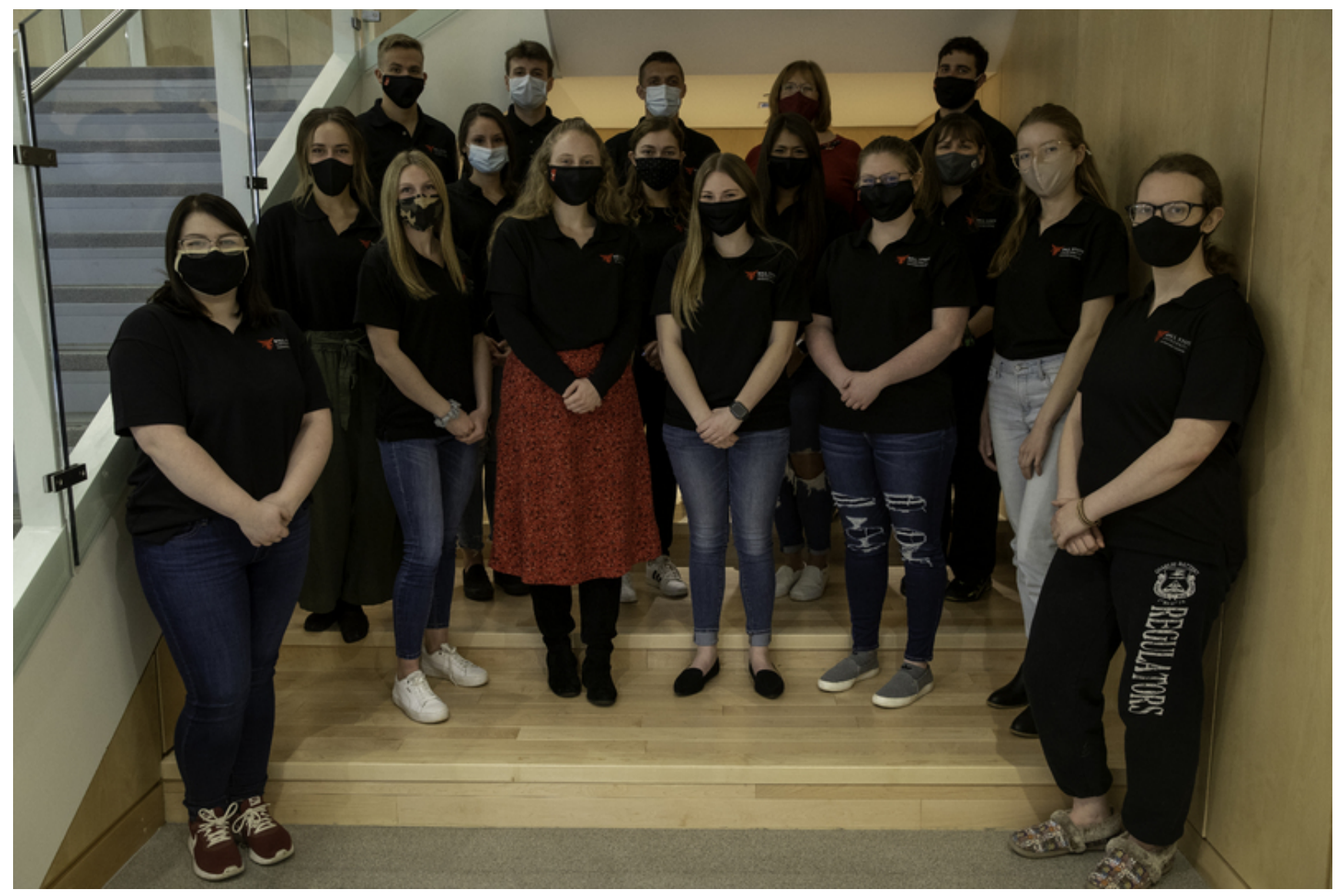

NUTR 456 Community Nutrition Class Photo

Neighbors Helping Neighbors: Recipe Bank Demonstration Videos Using Products Distributed at Second Harvest Tailgate Food Distribution Events

\section{Class:}

NUTR 456 Community Nutrition

\section{Instructor:}

Carol Friesen, PhD, RDN, Professor of Nutrition

\section{Students:}

Kara Beitler, Katelin Berebitsky, Brianna Caldwell, Cecilia Collins, Kelsie Coomer, Mark Feliciano, Andrea Garcia, Danielle Hoover, Jude Johannson, Tasha Lane, Lexi Meacham, Brittney Richwine, Brendan Rollin, Dylan Spina, Alexandrah Transier, Kara Tripp, Joe Van 
Hoosen

\section{Community Partner:}

Second Harvest Food Bank of East Central Indiana

- Kellie Arrowood, Volunteer Coordinator

- Jackson Eflin, Marketing Coordinator

\section{Problem:}

In the United States, an estimated 1 in 9 people (11.1\%) are food insecure and struggle with hunger. In Delaware County, however, the rate is much higher, with an estimated 1 in 6 people (17.7\%) being food insecure. Delaware County has one of the highest rates of food insecurity in the state. The impact of COVID-19 exacerbated the situation through the spike in unemployment and as a consequence of the lockdown that resulted in the loss of school breakfast, school lunch, and after-school snacks/meals.

To address the issue of hunger in Delaware County, Second Harvest Food Bank of East Central Indiana, our community partner, distributes food is through a "Tailgate" event, a drive-through program that meets people at a central location (i.e., a mall parking lot, a sports arena, a school, a business) in their community. Local volunteers help load the participants' cars with various foodstuffs as they drive through. Unlike most food pantries where people can choose the food they receive, during the tailgate events people typically are given large quantities of a few specific food items (i.e., 20\# of potatoes, 6 gallons of milk, 10 heads of lettuce). Unfortunately, when people do not know what to do with a specific item of food because it is unfamiliar to them or because they have too much of any one food at one time, the food is wasted. Thus, a need was identified by Second Harvest staff to develop a 'recipe bank' that includes easy to read recipes, the cost for each recipe, a fun nutrition fact, and a short video that demonstrates how to make the recipe, as many residents lack even rudimentary cooking skills.

\section{Outcome:}

To sensitize the students to the depth and breadth of food insecurity in our community, the senior dietetics students enrolled in this course first volunteered at several Tailgate events to see firsthand the 'faces of hunger' in our community. There, in the freezing cold of January and February, they helped load box after box of food into people's cares. Next, after receiving a list of the most frequently distributed foodstuffs at the tailgate events, each student was asked to select two healthy, simple recipes-one that included a frequently distributed food item from the tailgate and one that included a plant-based protein source (i.e., dried pea or beans, legumes, rice) and create a short video that demonstrated how to prepare the recipe. The students then created a recipe sheet that included the recipe, the cost per recipe/serving, and a fun nutrition fact. Lastly, they created or identified a corresponding "nutrition worksheet" (i.e., coloring page, word search, cross word puzzle, etc.) to that could be used by 
anyone in the household to provide a bit of nutrition education. The videos and the accompanying recipe sheet and handouts will be placed on the Second Harvest Facebook page and website for anyone to access. In addition, through course lecture and assignments, the students will be exposed to key resources that they can use in their professional future as dietitians to understand the prevalence of food insecurity and to identify where they can refer their patients in need in whatever communities they ultimately live and work.

\section{Links to Class Projects:}

- Link to Recipe Videos Recipe Video Link

- Link to Recipes Recipe Sheets

- Link to Handouts Educational Handouts

$\underline{\text { Recipe and Handout Material Example } \rightarrow}$

Overview 


\section{Recipe Videos and Ancillary Handouts}

7f digitalresearch.bsu.edu/immersive-learning-showcase-2021/exhibits/show/neighbors-helping-neighbors/recipe-videosand-ancillary-ha

Handout Examples
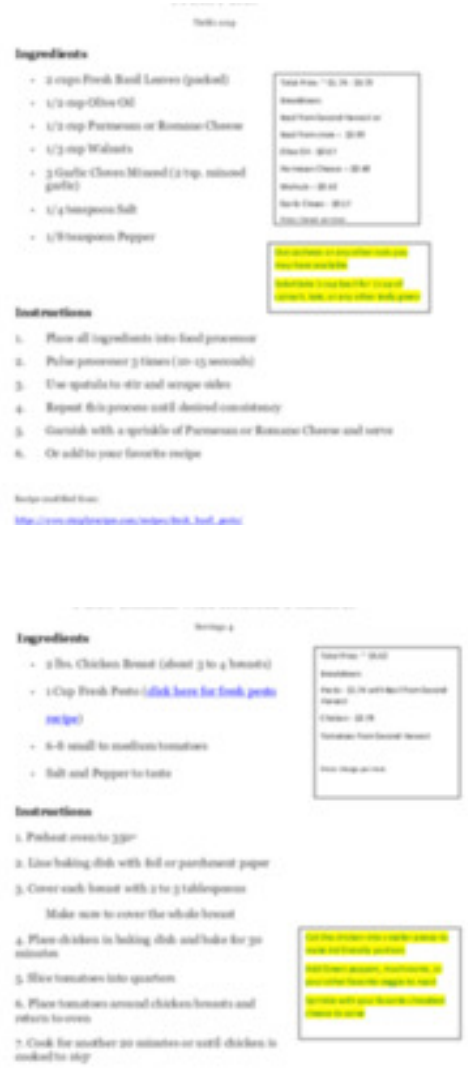

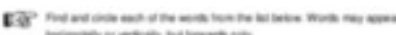

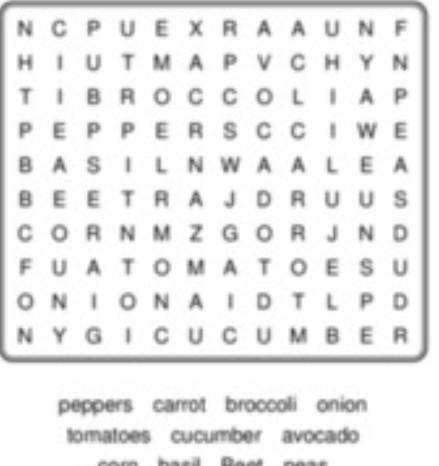




\begin{tabular}{|c|c|c|c|c|c|c|c|c|c|c|c|}
\hline$s$ & 0 & D & c & K & 5 & $A$ & 5 & 1 & t & $H$ & L \\
\hline P & $N$ & 8 & A & $A$ & $\mathrm{v}$ & 0 & C & $A$ & D & 0 & E \\
\hline 1 & 1 & C & 2 & 6 & 1 & $E$ & $E$ & $t$ & $v$ & D & $t$ \\
\hline$N$ & 0 & 0 & R & E & 0 & $p$ & $\varepsilon$ & A & 5 & $E$ & $t$ \\
\hline$A$ & $N$ & 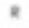 & 0 & c & T & 0 & $M$ & A & $\tau$ & 0 & $u$ \\
\hline c & $t$ & $N$ & $T$ & $z$ & $N$ & $P$ & J & 0 & p & 5 & c \\
\hline$H$ & $M$ & c & $v$ & c & $u$ & $M$ & 1 & $\epsilon$ & R & 3 & $t$ \\
\hline$p$ & If & $P$ & $p$ & E & $*$ & 5 & $v$ & ${ }_{t}$ & $N$ & $N$ & $\mathrm{H}$ \\
\hline \multicolumn{12}{|c|}{ 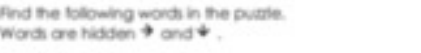 } \\
\hline \multicolumn{3}{|c|}{$\begin{array}{l}\text { AvochDo } \\
\text { west } \\
\text { set } \\
\text { Canot } \\
\text { cons }\end{array}$} & \multicolumn{5}{|c|}{$\begin{array}{l}\text { Cucumate } \\
\text { cult } \\
\text { utruct } \\
\text { ONeON } \\
\text { PES }\end{array}$} & \multicolumn{4}{|c|}{$\begin{array}{l}\text { nwetes } \\
\text { sinuor } \\
\text { somato }\end{array}$} \\
\hline
\end{tabular}




\section{Pesto Chicken with Roasted Tomatoes}

\section{Ingredients}

Servings 4

- 2 lbs. Chicken Breast (about 3 to 4 breasts)

- 1 Cup Fresh Pesto (click here for fresh pesto recipe)

- 6-8 small to medium tomatoes

- Salt and Pepper to taste

Total Price: $~ \$ 5.52$

Breakdown:

Pesto - \$1.74 with Basil from Second Harvest

Chicken - \$3.78

Tomatoes from Second Harvest

Prices change per store.

\section{Instructions}

1. Preheat oven to $350^{\circ}$

2. Line baking dish with foil or parchment paper

3. Cover each breast with 2 to 3 tablespoons

Make sure to cover the whole breast

4. Place chicken in baking dish and bake for 30 minutes

5. Slice tomatoes into quarters

6. Place tomatoes around chicken breasts and return to oven

Cut the chicken into smaller pieces to make kid friendly portions

Add Green peppers, mushrooms, or your other favorite veggie to roast

Sprinkle with your favorite shredded cheese to serve

7. Cook for another 20 minutes or until chicken is cooked to $165^{\circ}$

Recipe modified from:

https://cafedelites.com/2-ingredient-pesto-chicken-recipe/ 


\section{Pesto Recipe}

digitalresearch.bsu.edu/immersive-learning-showcase-2021/exhibits/show/neighbors-helping-neighbors/item/336

\section{Fresh Pesto}

Yields 1cup

\section{Ingredients}

- 2 cups Fresh Basil Leaves (packed)

- $1 / 2$ cup Olive Oil

- 1/2 cup Parmesan or Romano Cheese

- $1 / 3$ cup Walnuts

- 3 Garlic Cloves Minced (2 tsp. minced garlic)

- $1 / 4$ teaspoon Salt

- 1/8 teaspoon Pepper

\section{Instructions}

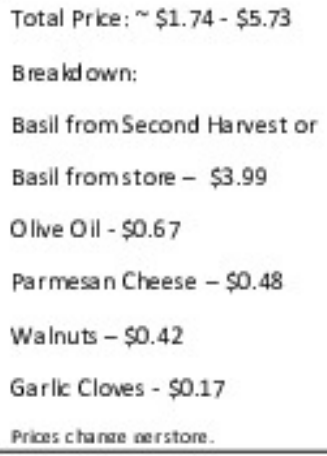

Use cas hews or any other nuts you may have availa ble

Substitute 1-cup bas il for 1cup of s pinach, kak, or any other kafy green

1. Place all ingredients into food processor

2. Pulse processor 3 times (10-15 seconds)

3. Use spatula to stir and scrape sides

4. Repeat this process until desired consistency

5. Garnish with a sprinkle of Parmesan or Romano Cheese and serve

6. Or add to your favorite recipe

Recipe modified from:

https://www.simplyrecipes.com/recipes/fresh_basil_pesto/

\section{Collection}


Neighbors Helping Neighbors

\section{Citation}

"Pesto Recipe," Immersive Learning Showcase 2021, accessed July 20, 2021, https://digitalresearch.bsu.edu/immersive-learning-showcase-2021/items/show/336. 


\section{Photos of Activities}

F digitalresearch.bsu.edu/immersive-learning-showcase-2021/exhibits/show/neighbors-helping-neighbors/photos-ofactivities

$\longleftarrow$ Recipe and Handout Material Example Photos
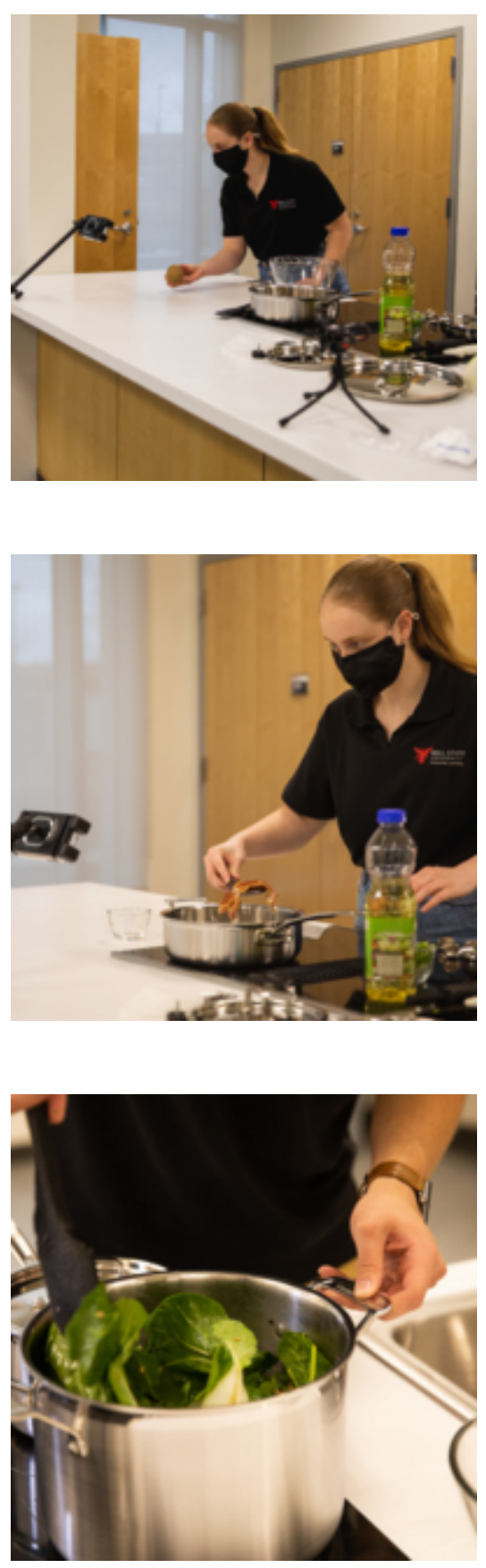

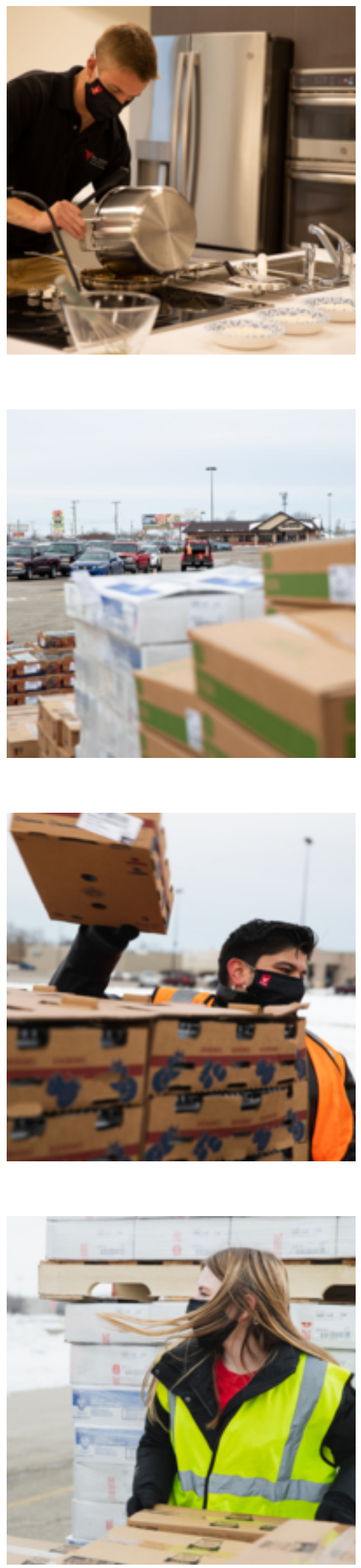

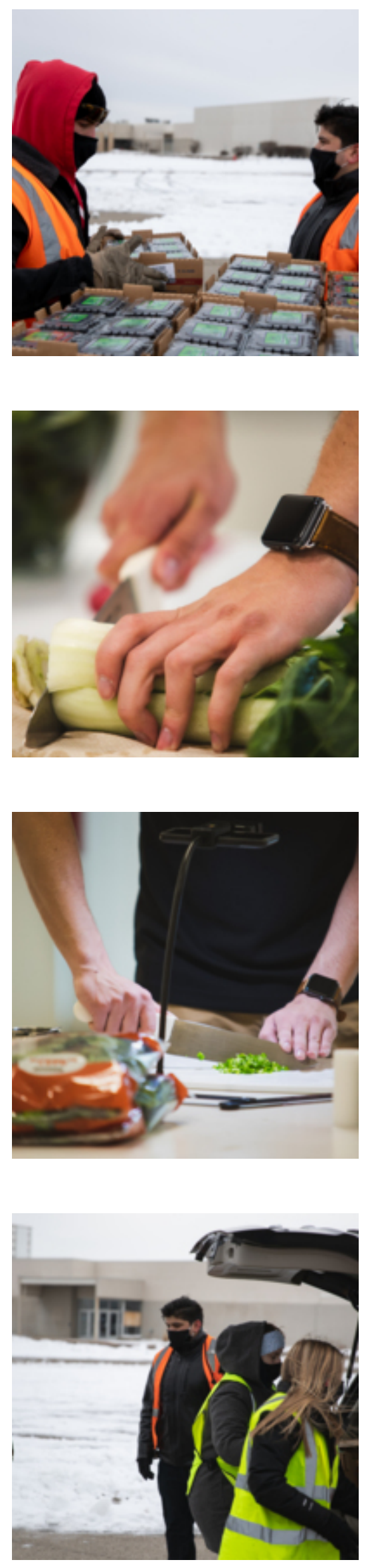


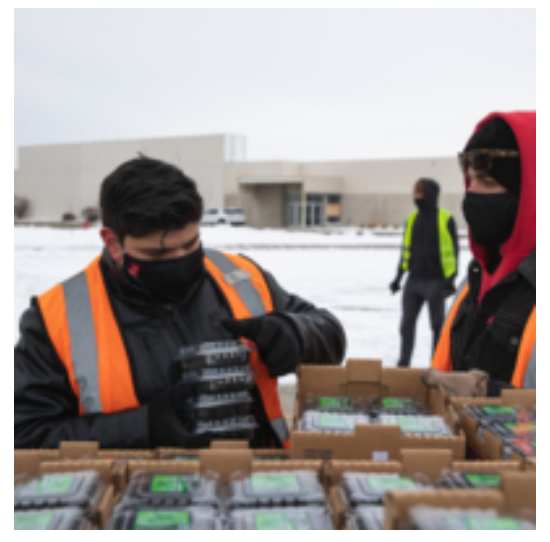




\section{Neighbors Helping Neighbors Photos}

W digitalresearch.bsu.edu/immersive-learning-showcase-2021/exhibits/show/neighbors-helping-neighbors/item/337

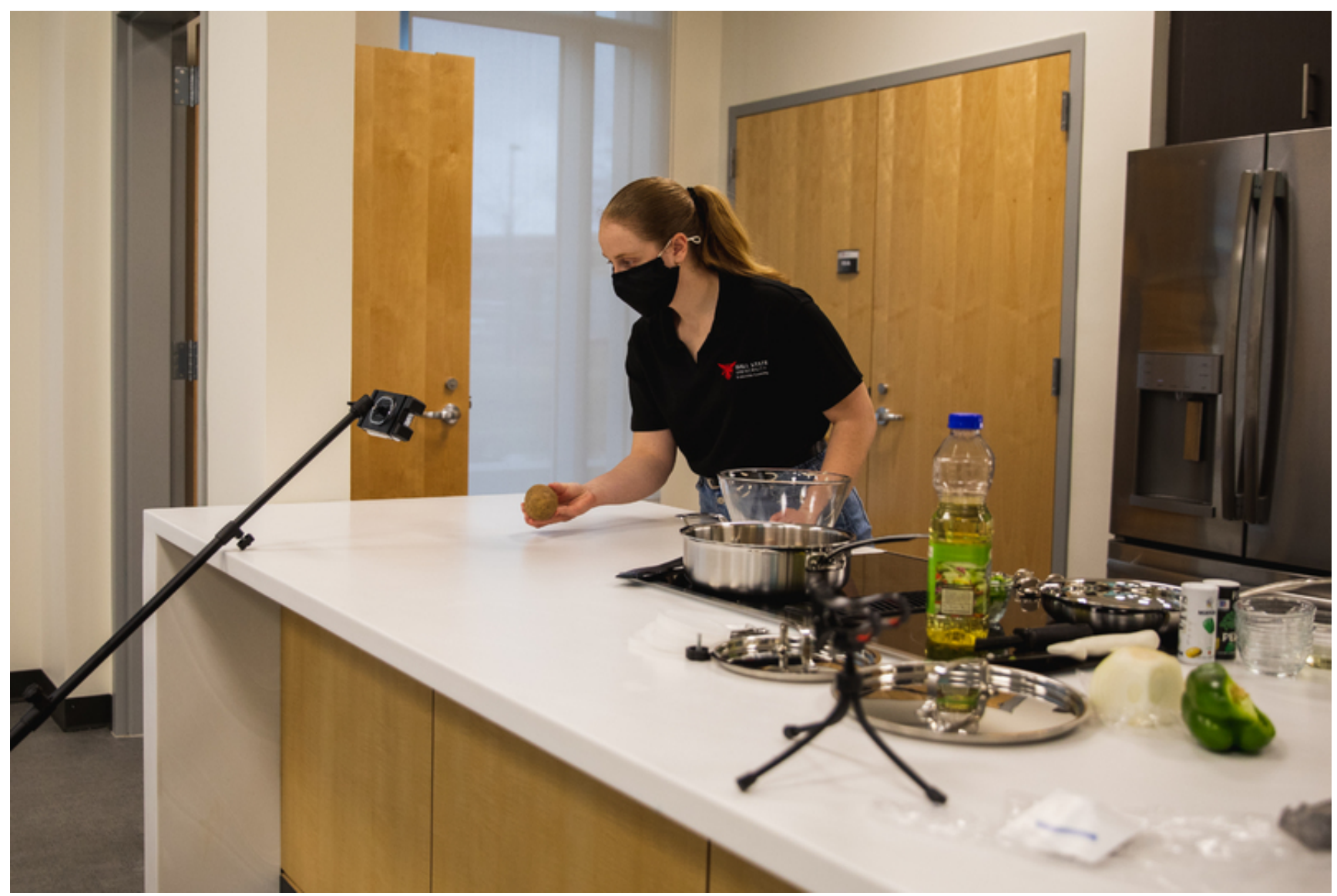



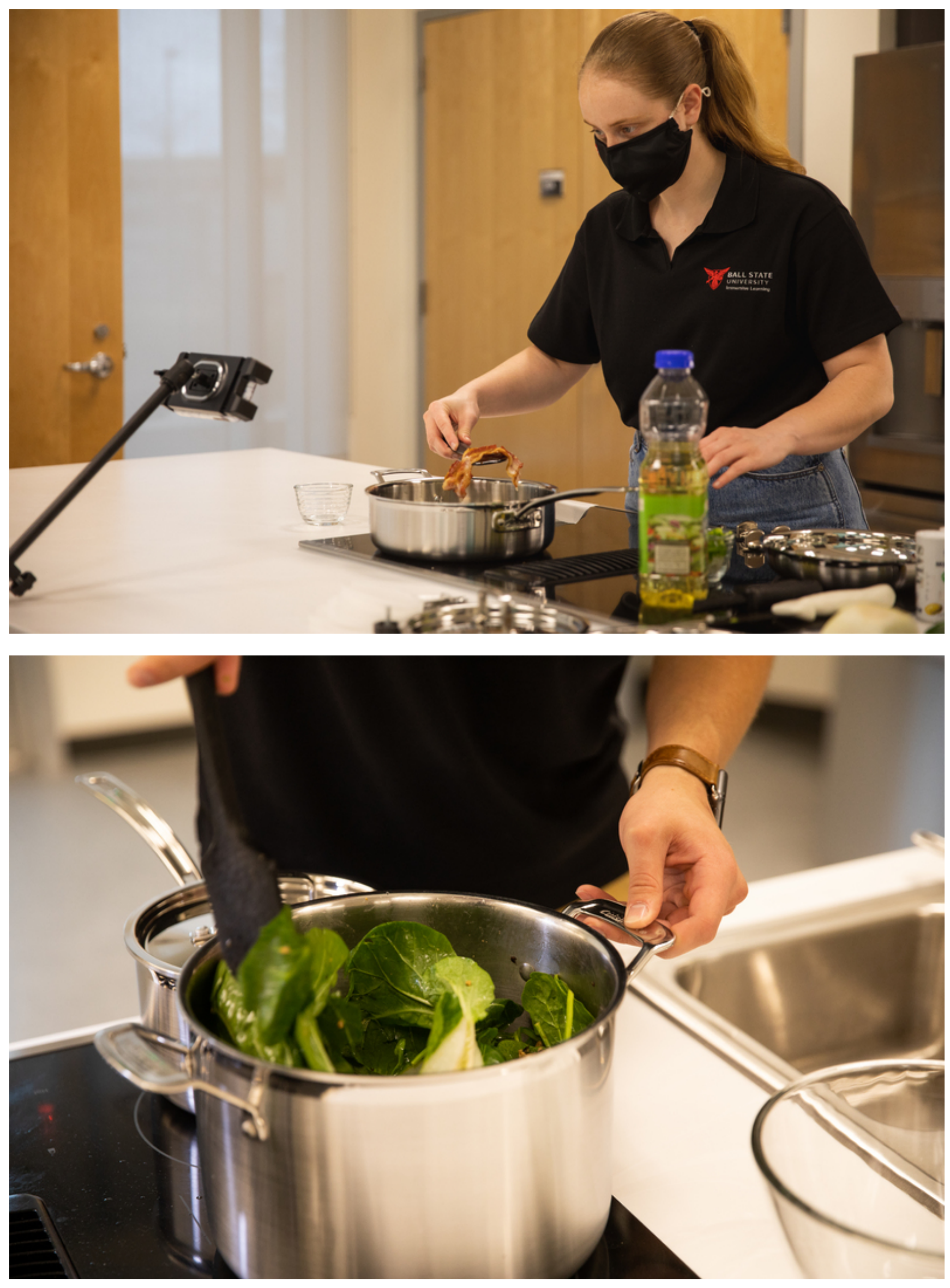

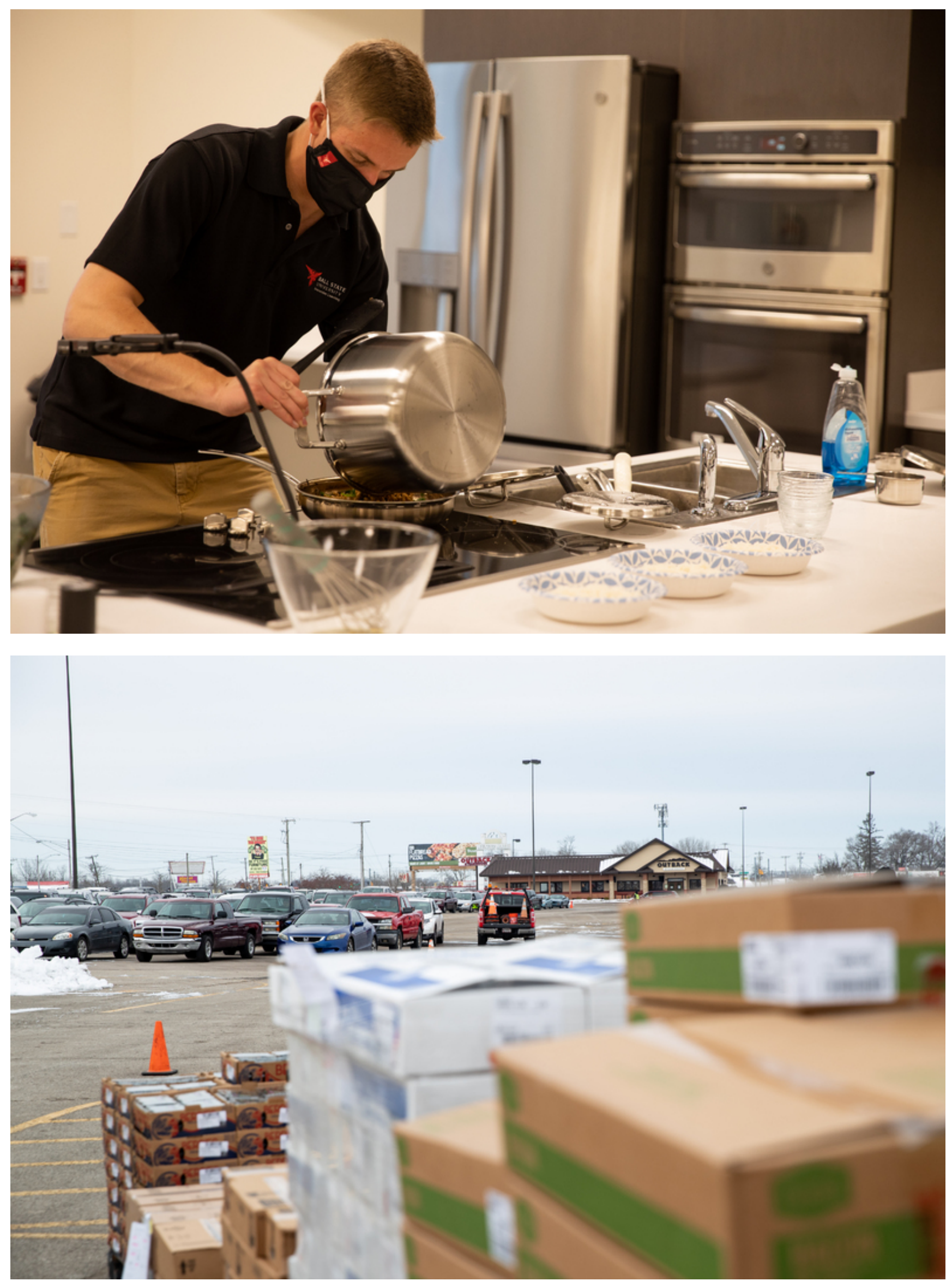

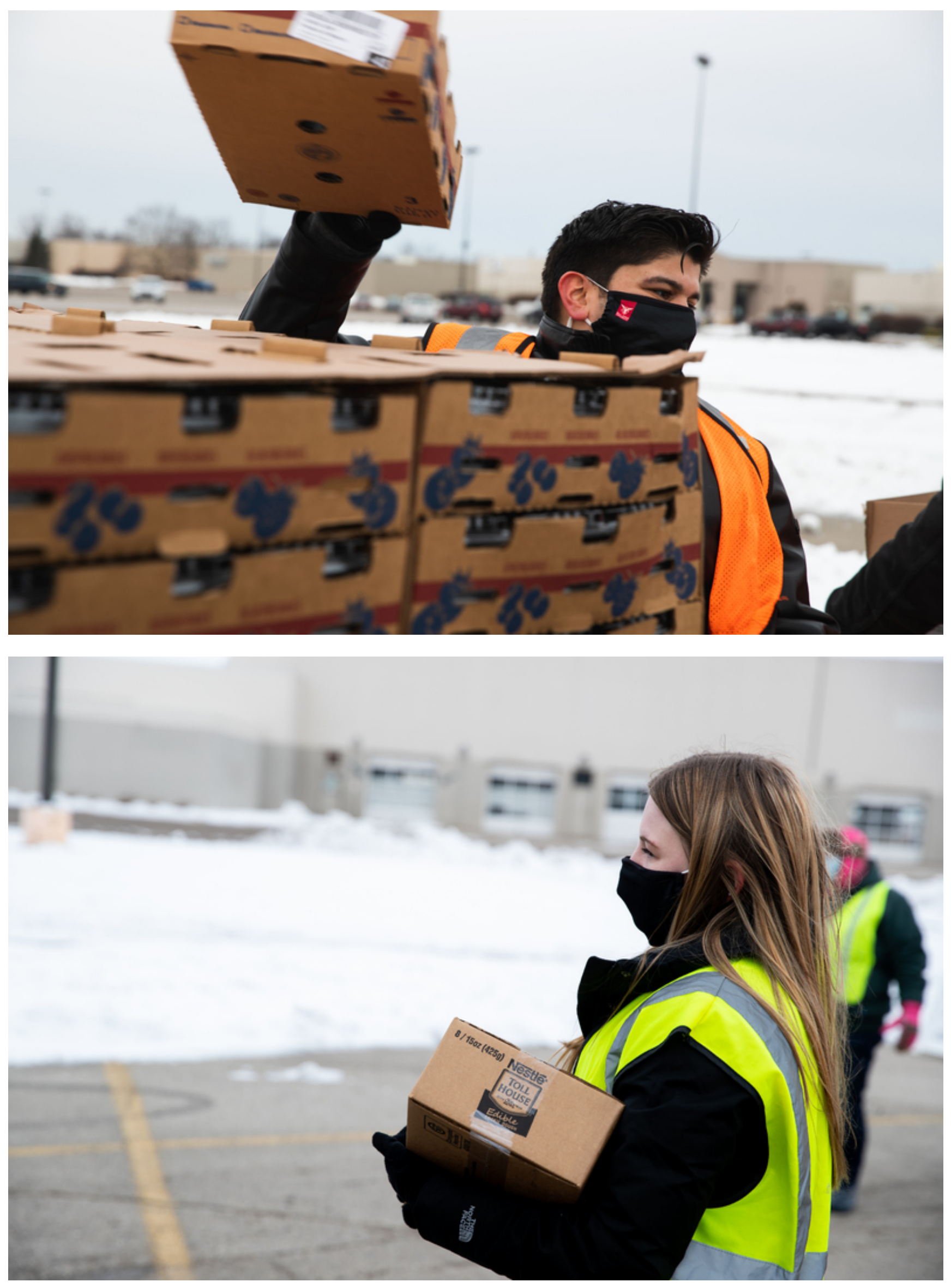

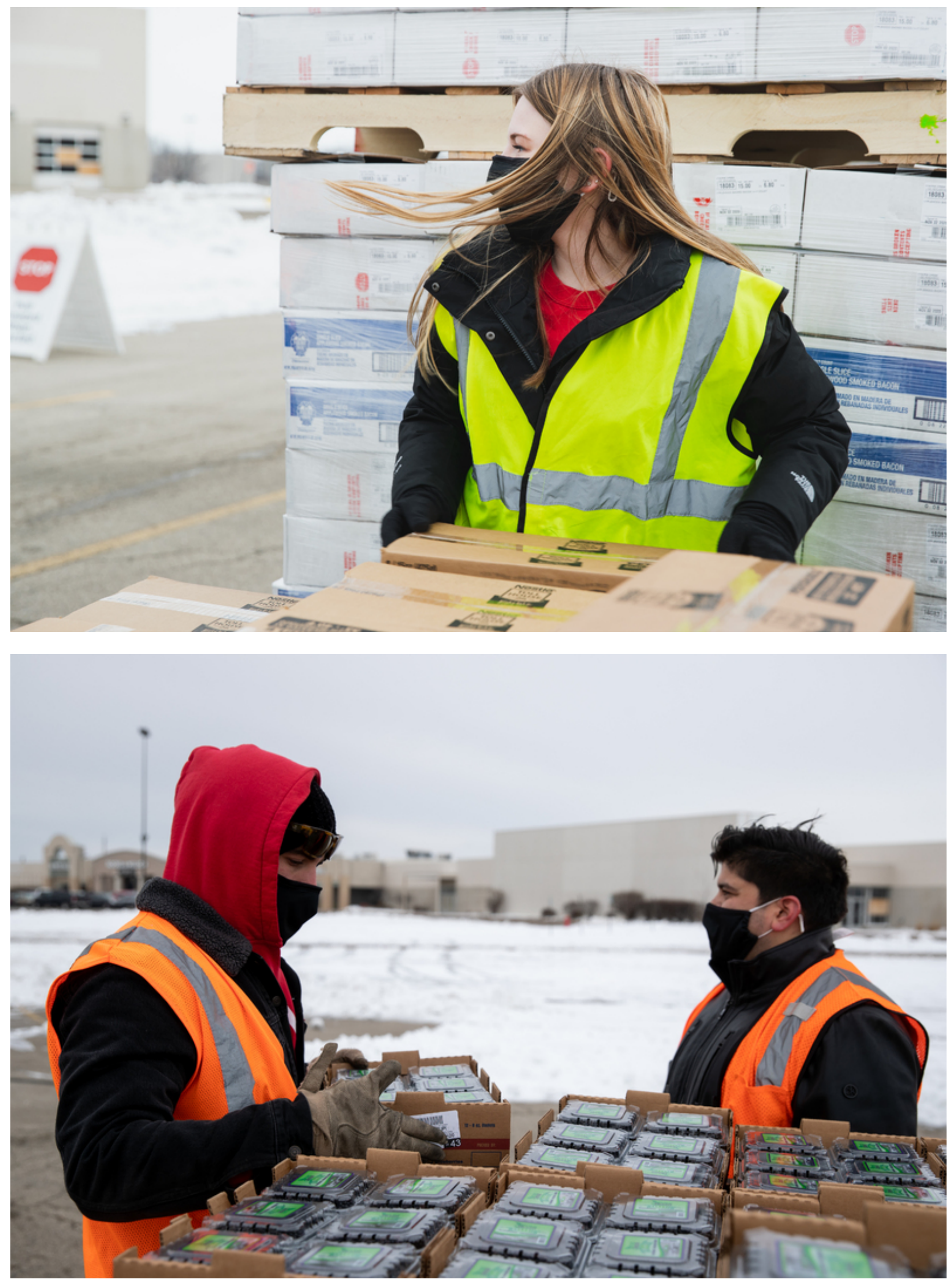

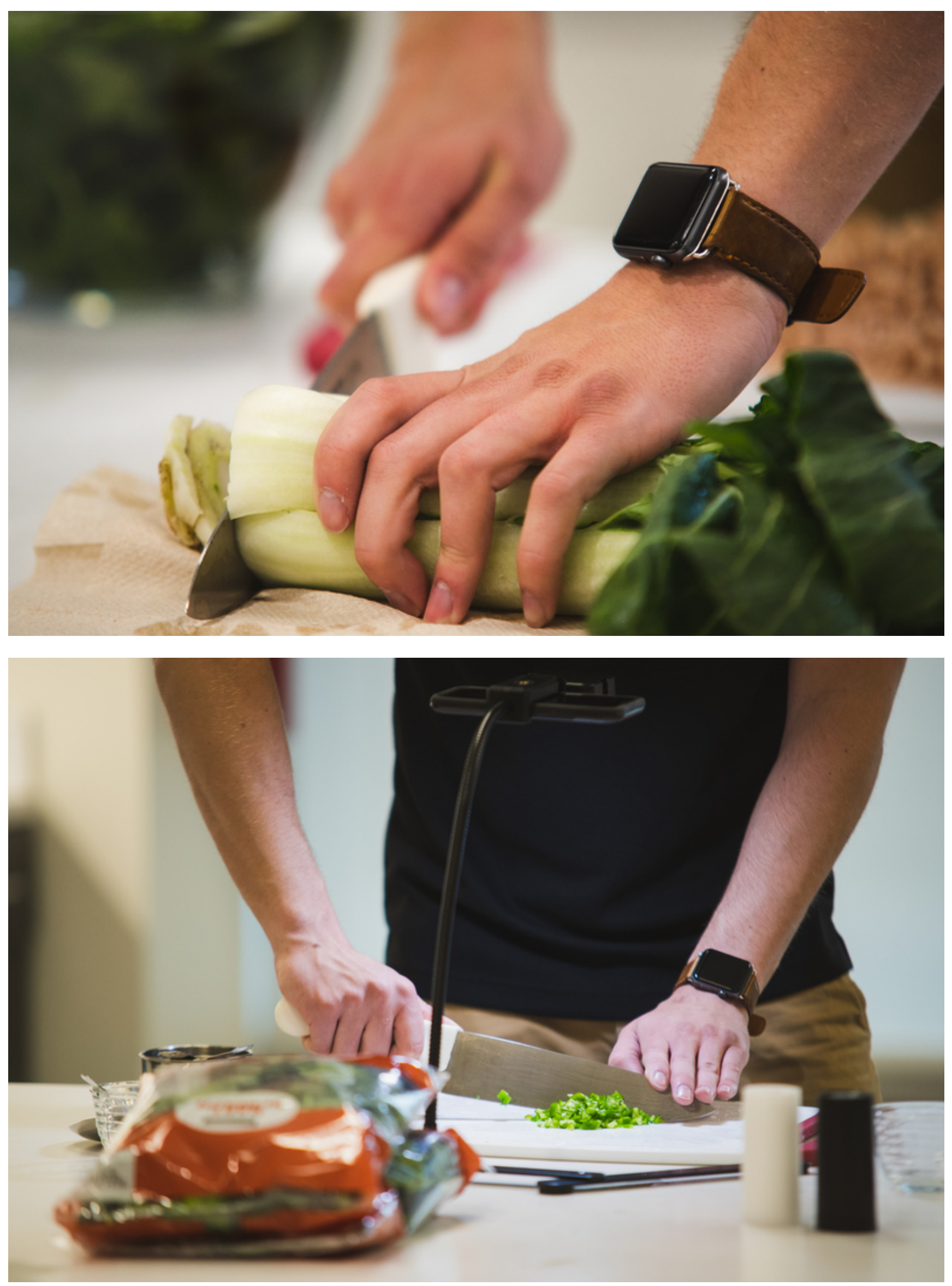

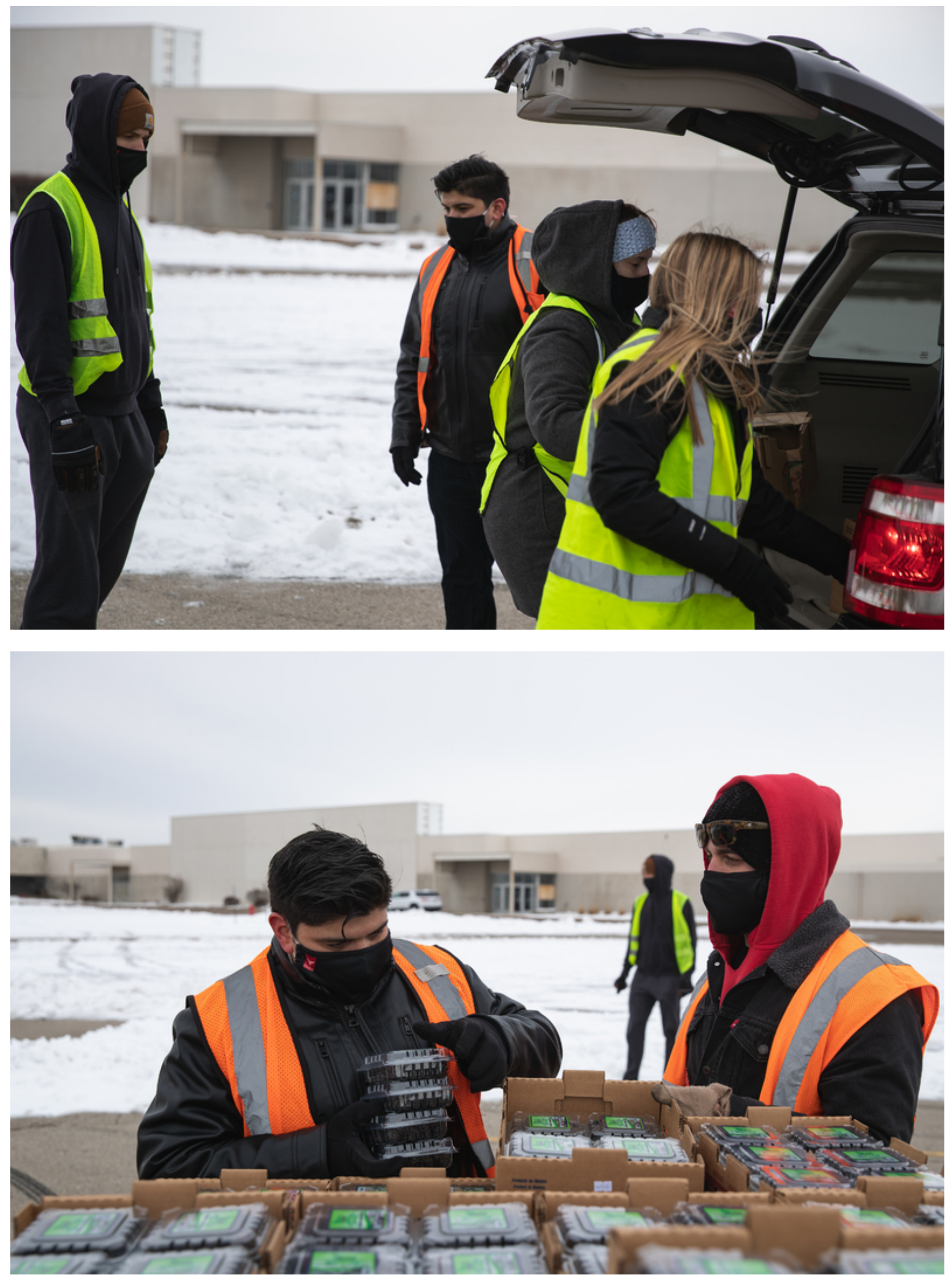

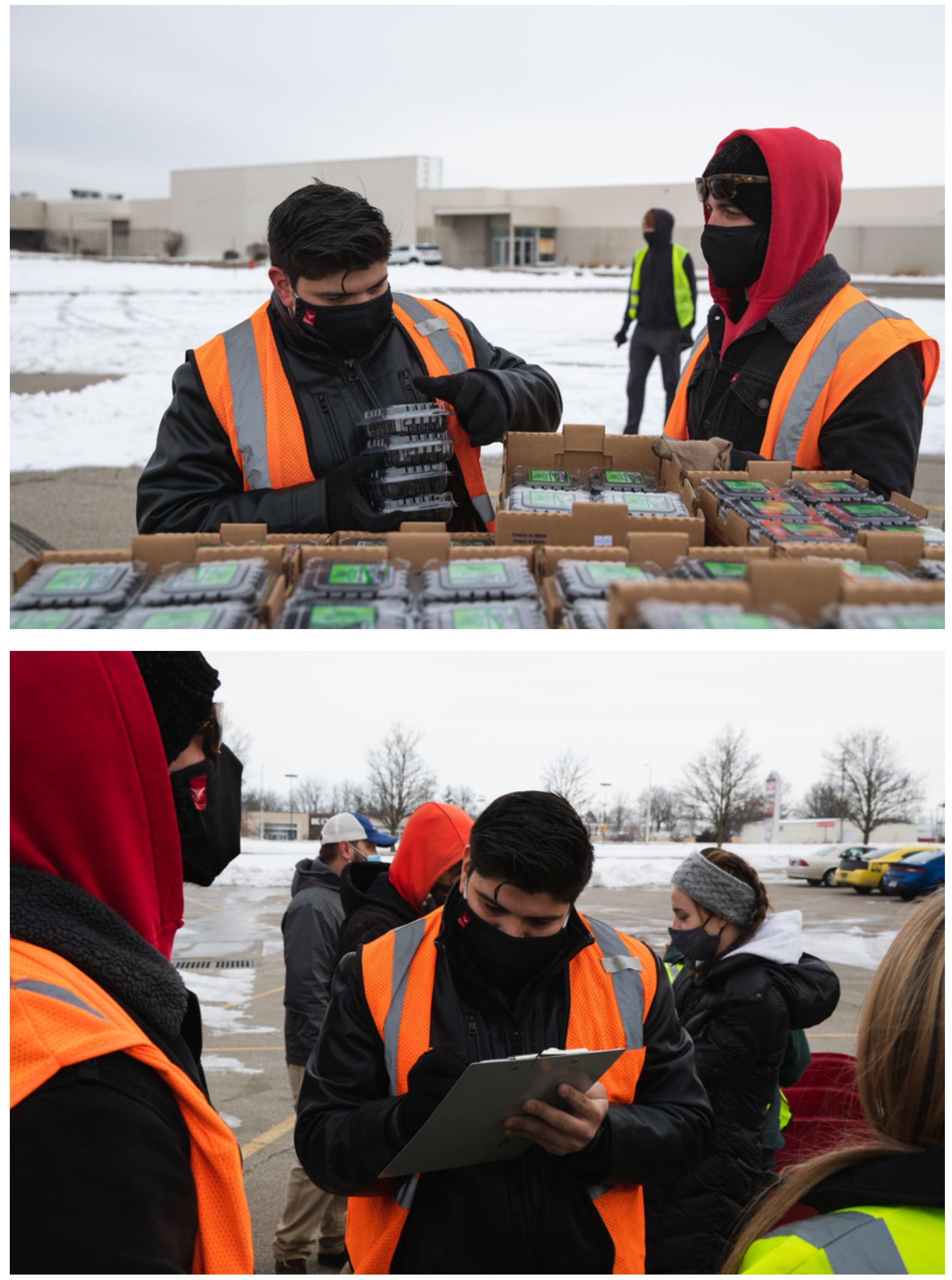

\section{Dublin Core}




\section{Title}

Neighbors Helping Neighbors Photos

\section{Collection}

Neighbors Helping Neighbors

\section{Citation}

"Neighbors Helping Neighbors Photos," Immersive Learning Showcase 2021, accessed July 20, 2021, https://digitalresearch.bsu.edu/immersive-learning-showcase2021/items/show/337. 


\section{Neighbors Helping Neighbors: Recipe Bank Demonstration Videos Using Products Distributed at Second Harvest Tailgate Food Distribution Events}

Instructor:

Carol A. Friesen, PhD, RDN, LD

Professor of Nutrition and Dietetics and Graduate Program Director

Students:

NUTR 456 Community Nutrition

- Kara Beitler

- Katelin Berebitsky

- Brianna Caldwell

- Cecilia Collins

- Kelsie Coomer

- Mark Feliciano

- Andrea Garcia

- Danielle Hoover

- Tasha Lane

- Jude Johannson

- Lexi Meacham

- $\quad$ Brittney Richwine

- Brendan Rollin

- Dylan Spina

- Alexandrah Transier

- $\quad$ Kara Tripp

- Joe Van Hoosen

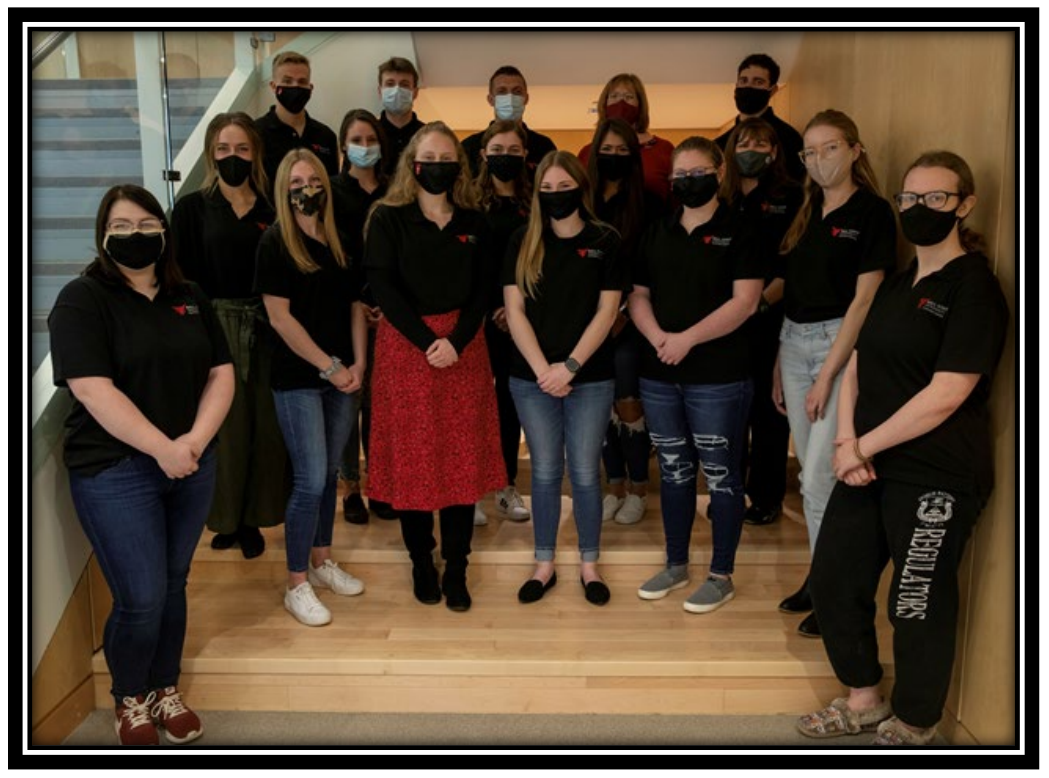

Community Partner: Second Harvest Food Bank of East Central Indiana

- Kellie Arrowood, Volunteer Coordinator

- Jackson Eflin, Marketing Coordinator

Problem:

In the United States, an estimated 1 in 9 people (11.1\%) are food insecure and struggle with hunger. In Delaware County, however, the rate is much higher, with an estimated 1 in 6 people (17.7\%) being food insecure. Delaware County has one of the highest rates of food insecurity in the state. The impact of COVID19 exacerbated the situation through the spike in unemployment and as a consequence of the lockdown that resulted in the loss of school breakfast, school lunch, and after-school snacks/meals. 
To address the issue of hunger in Delaware County, Second Harvest Food Bank of East Central Indiana, our community partner, distributes food through a "Tailgate" event, a drive-through program that meets people at a central location (i.e., a mall parking lot, a sports arena, a school, a business) in their community. Local volunteers load the participants' cars with various foodstuffs as they drive through. Unlike most food pantries where people can choose the food they receive, during the tailgate events people typically are given large quantities of a few specific food items (i.e., 20\# of potatoes, 6 gallons of milk, 10 heads of lettuce). Unfortunately, when people do not know what to do with a specific item of food because it is unfamiliar to them or because they have too much of any one food at one time, the food may be wasted. Thus, a need was identified by Second Harvest staff to develop a 'recipe bank' that includes easy to read recipes, the cost for each recipe, a fun nutrition fact, and a short video that demonstrates how to make the recipe, as many residents lack even rudimentary cooking skills.

Outcome:

To sensitize the students to the depth and breadth of food insecurity in our community, the senior dietetics students enrolled in this course first volunteered at several Tailgate events to see firsthand the 'faces of hunger' in our community. There, in the freezing cold of January and February, they helped load box after box of food into hundreds of cares. Next, after receiving a list of the most frequently distributed foodstuffs at the tailgate events, each student was asked to select two healthy, simple recipes-one that included a frequently distributed food item and one that included an inexpensive plant-based protein source (i.e., dried pea or beans, legumes, rice) and create a short video that demonstrated how to prepare the recipes. The students were asked to create a recipe sheet that included the recipe, the cost per recipe/serving, and a fun nutrition fact. Lastly, they created or identified a corresponding "nutrition worksheet" (i.e., coloring page, word search, cross word puzzle) that could be used by anyone in the household to provide a bit of nutrition education. The videos and the accompanying recipe sheet and handouts will be placed on the Second Harvest Facebook page and website for anyone to access. In addition, through course lecture and assignments, the students became exposed to key resources they can use in their professional future as dietitians to understand the prevalence of food insecurity and to identify where they can refer their patients in need in whatever communities they ultimately live and work.

Immersive Learning Prepared Videos/Pictures:

- Link to Class Video:

https://youtu.be/-ODtXz7X7gg

- Link to Photos: https://ballstate.app.box.com/s/od491vthp80rkdce5vpfeunwfryz17d3

Links to Class Projects:

- Link to Recipe Videos Recipe Video Link

- Link to Recipes Recipe Sheets

- Link to Handouts Educational Handouts 


\section{Blueberry Frozen Yogurt}

Demonstration Link

Prep Time:10 minutes

Ingredients:

- 2 cups blueberries (fresh or frozen)

- 2/3 cups yogurt

- 2 Tablespoons lemon juice

- 2 Tablespoons honey (or sweetener of choice)

- Splash of milk as needed

\section{Instructions:}

1. Add blueberries, yogurt, lemon juice, and honey to blender.

2. Secure lid onto blender.

3. Blend on high until there is a smooth, consistent texture. You may need to add a splash of milk or scrape the sides of the blender throughout blending process. *NOTE: turn blender off before removing lid or scraping the sides of the blender. Re-attach the lid before continuing blending process. Be very careful when handling or adjusting blender blades!

4. Once desired texture is reached, pour mixture into freezer-safe container and secure lid on container to seal.

5. Allow the mixture to freeze for at least 2 hours.

6 . Set container out of freezer 5 minutes to allow frozen yogurt to thaw slightly.

7. Serve and enjoy!

Total Cost:

- 2 C blueberries:

- 2/3 C yogurt:

- 2 tablespoons lemon juice:

- 2 tablespoons honey:
$\$ 0.92$

Free from Second Harvest

$\$ 0.58$

$\$ 0.08$

$\$ 0.26$

* Costs estimated using Walmart pricing. Cost may vary slightly depending on store. 


\section{Fruit and Kale Bowls (Salad) with Homemade Dressing}

\section{Ingredients}

Servings 4

- 5 cups of kale (common tailgate item from Second Harvest)

- Fruits of choice, 2 cups or so of each, chopped

- I used strawberries, raspberries, and apple since they were on sale (fruits are also a common tailgate item from Second Harvest)

- Dressing:
- $\quad 1 / 3$ cup olive oil
- 1/4 cup lemon or lime juice (fresh or bottled)
- 3 tbs honey, can adjust to taste
- 1/4 cup Ground flaxseed (OPTIONAL)
- 1/4 cup Shredded coconut (OPTIONAL)
- Dash of salt and pepper to tase

\section{Instructions}

1. Prep the kale - the bag will indicate if the kale is washed or unwashed

1. If washed, then it is ready to rip in to the desired shred size

2. If unwashed, rinse the kale with water first and pat dry with a towel or paper towel

3. Add the kale to the bowls, as much as desired

2. Prep the fruits:

1. For the strawberries, I cut off the green tops, and then sliced them length wise twice

2. For the apples, you may use an apple slicer if you have one, otherwise:

1. Cut the apple in half

2. Then slice those halves in half

3. Cut out the "core," or any seeds

4. Then face the apple skin-side up, and slice into silvers about the thickness of

\section{your ring finger}

Enhance the nutrient content

of your bowl by adding nuts,

chopped bacon, sliced veggies

like onion, tomato, or

cucumber! This is a great

opportunity to use bulk

products you get from the

Second Harvest tailgate, and

use up fruit, vegetables, or

leftover meats that can be

chopped up and thrown in!

This recipe is completely

customizable to what you have

in your kitchen, and easy to

make ahead of time for

lunches throughout the week.

** I use honey in the dressing

to counteract the bitterness of

the kale - a common kale

complain that keeps most

people from enjoying it**

Total Price after factoring in Second Harvest free produce: $\sim$ 1.30/4

servings, or $\$ 0.33 /$ serving

Price breakdown:

Olive oil, $1 / 3$ cup: $\$ 0.50$

Lemon juice, 1/4 cup: $\$ 0.45$

Honey, 3 tbs, $\$ 0.35$

Kale and Fruit free From Second Harvest!

Prices change per store. 
5. Line up the slices and chop in the opposite direction you have been cutting to get nice cubes (they will be uneven, as the shape of the apple changes)

3. Raspberries are already in the bite-size form for me

4. Add the fruit to the bowls, as much as desired

3. $\quad$ Prep the dressing

1. To a separate bowl, add the olive oil, lemon juice, honey, salt and pepper

1. Add ground flaxseed and shredded coconut if desired (optional)

2. Whisk together using a fork or a whisk until combined

4. Pour as much dressing as desired over the salads, and enjoy!

5. Leftover dressing may be kept in the refrigerator for future meals

Recipe modified from:

https://www.thespruceeats.com/fruit-and-kale-salad-3371506 


\section{Oven-Baked Potato Chips}

\section{Demonstration Link}

Prep Time:10 minutes

Cook Time: 15 minutes

Total Time: 25 minutes

Ingredients:

- 2 medium potatoes

- 1 Teaspoon Salt

- 2 Tablespoons Oil

\section{Instructions:}

1. Pre-heat oven to 400 degrees.

2. Scrub both potatoes under running water.

3. Slice potatoes in thin slices manually using a knife or using a slicer if available. Try to keep thickness of slices the same.

4. Cut out and throw away any dark spots on the potato slices.

5. Pat slices of potatoes dry.

6. Place potato slices into a medium-large size bowl.

7. Pat dry potato slices again if needed.

8. Pour oil over potato slices.

9. Sprinkle salt over potato slices *Use additional seasoning as desired

10. Toss potato slices in oil and seasoning until all slices are well coated.

11. Lightly grease a baking sheet or place a sheet of parchment paper over a baking sheet.

12. Arrange potato slices on baking sheet spaced so they do not overlap.

13. Bake for 15 minutes, flip after $\sim 8$ minutes using tongs or a spatula. *Adjust baking time depending on preference of crispiness

14. Enjoy! 
Total Cost:

- 2 medium potatoes:

- 1 teaspoon salt:

- 2 tablespoons oil:
$<\$ 0.06$

Free from Second Harvest

$\$ 0.0026$

$\$ 0.05$

*Costs estimated using https://www.sd5.k12.mt.us/userfiles/5/my20files/food\%20price\%20sheet.pdf?id=268

*Cost may vary slightly depending on store. 


\title{
Spicy Thai Basil Chicken Stir-Fry
}

\section{Ingredients}

\author{
Servings 4
}

- 1 pound ground chicken

- 5 garlic cloves, minced

Total Price: $\sim \$ 6.35$

Breakdown:

- 2 serrano chile, seeded and minced

Oils $\$ 0.30$

- 3 cups regular spinach leaves

Ground Chicken \$2.97

- 3 cups of bok choy

Garlic $\$ 0.30$

- 2 tablespoons canola oil

- $1 \frac{1 / 2}{2}$ cups of Rice

Spinach $\$ 2.68$

Rice $\$ 0.10$

Bok choy and serrano chile free From

Second Harvest!

Prices change per store.

- 2 tablespoons soy sauce

- 1 tablespoons fish sauce

- 1/4 cup chicken broth

- 2 teaspoons honey

- To taste: Salt and pepper

\section{Instructions}

In a medium bowl whisk together the soy sauce, fish sauce, broth, honey, salt, and pepper until combined. Set aside.

Enhance your dish by topping with crushed cashews or basil!

Boil $1 \frac{1}{1} 2$ cups of water and place rice in for 5 mins. Stir occasionally.

Heat a large skillet. Once hot add the canola oil, garlic, chile and sauté for about 30 seconds, until fragrant. WARNING the smoke from this is very painful if inhaled.

Add the ground chicken, and continue to cook until the chicken is browned, about 4-5 minutes.

Stir in the sauce along with the basil and bok choy in a separate pan. Let the stir-fry simmer until the bok choy is wilted, about 2-3 minutes, stirring frequently. Add both pans together.

Remove from the heat and serve over rice.

https://www.acedarspoon.com/spicy-thai-basil-chicken-stir-fry/ 


\section{Crispy Roasted Black Beans}

Ingredients: Yield (8 servings)

- 2, 15-ounce cans of Black Beans

- 2 Tablespoons of Olive Oil

- 1 Teaspoon Chili powder

- 1 Teaspoon Cumin

- 1 Teaspoon Garlic Powder

- $\quad 1 / 8$ Teaspoon Cinnamon

- $\quad 3 / 4$ Teaspoon Salt

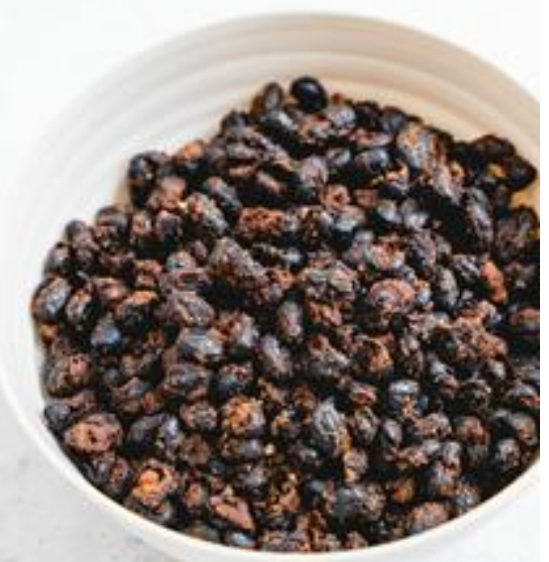

Directions: Preparation (10 minutes) Cook Time (1 hours)

Nutrition Facts

8 servings per container

Serving size

$1(1 \mathrm{~g})$

Amount Per Serving

Calories

110

Total Fat $4 \mathrm{~g}$

Saturated Fat $0 \mathrm{~g}$

Trans Fat $0 \mathrm{~g}$

Sodium $0 \mathrm{mg}$

Total Carbohydrate $15 \mathrm{~g}$

Dietary Fiber $6 g$

Total Sugars $0 \mathrm{~g}$

Includes 0g Added Sugars

Protein 6g

Not a significant source of cholesterol, vitamin D, calcium. iron, and potassium

-The \% Daily Value (DV) tells you how much a nutrient in a serving of lood contribules to a daily diet. 2,000 calories a

- $\quad$ Preheat oven to $350^{\star} \mathrm{F}$

- Rinse and drain black beans. Shake off as much water as ay is used for general nutrition advice. possible. Place on towel and GENTLY pat dry

- In a medium bowl, stir together black beans with oil and spices

- Pour beans on lined baking sheet, spreading into a single layer

- Bake for about 45 to $60 \mathrm{~min}$, stirring them around at $30 \mathrm{~min}$

- Pay careful attention not to overcook, check and taste test often. They are done when they are crispy and dry

- Cool for 10 min before storing

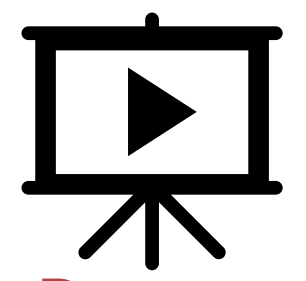

Recipe Demonstration 


\section{Crispy Roasted Black Beans Cost and Tips}

Cost ( ${ }^{*}$ From Walmart*)

1) Black Beans: 15 oz can $=\$ 0.88,2$ cans $=\$ 1.66$

2) Olive Oil: $25.5 \mathrm{oz}=\$ 4.76$, About 50 Tablespoons, $\$ 0.10$ per Tablespoon, 2 Tablespoons $=\$ 0.20$

3) Seasonings from Cabinet

$$
\text { Cost per recipe }=\$ 1.88 \text {, Cost per serving }=\$ 0.24
$$

TIPS:

1) Use any combination of seasonings you prefer! Mess around and see what strikes your taste buds!

2) Use Vegetable oils instead of olive oil for a cheaper cost

3) Use coconut oil instead of olive oil for a tropical flavor with health fats!

4) Store in a airtight container in the cupboard for about a week!

5) Cooling allows for extra crispiness 


\section{Easy Grape Sorbet}

Ingredients: Yield (4 servings approximately 1/2 cups)

- 3 cups of Grapes

- 2 Tablespoons of Sugar

- 1 Teaspoon of Lemon Juice

Directions: Preparation Time (5 min) Freeze (4hrs)

\begin{tabular}{|c|c|}
\hline Nutrition F & acts \\
\hline $\begin{array}{l}4 \text { servings per container } \\
\text { Serving size }\end{array}$ & $1(0.5 \mathrm{~g})$ \\
\hline $\begin{array}{l}\text { Amount Per Serving } \\
\text { Calories }\end{array}$ & \\
\hline & \% Daily Value" \\
\hline Total Fat $0 \mathrm{~g}$ & $0 \%$ \\
\hline Saturated Fat 0g & $0 \%$ \\
\hline Trans Fat $0 \mathrm{~g}$ & \\
\hline Sodium 0mg & $0 \%$ \\
\hline Total Carbohydrate $36 \mathrm{~g}$ & $13 \%$ \\
\hline Dietary Fiber $1 \mathrm{~g}$ & $4 \%$ \\
\hline Total Sugars 0g & \\
\hline Includes 0g Added Sugars & $0 \%$ \\
\hline Protein $1 \mathrm{~g}$ & $2 \%$ \\
\hline $\begin{array}{l}\text { Not a significant source of cholestorol, vetami } \\
\text { rion, and potassium }\end{array}$ & D, calcium, \\
\hline 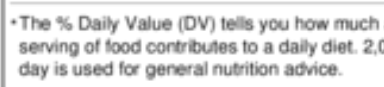 & $\begin{array}{l}\text { a nutrient in a } \\
\text { ano caionies a }\end{array}$ \\
\hline
\end{tabular}

Remove grapes from stems and put onto a plate or baking sheet in 1 layer.

Place into freezer, Freeze until hard. This should take about 4 hours.

2) BLEND: In blender or food processor,

place frozen grapes in blender and select puree option.

Scrape down sides as it builds up on sides.

Add remaining ingredients and puree until smooth.

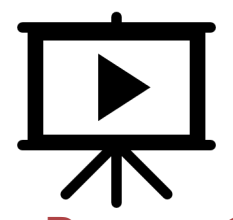

Recipe Demonstration 


\section{Easy Grape Sorbet Cost and Tips}

\section{Cost: (*From Walmart*)}

1) Grapes: *Free Tailgate Item* or $\$ 1.34$ per pound 3 cups $=\$ 2.03$

2) Sugar: $\$ 1.98$ per 4 pounds, or $\$ 0.50$ per pound. About 36 tablespoons per pound. 2 Tablespoons $=\$ 0.03$.

3) Lemon Juice: $\$ 0.99$ per 2.5 ounces. 1 ounce $=6$ teaspoons. 1 teaspoon $=\$ 0.07$

- $\quad$ Cost per recipe $=\$ 2.13$, Cost per serving $=\$ 0.53$

TIPS:

1) Use 2 Tablespoons of honey instead of sugar for a flavorful healthy switch up

2) Use $1 / 4$ Tablespoon of Stevia instead of sugar to lower overall sugar amount

3) No blender? After washing, Freeze cotton candy grapes and enjoy as frozen poppers 
- . + . . . . Cantaloupe Coalerr Servings: 8

Ingredients:

- 1 cantaloupe (ripe)

- $\quad 21 / 2$ cups orange juice (cold)

- 2 Tablespoons sugar (granulated)

- Ice

$+\cdot, \cdot, \cdot, \cdot, \cdot$

Directions:

1. Cut the melon in half. Scoop out the seeds, remove the skin, and discard. Cut the melon into 1 -inch cubes.

2. In a blender, blend the melon cubes with $1 / 2$ cup orange juice until smooth.

3. Pour the puree into a pitcher and stir in the remaining orange juice and the sugar. Stir until the sugar is dissolved.

4. Pour into glasses filled with ice.

5. Enjoy!

Recipe adapted from:

- https://www.myplate.gov/recipes/supplemental-nutritionassistance-program-snap/cantaloupe-cooler

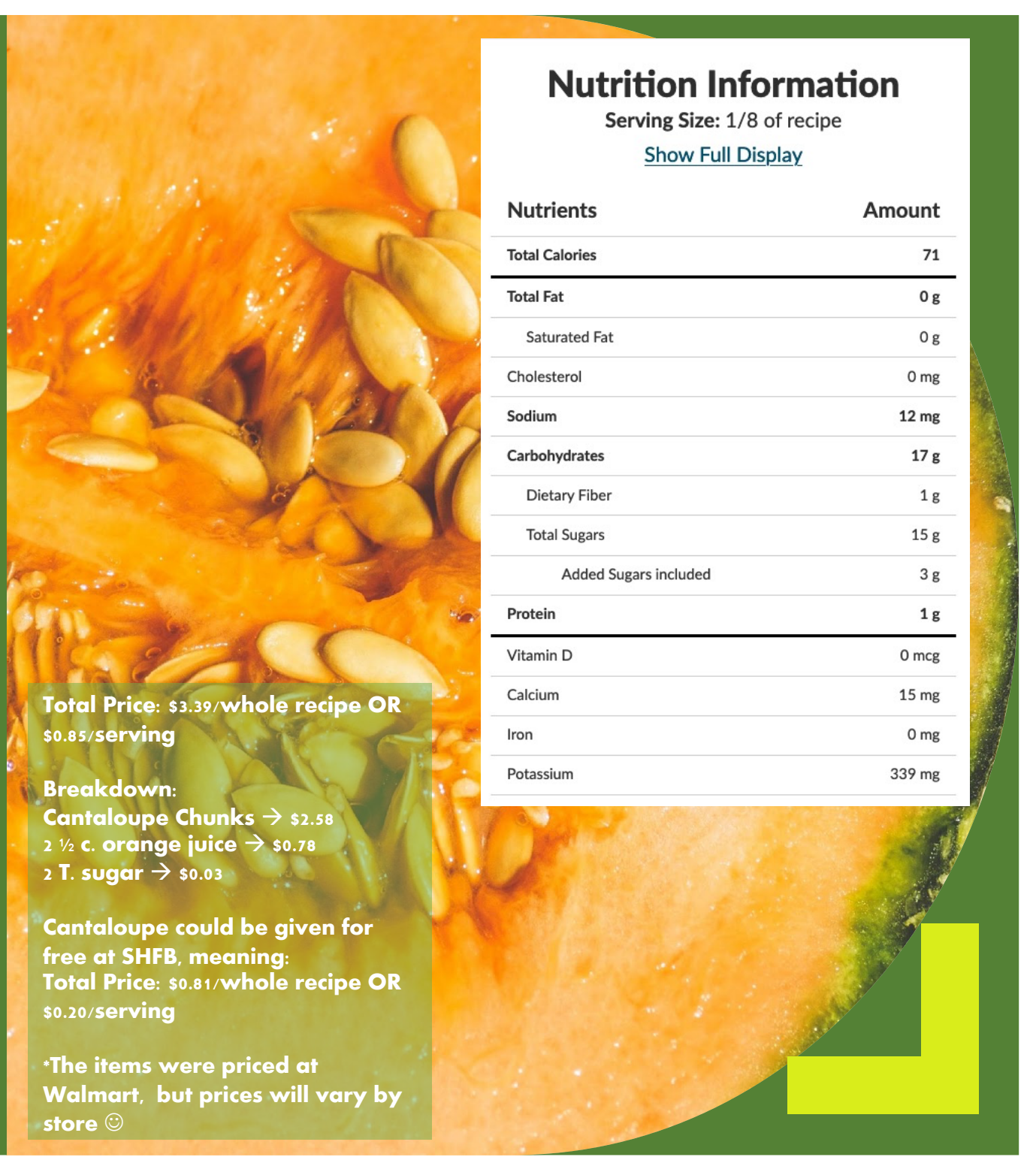




\section{Stuffed Bell Peppers}

Servings: 4

Ingredients

1 cup brown rice, uncooked

- 1 can black beans, unsalted (15 ounces.

4 bell peppers (any color)

1 cup cheddar cheese, shredded (reduced fat)

1 cup salsa

Salt (to taste, optional)

Directions:

1. Preheat the oven to $400^{\circ} \mathrm{F}$.

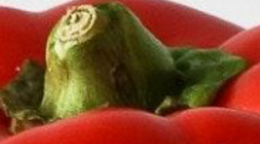

Cook the brown rice according to package directions.

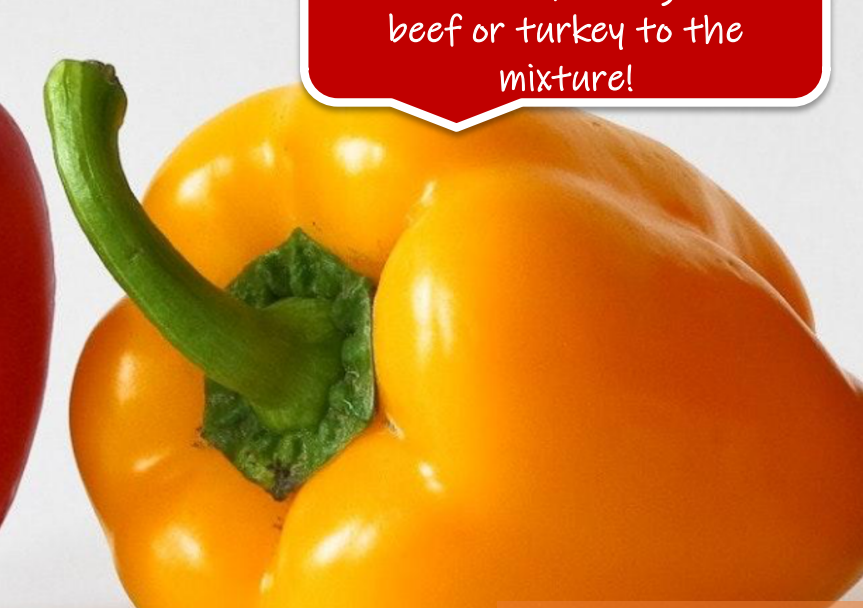

To add some protein to this dish, add 1 pound ground beef or turkey to the

Wash the peppers under running water.

Cut the tops off the peppers and spoon out the seeds.

Drain and rinse the black beans.

Combine the beans, rice, salsa, and salt (optional).

. Spoon 3 Tablespoons of the mixture into the bottom of each pepper. Sprinkle 2 Tablespoons of cheese on top.

. Repeat step 7 again until the pepper is filled, but do not put cheese on top layer.

9. Bake peppers for 30 minutes, top each with 2 Tablespoons of cheese and continue baking for 15 minutes more.

10. Enjoy!

Recipe adapted from:

https://www.myplate.gov/recipes/supplemental-nutrition-assistance-programsnap/simple-stuffed-peppers

Total Price: \$6.11/whole recipe OR $\$ 1.53 /$ serving

\section{Breakdown:}

$1 \mathrm{c}$. brown rice $\rightarrow \$ 0.31$

1 can black beans $\rightarrow \$ 0.54$

4 bell peppers $\rightarrow \$ 3.08$

1 c. cheddar cheese $\rightarrow \$ 1.19$

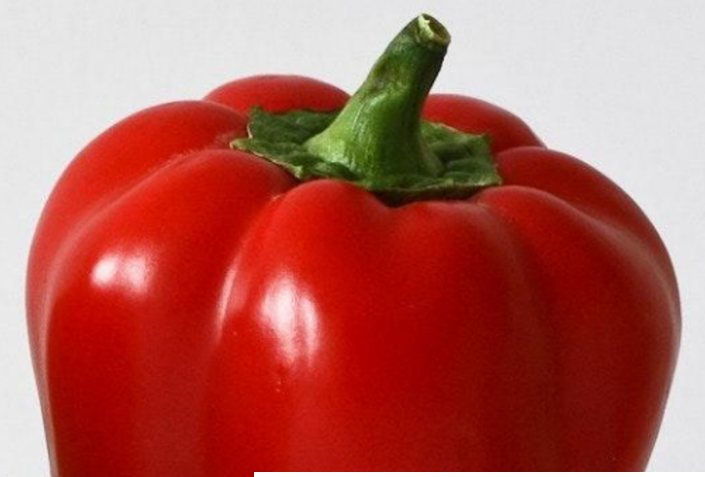

Nutrition Information

Serving Size: $1 / 4$ of recipe Show Full Display

Nutrients

Total Calories

Amount

Total Fat

Saturated Fat

Cholesterol

Sodium

Carbohydrates

Dietary Fiber

Total Sugars

Added Sugars included

Brown rice could be given free at SHFB, medning:

Total price: $\$ 5.80 /$ whole recipe OR \$1.45/serving

"The items were priced at Walmart. but prices will vary by store

\begin{tabular}{lr}
\hline \multicolumn{1}{r}{ Added Sugars included } & $\mathrm{Og}$ \\
\hline Protein & $19 \mathrm{~g}$ \\
\hline Vitamin D & $0 \mathrm{mcg}$ \\
\hline Calcium & $191 \mathrm{mg}$ \\
\hline Iron & $3 \mathrm{mg}$ \\
\hline Potassium & $788 \mathrm{mg}$ \\
\hline
\end{tabular}




\section{Crispy Cauliflower Po Boy Sandwich}

Ingredients: Yield (4 servings, 1 sandwich)

- $1 / 4$ cup panko bread crumbs

- 1.5 tablespoon Creole seasoning

- 1 egg, lightly beaten

- 2 cups cauliflower florets

- Olive oil

- 4 baguette pieces

- Lettuce

- Tomatoes

Remoulade:

- Chives

- $\quad 1 / 2$ cup mayo

- 1 tablescpoon mustard

- 2 garlic cloves, minced

- $\quad 1 / 2$ tsp paprika

- 1 tsp hot sauce

\begin{tabular}{|c|c|}
\hline Nutrition F & cts \\
\hline $\begin{array}{l}4 \text { servings per container } \\
\text { Serving size }\end{array}$ & $(270 \mathrm{~g})$ \\
\hline $\begin{array}{l}\text { Amount Per Serving } \\
\text { Calories }\end{array}$ & 350 \\
\hline Total Fat 30 & Daily Value" \\
\hline $\begin{array}{l}\text { Total fat 3g } \\
\text { Saturated Fat 1g }\end{array}$ & $\begin{array}{l}4 \% \\
5 \%\end{array}$ \\
\hline Trans Fat 0g & \\
\hline Cholesterol Omg & $0 \%$ \\
\hline Sodium $170 \mathrm{mg}$ & $7 \%$ \\
\hline Total Carbohydrate $55 \mathrm{~g}$ & $20 \%$ \\
\hline Dietary Fiber $6 \mathrm{~g}$ & $21 \%$ \\
\hline $\begin{array}{l}\text { Total Sugars } 1 \mathrm{~g} \\
\text { Includes } 0 \mathrm{~g} \text { Added Sugars }\end{array}$ & \\
\hline $\begin{array}{l}\text { Includes og Added Sugars } \\
\text { Protein } 4 \mathrm{~g}\end{array}$ & $8 \%$ \\
\hline $\begin{array}{l}\text { Not a signififaant source of vitamin D, calciu } \\
\text { optassium }\end{array}$ & \\
\hline 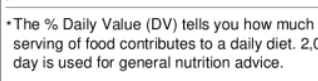 & $\begin{array}{l}\text { ient in a a } \\
\text { lories a }\end{array}$ \\
\hline
\end{tabular}

Directions: Preparation (10 min) Cook (20 min)

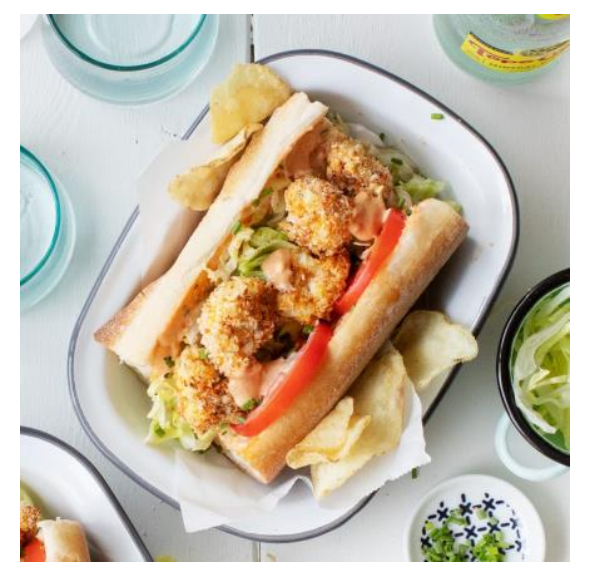

- $\quad$ Preheat the oven to $400^{\circ} \mathrm{F}$ and line a baking sheet with parchment paper.

- On a rimmed tray, mix together the panko, seasoning, and lemon zest. Place the egg in a small bowl nearby. Dip each cauliflower floret into the egg, coat with the panko mixture, then place onto the baking sheet Repeat with remaining cauliflower. Drizzle the coated cauliflower with olive oil and bake for 20 minutes or until crispy and golden brown.

- In a small bowl, mix together the mayo, mustard, garlic, paprika, and hot sauce.

- Assemble the sandwiches with a generous slather of the remoulade, lettuce, tomato, pickles, and cauliflower. Squeeze lemon over the cauliflower, top with chives, and serve with remaining remoulade sauce on the side. 


\section{Crispy Cauliflower Po Boy Sandwich}

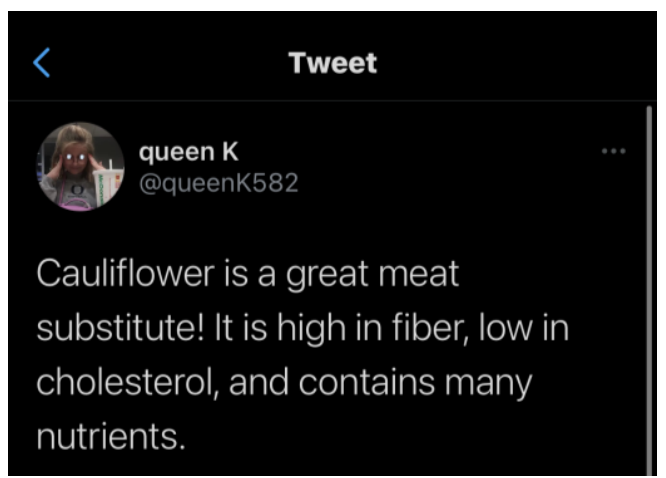

- 4 pieces of sandw ich bread (\$2.49)

- 3 roma tomatoes $(\$ 0.90)$

- Arugala (\$1.00)

- Chive $(\$ 0.45)$

- $\quad 3 / 4$ cup panko bread crumbs $(\$ 0.40)$

- Cauliflow er (FREE though tailgate)

- $\quad 1.5$ tbs Creole seasoning $(<\$ 0.01)$

- $\quad 1$ egg $(\$ 0.13)$

- 1 lemon (FREE fromtailgate)

- Olive oil $(\$ 0.10)$

- $\quad 1 / 2$ cup mayp ( $\$ 0.83)$

- 1 tbs mustard ( \$0.05)

2 garlic clove $(\$ 0.01)$

1 tsp hot Sause $(\$ 0.05)$

(Prices may vary by store) 


\section{Parmasean Crusted Broccoli with Lemon Zest}

Ingredients: Yield (6 servings approximately 1 cups)
- 2 lb broccoli florets (fresh or frozen)

- 4 cloves garlic, chopped

- 4 tablespoons olive oil

- 1 tsp salt

- 1 tsp black pepper
- Zest of 1 lemon

- Juice of $1 / 2$ lemon

- $1 / 3$ cup grated parmasean cheese
Nutrition Facts

\section{6 servings per container}

Serving size

(91g)

Amount Per Serving

130

Calories

$\%$ Daily Value ${ }^{\star}$

Total Fat $2 \mathrm{~g}$

Saturated Fat $1 \mathrm{~g}$

Trans Fat $0 \mathrm{~g}$

Cholesterol $<5 \mathrm{mg}$

Sodium $770 \mathrm{mg}$

Total Carbohydrate 21g

Dietary Fiber $7 g$

Total Sugars $5 \mathrm{~g}$

Includes $0 \mathrm{~g}$ Added Sugars

Protein 10g

$20 \%$

Nota signif
potassium

*The \% Daily Value (DV) tells you how much a nutrient in a serving of food contributes to a daily diet. 2,000 calories a
day is used for general nutrition advice.

Directions: Preparation (10 min) Cook (25 min)

1. Preheat the oven to 425 degrees $F$.

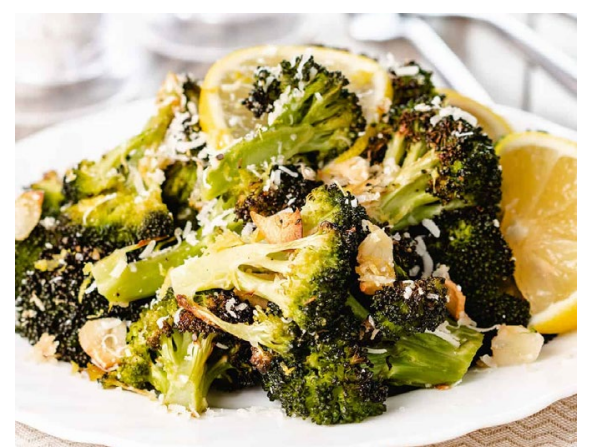

2. Cut the broccoli florets from the thick stalks, leaving an inch or two of stalk attached to the florets, discarding the rest of the stalks. Cut the larger pieces through the base of the head with a small knife, pulling the florets apart. You should have about 8 cups of florets. You may use frozen broccoli if you wish.

3. Place the broccoli florets on a sheet pan large enough to hold them in a single layer. Toss the garlic on the broccoli and drizzle with 5 tablespoons olive oil. Sprinkle with the salt and pepper.

4. Roast for 20 to 25 minutes, until crisp-tender and the tips of some of the florets are browned.

5. Remove the broccoli from the oven and immediately toss with 1 1/2 tablespoons olive oil, the lemon zest, lemon juice, and Parmesan. Serve hot. 


\section{Parmasean Crusted Broccoli with Lemon Zest}

whole recipe.

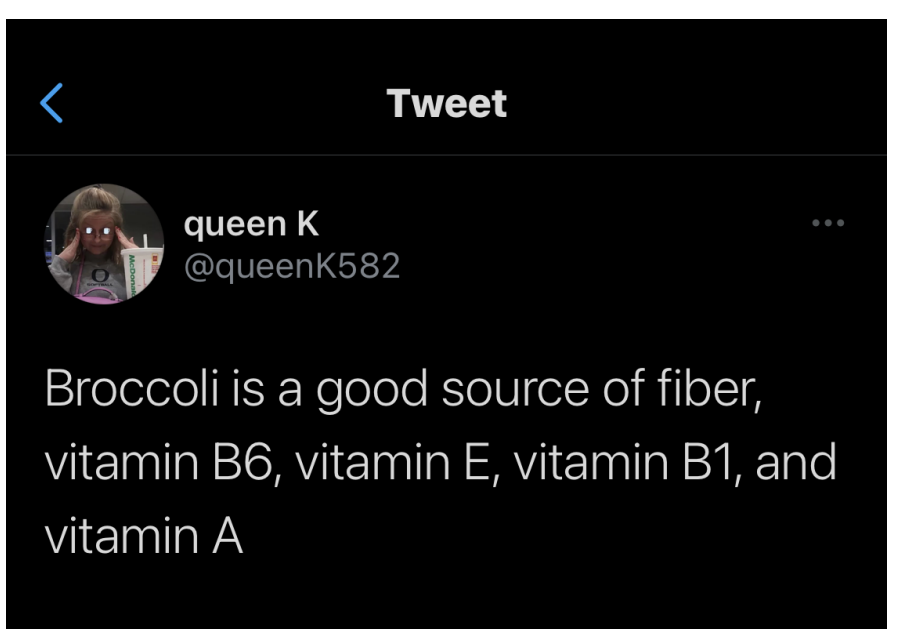

- 2lb borccoli florets (FREE through tailgate)

- 1 bulb garlic (\$0.45)

- 4 tablespoons olive oil $(\$ 0.10)$

- 1 tsp salt $(<\$ 0.01)$

- 1 tsp pepper $(<\$ 0.01)$

- 1 lemon for juice and zest (FREE through tailgate)

- 1/3 cup parmasean (\$0.24)

- (Prices may vary by store) 


\title{
Black Beans and Rice
}

\author{
Servings: 6-8
}

Ingredients:

- 1 cup brown rice

- 1 medium onion

- 1 green bell pepper

- 4 garlic cloves

- 1 can black beans

- 2 tbsp olive oil

- 1 tsp cumin

- 1 tsp oregano

- 1 tsp salt

- Juice from $1 / 2$ lime

- $\quad$ Fresh cilantro for garnish(optional)

\section{Instructions:}

1. Start rice. Follow directions on package.

2. Dice the onion and pepper; mince the garlic

a. Dice the garlic also if you don't have a mincer.

\section{Total cost: $\$ 3.13$}

- $\quad$ Rice: Free from Second Harvest

- Onion: Free from Second Harvest

- Green Pepper: $\$ 0.79$

- Garlic Cloves: $\$ 0.30$

- Black Beans: $\$ 0.79$

- Olive oil: $\$ 0.05$

- Cumin: $\$ 0.01$

- Oregano: $\$ 0.01$

- Salt: $\$ 0.01$

- Lime: $\$ 0.67$

- Cilantro: $\$ .50$

From Payless Groceries*

3. Drain and rinse beans.

4. In a skillet, add oil then cook onions, peppers, and garlic for 5-10 minutes or until the onions become translucent or see-through.

5. Add beans and seasonings and cook for 3 additional minutes.

6. Once rice is done, put onto plate and then place beans and vegetables over bed of rice.

7. Add lime juice to preference and top with fresh cilantro.

Try this recipe with some meat (chicken, pork, beef, steak) to add some additional protein to the meal. Try all of it with some tortillas and make some tacos! 


\title{
Pesto Pasta Recipe
}

\author{
Servings: 5
}

Ingredients:

- Salted water

- 8 oz spaghetti (or preferred pasta)

- $1 / 2$ cup grape tomatoes

- $\quad 1 / 2$ cup parmesan cheese

- 1 cup pesto (add preferred amount)

- Salt to taste
Total Cost: $\$ 3.04$

- Spaghetti: $\$ 0.63$

- Grape tomatoes: $\$ 0.90$

- Parmesan cheese: $\$ 1.50$

- Pesto: Free from Second Harvest

- Salt: $\$ 0.01$

From Payless Groceries*

\section{Instructions:}

1. Cook pasta according to package instructions (usually around 10 minutes). Use salted water.

2. While pasta is cooking, cut tomatoes in half and prepare parmesan cheese (sauté the tomatoes if you'd like)

3. Drain pasta once it is done cooking. Add pasta back into pot.

4. Add pesto sauce and stir.

5. Add tomatoes and parmesan cheese.

Recipe modified from: https://joyfoodsunshine.com/pesto-pasta-recipe/

\section{Nutrition Facts}

\section{5 servings per container}

Serving size $(0.5 \mathrm{~g})$

\section{Amount Per Serving}

Calories 250

\begin{tabular}{cr}
\hline & \% Daily Value* \\
\hline Total Fat $9 \mathrm{~g}$ & $12 \%$ \\
\hline Saturated Fat $2 \mathrm{~g}$ & $10 \%$
\end{tabular}

Trans Fat $0 \mathrm{~g}$

Cholesterol $<5 \mathrm{mg} \quad 1 \%$

Sodium 200mg $\quad 9 \%$

Total Carbohydrate $35 \mathrm{~g} \quad 13 \%$

Dietary Fiber $2 \mathrm{~g} \quad \mathbf{7 \%}$

Total Sugars $1 \mathrm{~g}$ Includes 0g Added Sugars $\quad 0 \%$

Protein $8 \mathrm{~g}$

Not a significant source of vitamin D, calcium, iron, and potassium

- The \% Daily Value (DV) tells you how much a nutrient in a serving of food contributes to a daily diet. 2,000 calories a day is used for general nutrition advice.
Try using whole grain noodles to see if you like them! They are a lot healthier option than regular noodles.

Try refrigerating the pasta and eat it cold for leftovers; just as good as it is warm! 


\section{Lemon Popsicles}

Ingredients: Yield (4 servings)

Nutrition Facts

- 3 cups filtered water

- $\quad 1 / 2$ cup fresh lemon juice

- 5 tablespoons honey or maple syrup (use 6

if you like lemonade on the sweeter side)

\section{Pinit}

Directions: Preparation (10 minutes) Freeze Time (4 hours)

- Juice the lemons and pour the measured juice into a large bowl, pitcher, or 2 quart measuring cup. (Make sure it's something that's easy to pour from)

- Add in the honey and water and whisk until well combined.

- Make sure there's an open spot in your freezer where the mold can safely sit where it's not going to tip over. Transfer your popsicle mold into the freezer and freeze for about 4-6 hours or overnight.

- Store your popsicles in a silicone freezer bag, or a gallon Ziplock bag for up to 2 weeks. 


\section{Lemon Popsicles}

When life gives you lemons - make lemon popsicles!

Fun fact! Lemons are a wonderful full of vitamin C. There are also about 15 calories in each lemon.

\section{Everyone can reply}

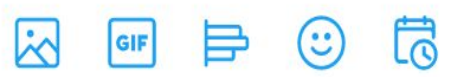

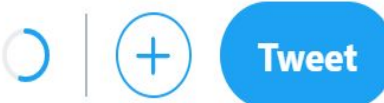

Price Breakdown: $\$ 0.70$ for the whole recipe

- A bundle of lemons

- Free Second Harvest Item

- Honey

- $\$ 3.29 / 24$ tablespoon $=$

$0.14 \times 5=0.7$ for 5 tablespoons.

- Water

- Free if you have access to it.

(Prices may vary by store) 


\section{Roasted Red Pepper Hummus}

Ingredients: Yield (6 servings approximately 1 1/2 cups)

- 2 Whole red peppers (or $3 / 4$ cup chopped jarred roasted red peppers)

- 1 (15-ounce) can chickpeas or $1 \frac{1}{2}$ (250 grams) cooked Chickpeas

- $\quad 1 / 4$ cup $(60 \mathrm{~mL}$ ) fresh lemon juice (about 1 large lemon)

- $\quad 1 / 4 \operatorname{cup}(60 \mathrm{~mL})$ tahini

- 1 small garlic clove, minced
- 1 tablespoons extra virgin olive oil

- $\quad 1 / 2$ teaspoon ground cumin

- $\quad$ Pinch cayenne pepper (optional)

- Salt to taste

\begin{tabular}{|c|c|}
\hline $\begin{array}{l}6 \text { servings per container } \\
\text { Serving size }\end{array}$ & 1/4 Cup \\
\hline \multicolumn{2}{|l|}{$\begin{array}{l}\text { Amount Per Serving } \\
\text { Calories }\end{array}$} \\
\hline \multicolumn{2}{|r|}{ \$ Daily Value" } \\
\hline Total Fat $0 \mathrm{~g}$ & $0 \%$ \\
\hline Saturated Fat $0 \mathrm{~g}$ & $0 \%$ \\
\hline \multicolumn{2}{|l|}{ Trans Fat $0 \mathrm{~g}$} \\
\hline Sodium 0mg & $0 \%$ \\
\hline Total Carbohydrate $18 \mathrm{~g}$ & $7 \%$ \\
\hline Dietary Fiber $5 \mathrm{~g}$ & $18 \%$ \\
\hline \multicolumn{2}{|l|}{ Total Sugars $4 \mathrm{~g}$} \\
\hline Includes $0 \mathrm{~g}$ Added Sugars & $0 \%$ \\
\hline Protein 6g & $12 \%$ \\
\hline \multicolumn{2}{|c|}{$\begin{array}{l}\text { Not a significant source of cholesterol, veamin D, calcium, } \\
\text { iron, and potassium }\end{array}$} \\
\hline $\begin{array}{l}\text { - The \% Daily Value (DV) tells you how much } \\
\text { senving of food contrbules to a dalily diet. } 2 \text {. } \\
\text { day is used for general nutrition advice. }\end{array}$ & $\begin{array}{l}\text { a nutrient in a } \\
00 \text { calories a }\end{array}$ \\
\hline
\end{tabular}

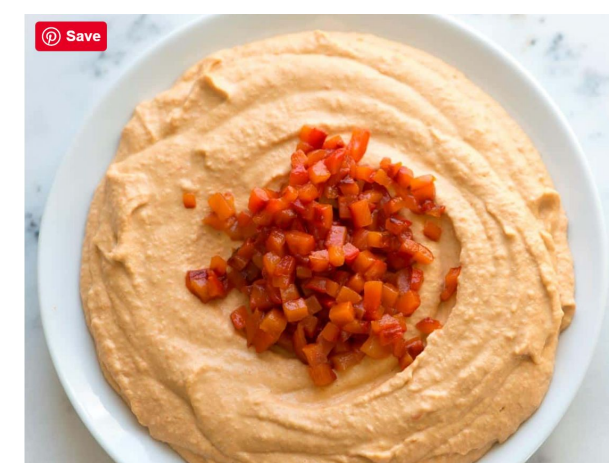

Directions: Preparation (25 min) Cook (10 min)

- Move an oven rack so that it is about 5 inches from the broiler. Turn oven broiler on

- Remove the core of the peppers then cut into large flat pieces.

- Arrange pepper pieces, skin-side up, on a baking sheet. Broil 5 to 10 minutes until the peppers skin has charred.

- Add peppers to a resealable plastic bag, seal then wait 10 to 15 minutes until cool enough to handle. Gently peel away the charred pepper skin and discard. Reserve 1 to 2 pieces of the peeled roasted pepper pieces to use as a garnish when serving then roughly chop the rest

- In the bowl of a food processor, combine the tahini and lemon juice and process for 1 minute, scrape the sides and bottom of the bowl

then process for 30 seconds more.

- Add the olive oil, minced garlic, cumin, and a $1 / 2$ teaspoon of salt to the whipped tahini and lemon juice. Process for 30 seconds, scrape the sides and bottom of the bowl then process another 30 seconds or until well blended.

- Open, drain, and rinse the chickpeas. Add half of the chickpeas to the food processor and process for 1 minute. Scrape sides and bottom of the bowl, then add remaining chickpeas and process until thick and quite smooth; 1 to 2 minutes.

- $\quad$ Add the roasted peppers and continue to process for 1 to 2 minutes or until smooth. If the hummus is too thick or still has tiny bits of chickpea, with the food processor turned on, slowly add 1 to 3 tablespoons of water until you are happy with the consistency.

- $\quad$ Taste for salt and adjust as needed. Finely chop the reserved peppers. Spoon hummus into a bowl, make a small well in the middle and add the chopped peppers. Store homemade hummus in an airtight container and refrigerate up to one week. 


\section{Roasted Red Pepper Hummus}

Fun Fact! Chickpeas are packed with nutrients! They are a rich source of vitamins, minerals and fiber!

They also improve digestion and aid in weight management!

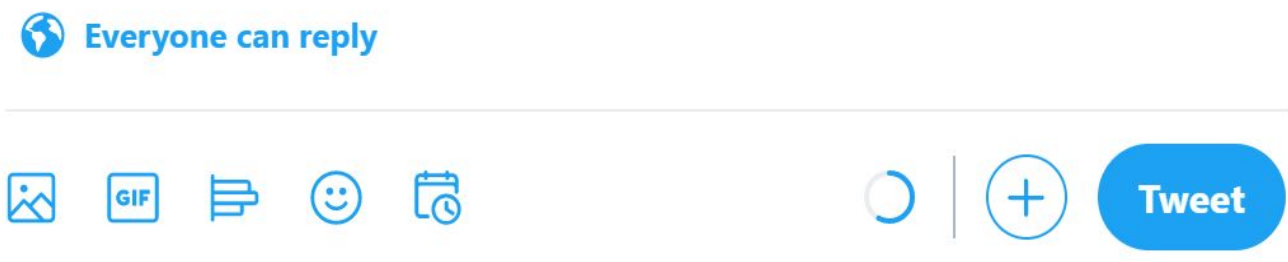

Total Price Breakdown: $\$ \mathbf{5 . 9 0}$ total for the whole recipe.

- $\quad 2$ whole red peppers

- $\$ 3.00$

- $\quad 1$ (15 oz) can chickpeas

- FREE through Tailgate

- 1 large lemon

$$
\text { - } 0.59
$$

- $\quad 1 / 4$ cup tahini

$$
\text { - } \$ 1.07
$$

- $\quad$ ! small garlic clove

$$
\text { - } 0.49
$$

- $\quad 1$ tsp Olive Oil

- $\quad 0.25$

- $\quad 1 / 2$ tsp cumin

- 0.01

- Salt to taste

$$
\text { - } 0.49
$$

(Prices may vary by store) 


\section{Aloo Matar (Potatoes and Peas Curry)}

Servings 6

Total Price: $\sim \$ 3.30$

Breakdown:

Oil $\$ 0.30$

Potatoes: free

Peas: 1.00

Tomatoes: 1.00

Onion: free

4 cloves garlic: 0.20

Ginger: 0.20

Turmeric: 0.20

Garam masala: 0.10

Cumin: 0.15

Coriander: 0.15

\section{Ingredients}

Prices change per store.

- 3 Tablespoons Oil, butter, or ghee

- 3 large russet potatoes, peeled and chopped

- $115^{-o z}$ bag of frozen peas (or $115^{-o z}$ can of peas)

- 128-oz can of crushed tomatoes or tomato puree

- $\quad 1 / 2$ large onion, finely diced

- 4 cloves of garlic, minced

- 12 -inch piece of ginger, minced (or $1 / 2$ tsp ground ginger)

- 1 inch piece of turmeric, minced (or $1 / 4$ tsp ground turmeric)

- 1 tsp garam masala

- 1 tsp cumin seeds (or ground cumin)

- 1 tsp coriander seeds

- $\quad$ salt to taste 
Instead of red wine, you can substitute 2 tbsp of red wine vinegar $+1 / 2$ cup water.

\section{Instructions}

1. Boil water.

2. Peel potatoes, and chop into 3 inch pieces.

3. Add potatoes to the boiling water and boil until fork tender, about 10 minutes.

4. While the potatoes are boiling, dice onion and mince garlic. Also mince ginger and turmeric, or use ground ginger and turmeric in step 6.

5. Heat oil in a large pot.

6. Once heated, add onion, ginger, turmeric, and garlic. Cook on medium high for 2-3 minutes.

7. Add cumin and coriander seeds. Cook for another 1 minute.

8. Add potatoes, tomatoes, peas and garam masala, and mix together. Add salt to taste. Cook for another 5 minutes.

9. Serve and enjoy by itself, or with rice or flatbread.

Recipe modified from:

https://www.indianhealthyrecipes.com/aloo-matar-recipe-aloo-mutter-recipe/ 


\title{
French Onion Lentil Soup
}

\section{Ingredients}

\author{
Servings 4
}

\author{
Total Price: $\sim \$ 5.70$ \\ Per serving: 1.43 \\ Breakdown: \\ Oil $\$ 0.30$ \\ garlic: $\$ 0.20$ \\ Onions: free \\ Lentils: 0.50 \\ Vegetable broth: 2.00 \\ Red wine: 1.00 \\ Bay leaves: 0.10 \\ Thyme: 0.10 \\ Croutons: 0.50 \\ Cheese: 1.00 \\ Prices change per store.
}

- 2 Tablespoons Olive Oil or butter

- 4 large or 5 medium onions, sliced thinly (sweet, white, or yellow onions work well)

- 4 cloves of garlic, minced

- $\quad 1 / 2$ cup of green or brown lentils

- $1 / 2$ cup of red wine

- 5 cups vegetable or chicken broth

- 2 bay leaves, dried

- 1 tsp dried thyme

- 1 cup croutons

- 1 cup shredded cheese (Swiss cheese or mozzarella would work)

- 1 teaspoon salt or more to taste

- pepper to taste 


\section{Instructions}

1. Preheat oven to $450 \mathrm{~F}$

2. Slice onions and mince garlic.

Instead of red wine, you can

substitute 2 tbsp of red wine

vinegar $+1 / 2$ cup water.

3. Heat oil in a large pot.

4. Once heated, add garlic and onion, stirring frequently. Cook for about 30 minutes, until onions are caramelized.

5. Add broth, red wine, bay leaves, thyme, salt, and pepper.

6. Add lentils and cook until tender, about 20 minutes.

7. Spoon soup into oven-safe bowls, and top with croutons and cheese

8. Place the bowls into the oven for 5-10 minutes, until the cheese is browned.

9. Serve and enjoy

Recipe modified from:

https://www.kudoskitchenbyrenee.com/french-onion-lentil-soup/ 


\section{Breakfast Skillet}

Ingredients: Yield (4 person)

\section{Enjoy!}

2 tablespoons of a neutral oil

$\checkmark 4$ medium potatoes

0.5 of a large onion

1 green bell pepper

- 8 pieces of bacon

1 cup of shredded cheddar cheese

$\checkmark 4$ eggs

- Salt and pepper to taste

\section{Directions:}

1. Fry bacon to desired crispiness; leave on paper towel to absorb excess oil and drain grease from pan; crumble the bacon after cooling.

2. Add your oil of choice and cook peppers and onions until soft, about 5-6 mins; season as desired.

3. Meanwhile, shred your potatoes and squeeze out the excess water using a towel; add potatoes to veggies and cook thoroughly.

4. In a separate pan, fry an egg to top your skillet with; sunny-side up is recommended, but any way will work!

5. Transfer potato mixture to a bowel, top with a hearty sprinkle of cheese, top with crumbled bacon, and your fried egg.

\section{Nutrition Facts}

Servings 4.0

Amount Per Serving

calories 421

$\%$ Daily Value

\begin{tabular}{|ll|}
\hline Total Fat $25 \mathrm{~g}$ & $38 \%$ \\
\hline Saturated Fat $8 \mathrm{~g}$ & $42 \%$ \\
\hline
\end{tabular}

Monounsaturated Fat 7

Polyunsaturated Fat $5 \mathrm{~g}$

Trans Fat $0 \mathrm{~g}$

Cholesterol $227 \mathrm{mg}$

Sodium $592 \mathrm{mg}$

Potassium $842 \mathrm{mg}$

Total Carbohydrate $30 \mathrm{~g}$

$10 \%$

Dietary Fiber $3 \mathrm{~g}$

$11 \%$

Sugars $3 \mathrm{~g}$

Protein $21 \mathrm{~g}$

Vitamin A

Vitamin C

Calcium

Iron

- The Percent Daily Values are based

on a 2,000 calorie diet, so your values

may change depending on your

calorie needs. The values here may

not be $100 \%$ accurate because the

recipes have not been professionally

evaluated nor have they been

evaluated by the U.S. FDA. 


\section{Let's break it down!}

- Potatoes $=\$ 1.92$

- Onion = FREE from Tailgate! $:$

- Green pepper $=\$ 0.77$

- Bacon $=\$ 1.62$

$>$ Cheese $=\$ 0.90$

$>\mathrm{Egg}=\$ 0.20$

TOTAL: \$5.41 for 4 servings OR \$1.35 per person

*does not include pantry staples such as oil, salt, and pepper 


\section{Cheesy Baked Onions}

Serving Size: 2 servings $\$ 1.56$ per serving $\$ 3.12$ overall (if using free onions $\$ 0.56$ overall)

\section{INGREDIENTS}

1 medium onion

1 tablespoon butter

1 tablespoon flour

$1 / 2$ cup $2 \%$ milk

$1 / 3$ cup shredded cheddar cheese

\section{DIRECTIONS:}

- Slice onion and separate into rings; place in a greased baking dish and set aside.

- In a small saucepan over low heat, melt the butter. Stir in the flour until smooth. Gradually add milk; bring to boil over medium heat. Cook and stir for 2 minutes. Remove from heat; stir in cheese until melted.

- Pour over onions. Bake, uncovered, at 350 degrees for 45-50 minutes or until onions are tender and cheese is browned.

Trans Fat og

Cholesterol $40 \mathrm{me}$ 


\section{Cheesy Onions Substitution Options}

- If onions are not available and you receive potatos as a free tailgate food, cut up the potatoes and create a side dish of cheesy potatoes!

- Add some extra oregano, basil, paprika, or even chili powder to spice up this easy recipe!

- To unpeel your onions, roll the onion (unpeeled) on the counter or shake within a closed mason jar to help start the process.

- Add these on top of tacos, chicken or beef to add another layer of wonderful flavor!
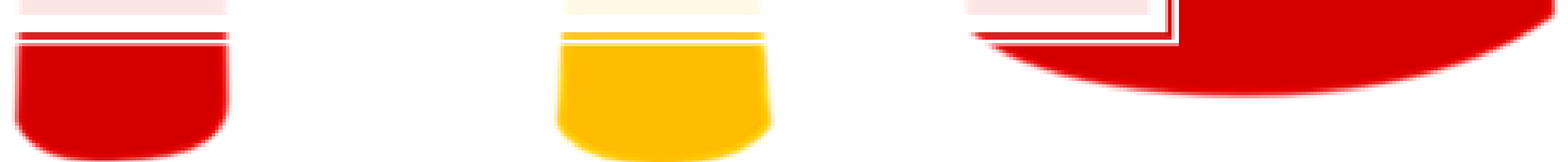


\section{Tasty Lentil Meat Tacos}

Serving Size: 6 servings $\$ 1.13$ per serving $\$ 6.78$ overall (if using free onions $\$ 5.40$ overall)

\section{Ingredients:}

1 teaspoon oil

1 medium onion, finely chopped

1 garlic clove, minced

1 cup dried lentils, rinsed

2-1/2 cups vegetable or reduced-sodium chicken broth
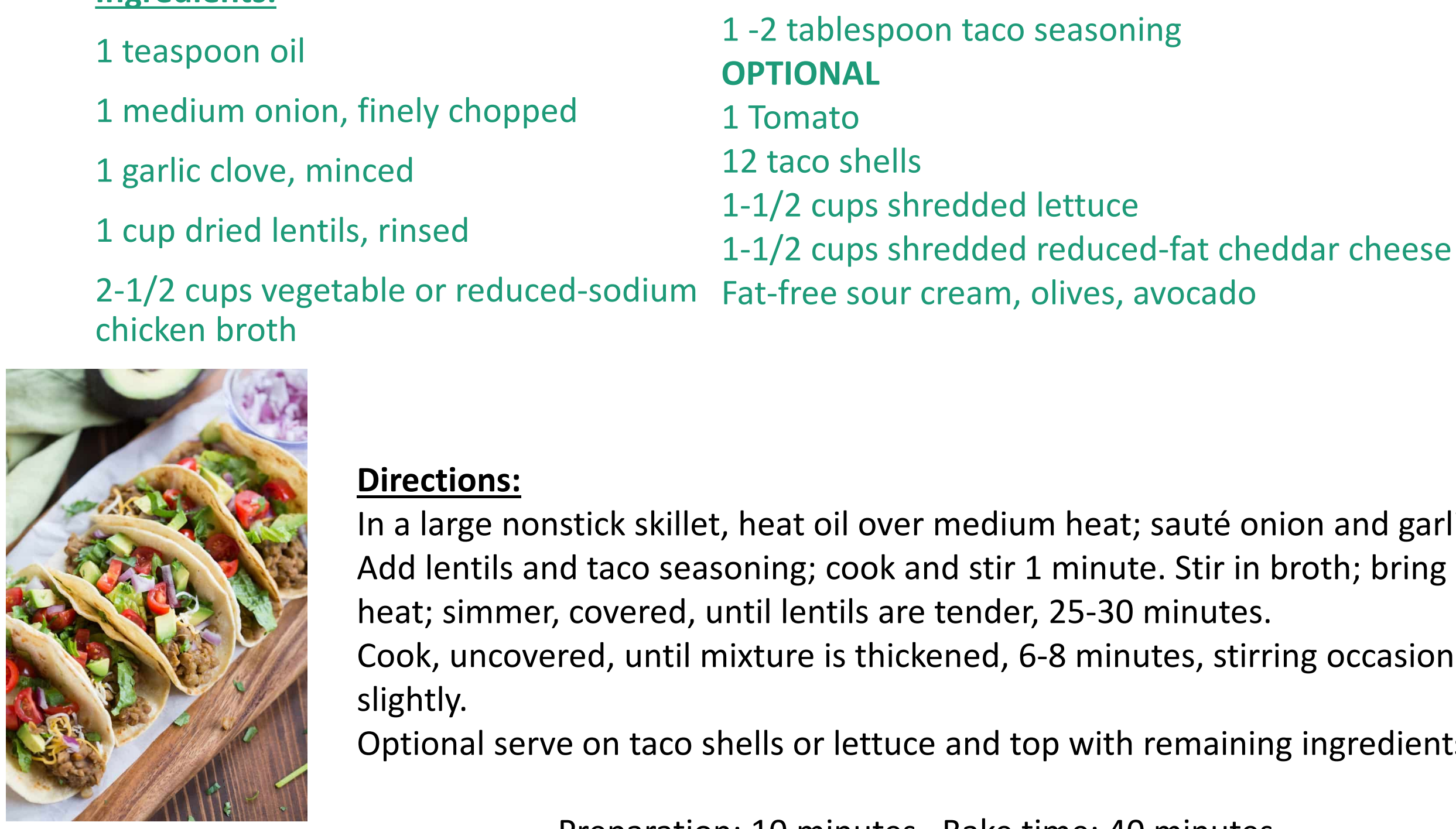

\section{Directions:}

In a large nonstick skillet, heat oil over medium heat; sauté onion and garlic until tender. Add lentils and taco seasoning; cook and stir 1 minute. Stir in broth; bring to a boil. Reduce heat; simmer, covered, until lentils are tender, 25-30 minutes.

Cook, uncovered, until mixture is thickened, 6-8 minutes, stirring occasionally. Mash lentils slightly.

Optional serve on taco shells or lettuce and top with remaining ingredients. 


\section{Tasty Tacos Substitution Options}

- If you do not want to put your taco meat on lettuce or in a taco shell, try putting this over brown rice!

- Lentils can also be substituted for cooked tofu, chicken or beef for wonderful tasty tacos!

- If you do not think you have enough liquid when boiling the lentils, add more chicken/veggie broth or even water!
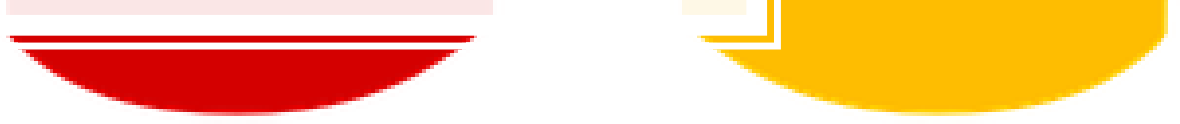


\section{Banana Muffins}

Ingredients: Yield 12 muffins

- 3 ripe bananas

- 1 cup sugar

- 1 egg

- $1 / 4$ cup melted butter

- $11 / 2$ cups all purpose flour

- 1 tsp baking soda

- 1 tsp salt
Extras:

1 tsp cinnamon

1 tsp vanilla

Topping ideas:

Walnuts

Chocolate chips

Frozen or fresh berries

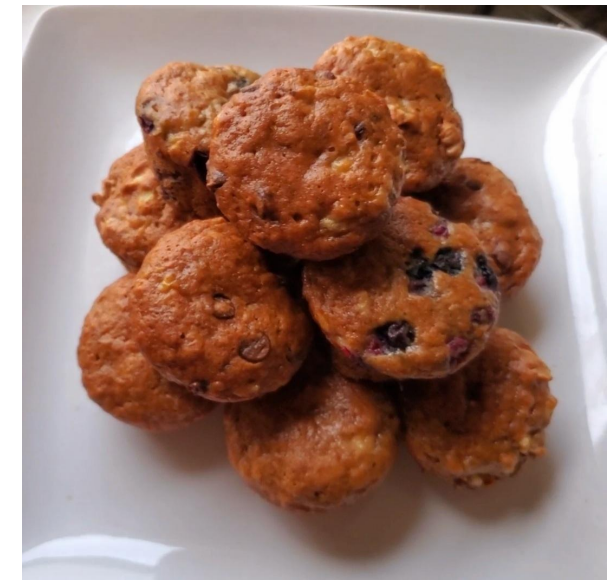

Directions: Preparation (15 min) Cook (25 min)

- $\quad$ Preheat oven to 325 degrees F (165 degrees C). Grease a muffin pan.

- Combine bananas, sugar, egg, and butter together in a bowl.

- Mix flour, salt, and baking soda together in a separate bowl; stir into banana mixture until batter is just mixed.

- Add in any additional toppings such as walnuts, chocolate chips, or berries to batter.

- Bake in the preheated oven for 25 minutes.

\section{Nutrition Facts}

Servings: 12

\section{Amount per serving}

Calories

$\%$ Daily Value*

Total Fat $4.3 \mathrm{~g}$

$5 \%$

Saturated Fat $2.6 \mathrm{~g}$

$13 \%$

Cholesterol 24mg

$8 \%$

Sodium $33 \mathrm{mg}$

$1 \%$

Total Carbohydrate 26.3g

$10 \%$

Dietary Fiber $0.9 \mathrm{~g}$

$3 \%$

Total Sugars $20.4 \mathrm{~g}$

Protein $1.2 \mathrm{~g}$

Vitamin D $4 \mathrm{mcg}$

$20 \%$

Calcium 5mg

Iron Omg

Potassium 112mg

$0 \%$

$2 \%$

$2 \%$

*The \% Daily Value (DV) tells you how much a nutrient in a food serving contributes to a daily diet. 2,000 calorie a day is used for general nutrition advice. 


\section{Banana Muffins}

Total Price Breakdown for basic recipe:

$\$ 1.08$ for the whole recipe

$\$ 0.09$ per serving

3 bananas

1 cup sugar

1 egg

4 lbs=8 cups

1 dozen/12

$1 / 2$ stick $\$ 2.98 / 4$

$1 / 4$ cup melted butter

$1 \frac{1}{2}$ cups all purpose flour 5 lbs=18.1 cups 18.1/1.5

1 tsp baking soda

1 tsp salt

Total Price Breakdown if Bananas are free:

$\$ 0.84$ for the whole recipe

\$0.07 per serving
Tips:

- You can use either brown or regular

$\$ 0.08 \times 3$

$\$ 0.24$

$\$ 1.98 / 8$

$\$ 0.25$

$\$ 0.68 / 12 \quad \$ 0.06$

$\$ 0.75 / 2 \quad \$ 0.37$

$\$ 1.78 / 12 \quad \$ 0.15$

$\$ 0.52 / 95 \quad \$ 0.01$

$\$ 0.38 / 123 \$ 0.00$

$\$ 0.00$

(1)

(1)

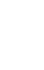




\section{Black Bean Corn Salsa}

\section{Ingredients: Yield 12 servings}

- 1-15 oz can black beans

- 1-15 oz can whole kernel corn

- $1 / 3$ of a bundle of cilantro (about $1 / 4$ cup chopped)

- 1 roma tomato

- $1 / 4$ red onion

- juice from $1 / 2$ of a lime

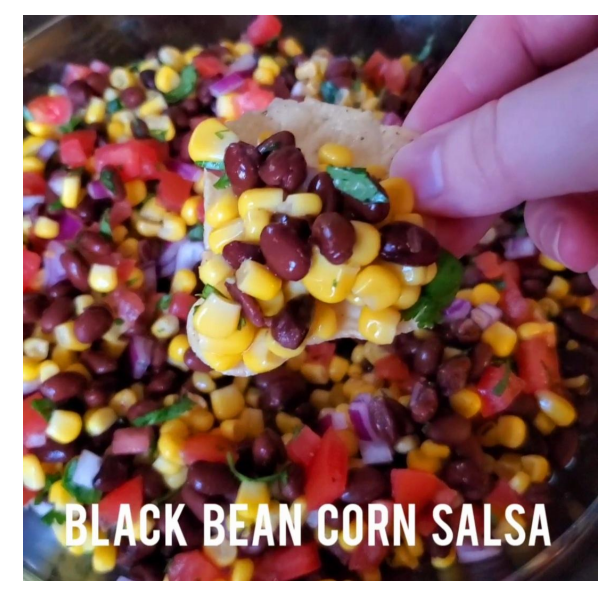

Directions: Preparation (10 $\mathrm{min}$ )

- Rinse black beans and corn together and place aside in a bowl

- Rinse about $1 / 3$ of a bundle of cilantro, remove leaves from the stems, and finely chop the leaves

- Cut one roma tomato in half, slice, and then chop into small cubes

- Chop $1 / 4$ of an onion (color doesn't matter, but red onion is seen in picture) to about the same size as the tomatoes

- Place all ingredients into the bowl with the beans and corn

- Roll a lime on a hard surface, cut it in half, and squeeze the juice of half of it in the bowl

- Mixed together and enjoy with chips, on tacos, and on burritos

\section{Nutrition Facts}

Servings: 12

\section{Amount per serving}

Calories

$\%$ Daily Value*

Total Fat $0.4 \mathrm{~g}$

$1 \%$

Saturated Fat $0 \mathrm{~g}$

$0 \%$

Cholesterol Omg

$0 \%$

Sodium $79 \mathrm{mg}$

$3 \%$

Total Carbohydrate $8.9 \mathrm{~g}$

$3 \%$

Dietary Fiber $1.8 \mathrm{~g}$

$6 \%$

Total Sugars $1.5 \mathrm{~g}$

Protein $2 \mathrm{~g}$

Vitamin D Omcg

$0 \%$

Calcium 5mg

Iron $1 \mathrm{mg}$

Potassium 116mg

${ }^{*}$ The \% Daily Value (DV) tells you how much a nutrient in a food serving contributes to a daily diet. 2,000 calorie a day is used for general nutrition advice. 


\section{Black Bean Corn Salsa}

Tips:

- You can use any color onion for this recipe. Don't have red? Use White!

- Keep your cilantro longer in the fridge by putting the stems in water like they are flowers

- For more flavor, add salt and pepper to taste and 1 tsp garlic powder
Total Price Breakdown:

$\$ 2.57$ for the whole recipe

$\$ 0.21$ per serving

15 oz can black beans

$\$ 0.54$

15 oz can whole kernel corn

$\$ 0.98$

$1 / 3$ of a bundle of cilantro $\$ 0.88 / 3$

$\$ 0.29$

1 roma tomato

$\$ 0.29$

$1 / 4$ onion

$\$ 0.78 / 4$

$\$ 0.20$

$1 / 2$ of a lime

$\$ 0.54 / 2$

$\$ 0.27$

Total Price Breakdown if Onion is free:

$\$ 2.37$ for the whole recipe

$\$ 0.20$ per serving 


\section{Garlic Spinach and White Beans}

Prep Time- 5 minutes

Cook Time- 5 minutes

Serves-2

Ingredients

- 1 Tablespoon of Extra Virgin Olive Oil

- 2 Garlic Cloves

- 1 cup White Beans

- $1 \frac{1}{2}$ cups Baby Spinach

- $1 / 2$ Tablespoon of Parsley

- $1 / 2$ Tablespoon of Lemon Juice

- Pinch of Salt

- Pinch of Pepper

\section{Instructions}

1. Heat a medium saucepan, then add extra virgin olive oil into the saucepan allow the oil to heat up. Add minced garlic and stir until brown.

2. Add drained white beans in saucepan and stir.

3. After stirring for 1 to 2 minutes add baby spinach into the saucepan and continue stirring.

4. Pour lemon juice into the saucepan and stir, then add salt pepper, and parsley. Stir and the dish is ready to serve

\section{Additional options}

- You may consider adding seafood, chicken or ground beef to this dish.

- You may also consider adding other vegetables to this dish. 


\section{Watermelon Lemonade}

\section{Prep Time-15 minutes}

\section{Serves-3}

\section{Ingredients}

- 3 cups cubed Watermelon

- 2 cups of Cold Water

- $1 / 4$ cup Lemon Juice

- $1 / 3$ cup sugar

- Ice

- Mint leaf for garnish (optional)

\section{Instructions}

1. Begin by carving and dicing watermelon, then place the diced watermelon into the blender.

2. Next pour lemon juice into the blender, then pour two cups of water into the blender.

3. Add sugar into the blender then blend ingredients together.

4. Blend until a smooth texture

5. Pour over a cup of ice, add mint for garnish and enjoy. 


\section{Avocado Chickpea Salad}

Servings: 4

\section{Ingredients}

- 1 Can of Garbanzo Beans (chickpeas)

○ 1/2 Cucumber

○ 1 Avocado

- 3/4 Cup of Grape Tomatoes

○ 1 Cup of Mozzarella Pearls

- 1/4 Cup of Balsamic Vinaigrette Dressing
Total Price: $\sim \$ 9.38$

Breakdown:

Chickpeas: $\$ 0.79$

Cucumber: $\$ 0.49$

Avocado: \$o.69

Grape Tomatoes: $\$ 2.50$

Mozzarella Pearls: $\$ 3.99$

Balsamic Vinaigrette: $\$ 0.92$ (full container)

Prices change per store.

\section{Instructions}

1. Open and wash can of garbanzo beans, grape tomatoes, and cucumber. Let garbanzo beans dry.

2. Cut cucumber and avocado into small dices, cut grape tomatoes into halves, and place in a large bowl.

3. Add mozzarella pearls and garbanzo beans into bowl.

4. Pour dressing into bowl and mix.

5. Add more pearls, avocado, dressing, etc. as wanted, and serve.

Garbanzo beans are a great source of vitamins, minerals, fiber, and protein. Also, a great food source for those who do not eat animal products. 


\section{Roasted Carrots and Potatoes}

Servings: 6

\section{Ingredients}

- 1 lb. Small Red Potatoes

○ 1 lb. Carrots

○ 1 Medium Onion

- 3 Tbsp Olive Oil

○ 2 tsp Minced Garlic

○ 1 tsp Thyme

○ 1 tsp Salt

○ 1 tsp Pepper

\section{Instructions}

Total Price: $\sim \$ 6.52$
Breakdown:
Onion: $\$ 0.90 \rightarrow$ Tailgate Item
Red Potatoes: $\$ 1.24 \rightarrow$ Tailgate Item
Carrots: $\$ 1.20 \rightarrow$ Tailgate Item
Oil: $\$ 0.50$
Thyme: $\$ 0.94$ (full container)
Minced Garlic: $\$ 1.74$ (full container)
Salt and Pepper: common home item
Prices change per store.
Have you tried sweet potatoes?!
They are a great source of
Vitamin C, try this as a
substitution for any potato.

Total Price: $\sim \$ 6.52$

Breakdown:

Onion: $\$ 0.90 \rightarrow$ Tailgate Item

Carrots: $\$ 1.20 \rightarrow$ Tailgate Item

Oil: $\$ 0.50$

Thyme: \$0.94 (full container)

Minced Garlic: \$1.74 (full container)

Salt and Pepper: common home item

Prices change per store.

Have you tried sweet potatoes?!

They are a great source of Vitamin C, try this as a

1. Preheat oven to $425^{\circ} \mathrm{F}$. Line a baking sheet with foil or parchment paper.

2. Wash and dry the potatoes. Chop the small potatoes into quarters. Potatoes should be smaller than carrots, to ensure they cook at the same time.

3. Chop onion.

4. Mix olive oil, garlic, thyme, salt, and pepper in a large bowl. (Mix seasonings first, before adding the oil)

5. Add potatoes, carrots, and onions to the bowl. Mix and coat the vegetables with oil and seasonings.

6. Spread potatoes, carrots, and onions in a single layer on the baking sheet. Roast in the oven for 40 minutes or until they reach tenderness. Stir halfway through cooking time.

7. Season with more salt and pepper (optional), serve warm.

Recipe modified from: https://thesimpleparent.com/roasted-potatoes-and-carrots/ 


\section{Lentil-Beef Meatloaf Muffins}

Servings: 3

\section{Ingredients}

- $\quad 1 / 2$ cup dry lentils

- $1 / 2 \mathrm{lb}$. lean ground beef

- $1 / 2$ cup breadcrumbs

- 1 large egg

- 2 Tbsp ketchup

- 2 tsp Worcestershire sauce

- $1 / 2$ tsp onion powder

- $1 / 2$ tsp garlic powder

- $1 / 8$ tsp salt

- $1 / 8$ tsp pepper

\section{Sauce}

- $1 / 4$ cup ketchup

- $1 / 2$ Tbsp brown sugar

- $\quad 1 / 2$ tsp Dijon mustard
Total Cost: $\$ 2.78$

Lentils - Free from Second Harvest

Lean ground beef $-\$ 2.44$

Breadcrumbs - $\$ 0.21$

Egg $-\$ 0.06$

Ketchup - $\$ 0.14$

Worcestershire $-\$ 0.03$

Onion powder $-\$ 0.01$

Garlic powder $-\$ 0.01$

Brown sugar $-\$ 0.01$

Dijon mustard- $\$ 0.01$

Prices change per store.

Add some oregano or basil for even more flavor!

\section{Instructions}

1. Combine lentils and water in a small pot. Simmer $\sim 30$ min or until tender.

2. Drain any remaining liquid from the lentils.

3. Preheat oven to $375 \mathrm{~F}$.

4. In a large bowl, mix together lentils, beef, breadcrumbs, an egg, ketchup, Worcestershire sauce, onion powder, garlic powder, salt, and pepper.

5. For the sauce: In a small bowl, mix together ketchup, brown sugar, and Dijon mustard.

6. Top each meatloaf muffin with equal amounts of sauce.

7. $\quad$ Bake for about 25 minutes, or until $165 \mathrm{~F}$

8. Rest for 5 minutes and serve!

Recipe modified from: https://www.todaysparent.com/recipe/make-ahead-meals/lentil-and-beef-minimeat-loaves-recipe/ 


\section{Yogurt Apple Dip}

Servings: $\mathbf{1 - 2}$

\section{Ingredients}

- 1 large apple, any variety

- 1 cup plain yogurt

- 1 tbsp peanut butter

- $1 / 4$ tsp cinnamon powder

- 1 tsp honey

\section{Total Cost: $\$ 1.29$}

Yogurt - Free from Second Harvest

Honey Crisp Apple - \$1.18

Peanut butter - $\$ 0.04$

Cinnamon Powder - \$0.01

Honey - $\$ 0.06$

Prices vary per store.

\section{Pumpkin pie spice is a nice substitute for cinnamon if you have \\ it!}

\section{Instructions}

1. Rinse the apple well.

2. Slice the apple into $1 / 4$ inch thick pieces.

3. In a small bowl, add yogurt, cinnamon, honey, and peanut butter.

4. Mix until well combined.

5. Serve with sliced apple and enjoy! 


\title{
Roasted Broccoli with Garlic
}

\section{Ingredients}

\author{
Servings 2
}

- 2 Tablespoons Olive Oil

- 1 head of broccoli

- 2 cloves of garlic

- 1 teaspoon salt

- 1 teaspoon pepper

\section{Instructions}

1. Preheat oven to 375 degrees

2. Chop a head of broccoli into bite size pieces

3. Mince 2 cloves of garlic into small bowl

4. Place aluminum foil onto baking sheet

5. $\quad$ Spread broccoli onto baking sheet

6. Place garlic all over broccoli

7. Drizzle olive oil onto broccoli

8. Sprinkle salt and pepper onto broccoli

9. $\quad$ Place tray in oven for 30 minutes

10. Serve and enjoy

Recipe modified from:

https://www.pinterest.com/pin/5418462035423181/

Broccoli is a good source of

Vitamin K, which helps

improve cognitive

functioning. 


\title{
Smashed Potatoes
}

\section{Ingredients}

\author{
Servings 6
}

- 3 Tablespoons Olive Oil

- 12 whole potatoes

Total Price: $\sim \$ 5.79$

Breakdown:

- Salt (to taste)

Oil \$0.30

- Pepper (to taste)

- Rosemary (to taste)

5lbs of potatoes: $\$ 3.49$

1 bag of parmesan cheese: $\$ 2.00$

Prices change per store.

- Parmesan, finely grated.

\section{Instructions}

1. Preheat oven to 450 degrees

2. Bring a pot of salted water to a boil. Add in as many potatoes as you wish to make and cook them until they are fork tender.

3. Drizzle a sheet pan with olive oil. Place tender potatoes on the sheet pan, leaving plenty of room between each potato.

4. With a potato masher, gently press down each potato until it slightly mashes, then push the excess out of the masher back on top of the potatoes. Rotate the potato masher 90 degrees and mash again, pushing out the excess. Drizzle the tops of each crushed potato generously with more olive oil. Sprinkle potatoes with kosher salt, fresh ground black pepper and fresh chopped rosemary (or chives or thyme or whatever herb you have available.) Add grated Parmesan.

5. $\quad$ Bake in a 450 degree oven for 20-25 minutes until golden brown and sizzling.

Potatoes are a good source of fiber, which can help prevent heart disease by keeping cholesterol levels

Recipe modified from: steady. 


\section{Fresh Pesto}

Yields 1cup

\section{Ingredients}

- 2 cups Fresh Basil Leaves (packed)

- $1 / 2$ cup Olive Oil

- 1/2 cup Parmesan or Romano Cheese

- $1 / 3$ cup Walnuts

- 3 Garlic Cloves Minced (2 tsp. minced garlic)

- 1/4 teaspoon Salt

- 1/8 teaspoon Pepper

\section{Instructions}

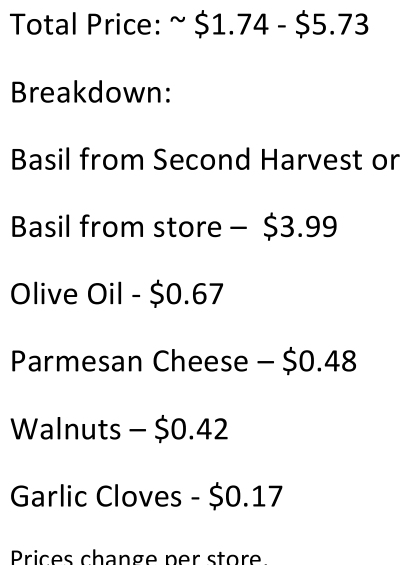

Use cashews or any other nuts you may have available

Substitute 1-cup basil for 1 cup of spinach, kale, or any other leafy green

1. Place all ingredients into food processor

2. Pulse processor 3 times (10-15 seconds)

3. Use spatula to stir and scrape sides

4. Repeat this process until desired consistency

5. Garnish with a sprinkle of Parmesan or Romano Cheese and serve 6. Or add to your favorite recipe

Recipe modified from:

https://www.simplyrecipes.com/recipes/fresh_basil_pesto/ 


\section{Pesto Chicken with Roasted Tomatoes}

\section{Ingredients}

Servings 4

- 2 lbs. Chicken Breast (about 3 to 4 breasts)

- 1 Cup Fresh Pesto (click here for fresh pesto recipe)

- 6-8 small to medium tomatoes

- Salt and Pepper to taste

Total Price: $~ \$ 5.52$

Breakdown:

Pesto - \$1.74 with Basil from Second Harvest

Chicken - $\$ 3.78$

Tomatoes from Second Harvest

Prices change per store.

\section{Instructions}

1. Preheat oven to $350^{\circ}$

2. Line baking dish with foil or parchment paper

3. Cover each breast with 2 to 3 tablespoons

Make sure to cover the whole breast

4. Place chicken in baking dish and bake for 30 minutes

5. Slice tomatoes into quarters

6. Place tomatoes around chicken breasts and return to oven

Cut the chicken into smaller pieces to make kid friendly portions

Add Green peppers, mushrooms, or your other favorite veggie to roast

Sprinkle with your favorite shredded cheese to serve

7. Cook for another 20 minutes or until chicken is cooked to $165^{\circ}$

Recipe modified from:

https://cafedelites.com/2-ingredient-pesto-chicken-recipe/ 


\section{Chickpea Trail Mix}

\section{Ingredients}

Makes about 4 cups of trail mix

- 1 can of garbanzo beans (chickpeas) (common tailgate item from Second Harvest)

- 1 tbs seasoning of choice (I used an "Everything Bagel" seasoning since I couldn't find sesame seeds in the store, you may use smoked paprika, cinnamon, keep it simple with salt and pepper, or whatever seasoning you enjoy)

- $1 / 2$ cup of dried fruit

- $1 / 2$ cup of dark chocolate chunks

- $1 / 2$ cup of nuts (I used cashews, you may use others or a mix of types if you'd like)

- $1 / 2$ pepitas (pumpkin seeds)

- Any of your favorite trail mix ingredients!

\section{Instructions}

1. Open can of garbanzo beans (chickpeas) using a handheld can opener, or peel open if the easy-open tab is available

2. You may hold the lid on top to drain the can of its fluids while retaining the beans, or dump them into a colander to drain (I also like to rinse them, but not necessary)

3. Spread beans out on a kitchen towel or paper towel, and use another to dry them off the best you can

4. Once dry, put the beans into a bowl and add seasoning

1. (I used a little honey in the video as an experiment to help the seasoning stick - I do not recommend this as it prevented the chickpeas from getting nice and crunchy)

5. Mix thoroughly to evenly distribute seasoning

6. Spread beans out on a baking sheet

7. Insert into an oven preheated to 375 degrees $\mathrm{F}$.

8. Bake chickpeas for 10 minutes, or until nice and slightly crunchy

9. Allow the chickpeas to cool off to room temperature (to avoid getting the chocolate all melty)

10. In a storage container you plan to keep the trail mix in, add the cooledoff chickpeas and all trail mix ingredients

11. Hand mix the mixture, and enjoy!

Total Price: $\sim \$ 1.68 / 4$ cups of trail mix

Breakdown:

1 tbs seasoning of choice: $~ \$ 0.02$

1/2 cup dried fruit: $\$ 0.35$

1/2 cup dark chocolate chunks: $\$ 0.45$

1/2 cup cashews: $\$ 0.55$

$1 / 2$ cup pepitas: $\$ 0.31$

Chickpeas free From Second Harvest!

Recipe modified from:

Prices change per store. 
https://www.wellplated.com/roasted-chickpea-snack-mix/ 
JOIN CHEF SOLUS AND THE FRESH PRODUCE BUNCH, IN CREATING A HEALTHY AND BALANCED MEAL!

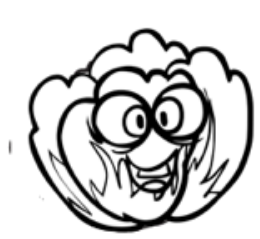

LETTUCE

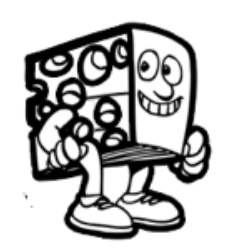

CHEESE
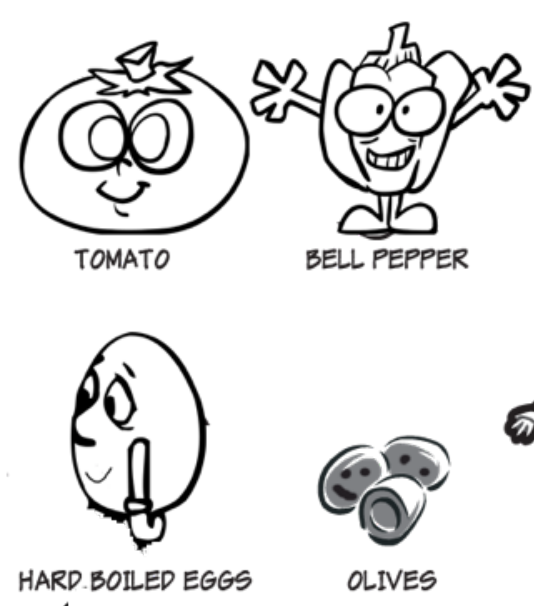

ARD

\section{CAN YOU CIRCLE WHAT WOULD BE IN} YOUR SALAD?
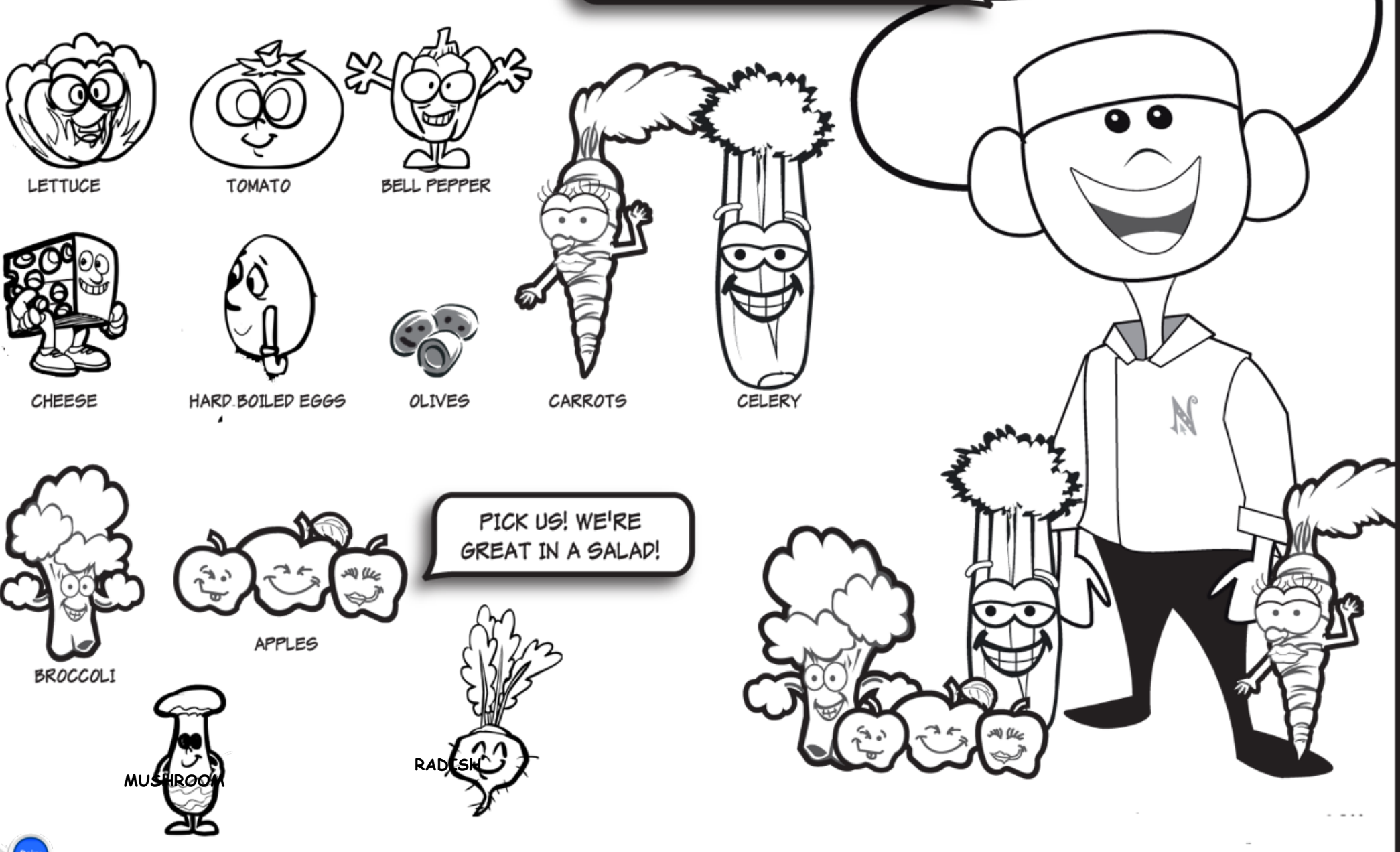


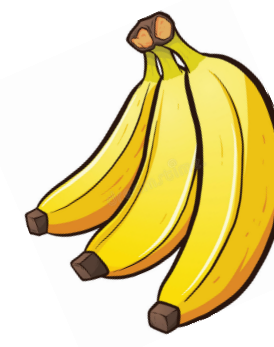

$$
\begin{aligned}
& \text { Bananas for Nutrition Cross Word }
\end{aligned}
$$

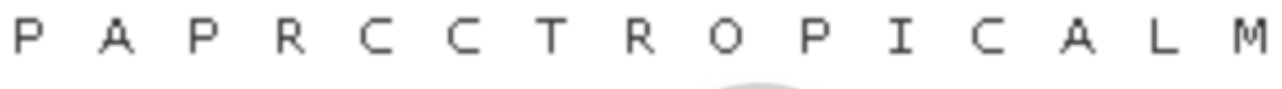

$$
\begin{aligned}
& M \quad U \times I \quad I \quad \vee \quad O \quad L \quad N \quad Q \quad B \quad R \quad V \quad J \quad U \quad Q
\end{aligned}
$$

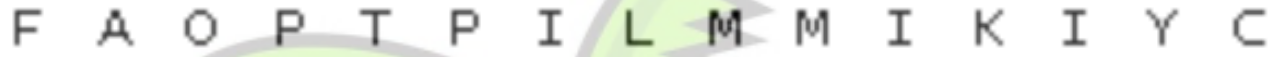

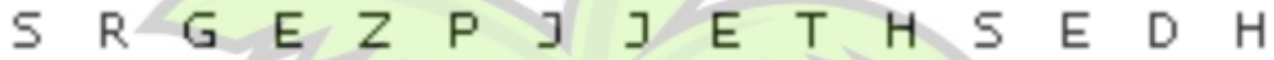

$$
\begin{aligned}
& H \quad T U N L E R \quad L A C T S K \times A, H
\end{aligned}
$$

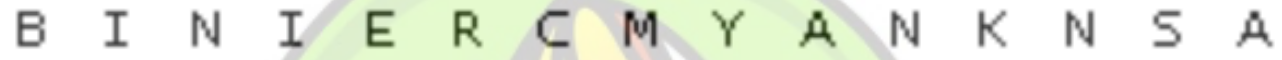

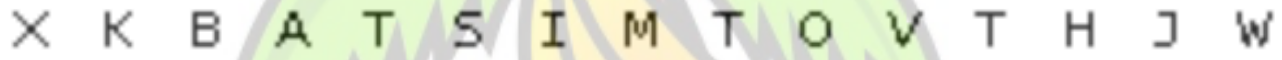

$$
\begin{aligned}
& L \quad B \quad \times \quad Z \quad D \quad N \quad I \quad O \quad M J
\end{aligned}
$$

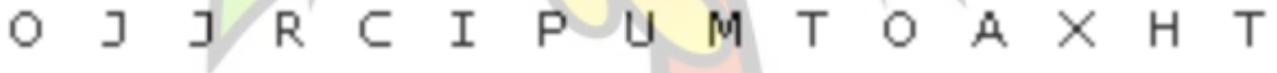

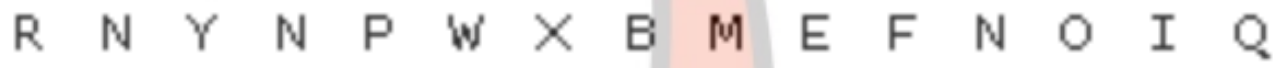

$$
\begin{aligned}
& G \subset \text { G }
\end{aligned}
$$

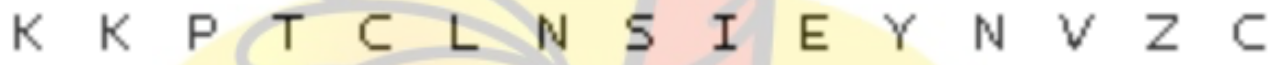

$$
\begin{aligned}
& \text { W } F \quad K \quad S \quad L \quad L \quad M \quad A \quad D \quad T \quad P \quad A \quad C K \quad K \\
& Q \quad N \times J K E \quad S \quad K \quad K M N B N K V
\end{aligned}
$$

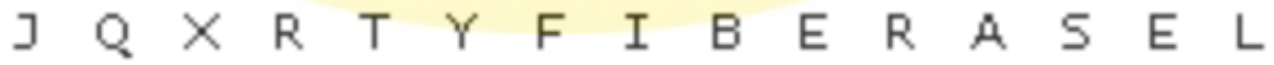

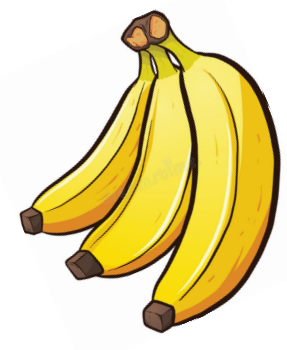

$\begin{array}{llll}\text { Antioxidants } & \text { Tropical } & \text { Potassium } & \text { Magnesium } \\ \text { Fiber } & \text { Banana } & \text { VitaminC } & \text { Yellow } \\ \text { Monkey } & \text { Fruit } & \text { Copper } & \end{array}$


Key

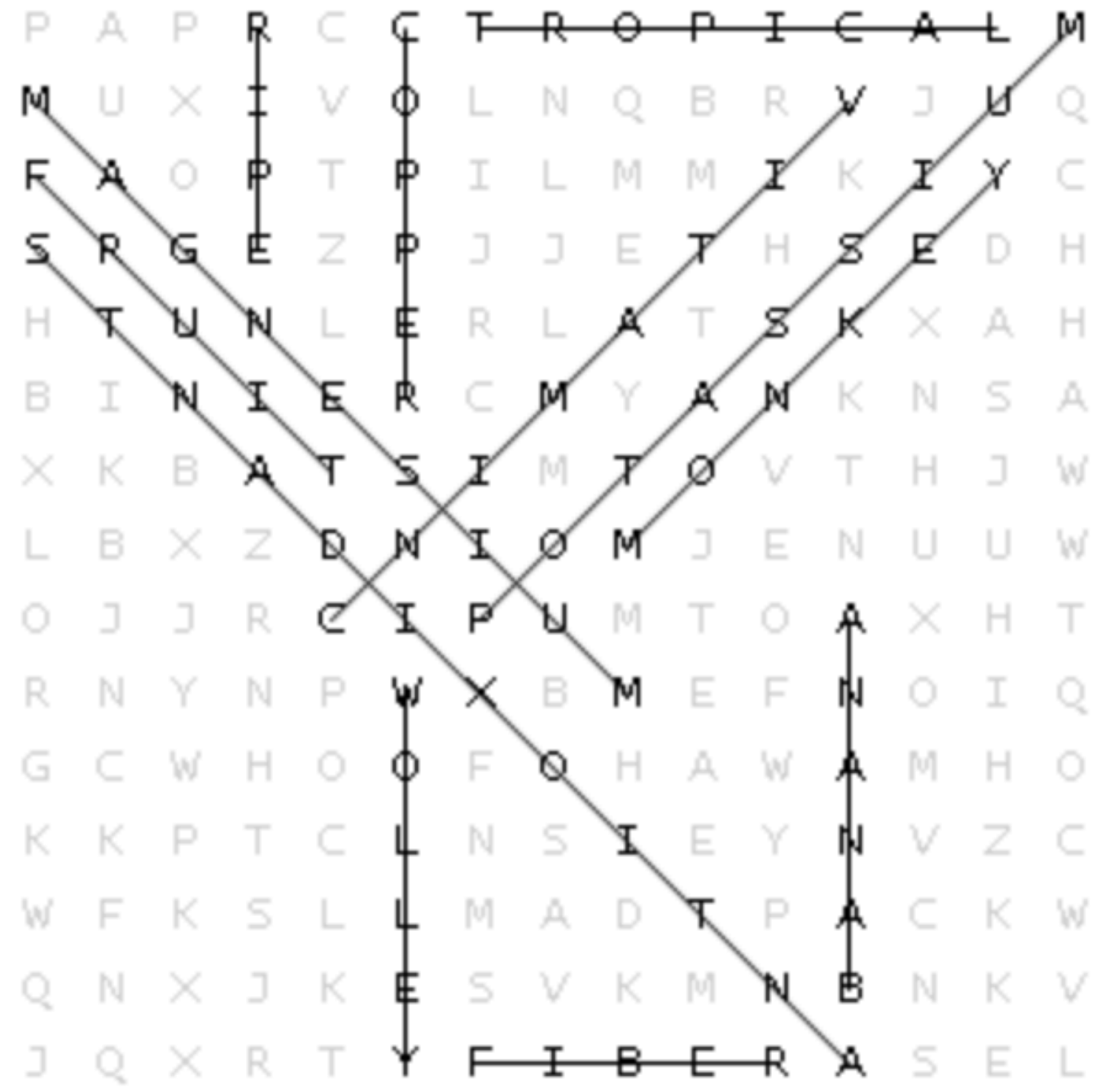




\section{KIDS FOOD CRITIC ACTIVITY}

Let kids select a new fruit, vegetable, or recipe to sample. Have them taste the food and rate it based on visual appeal, smell, taste, and texture using a scale of 1 to 5 where 5 is the best.

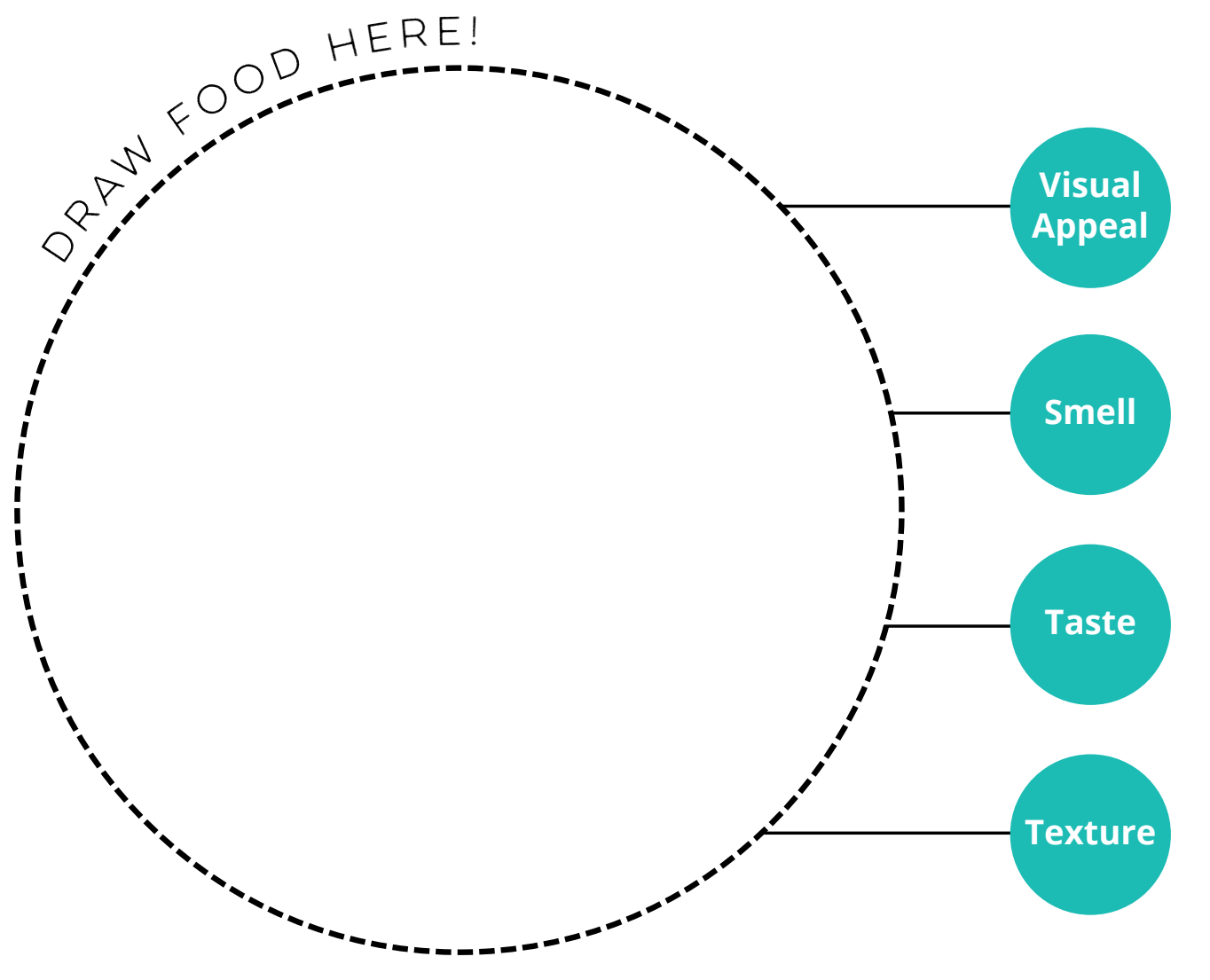

$\begin{array}{lllll}1 & 2 & 3 & 4 & 5 \\ 0 & 0 & 0 & 0 & 0\end{array}$

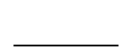

\section{TOTAL SCORE}

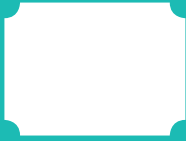

$\begin{array}{lllll}1 & 2 & 3 & 4 & 5 \\ 0 & 0 & 0 & 0 & 0\end{array}$

$\begin{array}{lllll}1 & 2 & 3 & 4 & 5 \\ 0 & 0 & 0 & 0 & 0\end{array}$

1
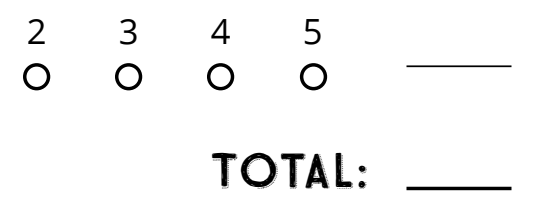

Serve it again?

YES NO

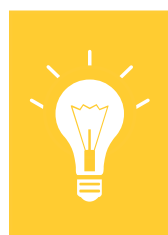

\section{FOR EXTRA FUN:}

- Have kids choose and prepare foods and have friends, siblings, or parents sample and rate them.
- Present 3 new recipes to sample and compare them. 
(:) WORD UN-SCRAMBLE! :)

1. TOAPOT

2. FBRASETAK

3. TEILKSL

4. REGEN REPEPP

5. CEHRDAD CEEEHS

6. ELSAEEGBVT

7. OITPERN

8. OEUCISDL

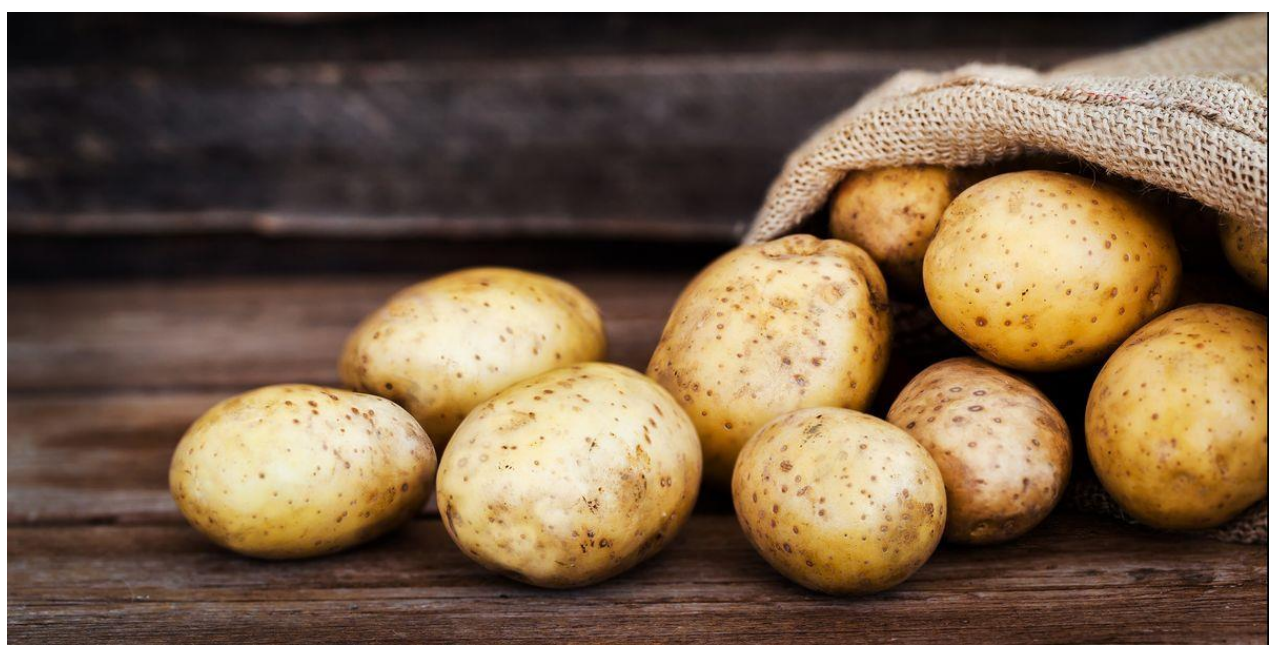




\section{(:) WORD UN-SCRAMBLE! :)}

1. TOAPOT

potato

2. FBRASETAK_ breakfast

3. TEILKSL_skillet

4. REGEN REPEPP_green pepper

5. CEHRDAD CEEEHS cheddar cheese

6. ELSAEEGBVT vegetables

7. OITPERN protein

8. $\bar{O} E U C I S D L \_$delicous

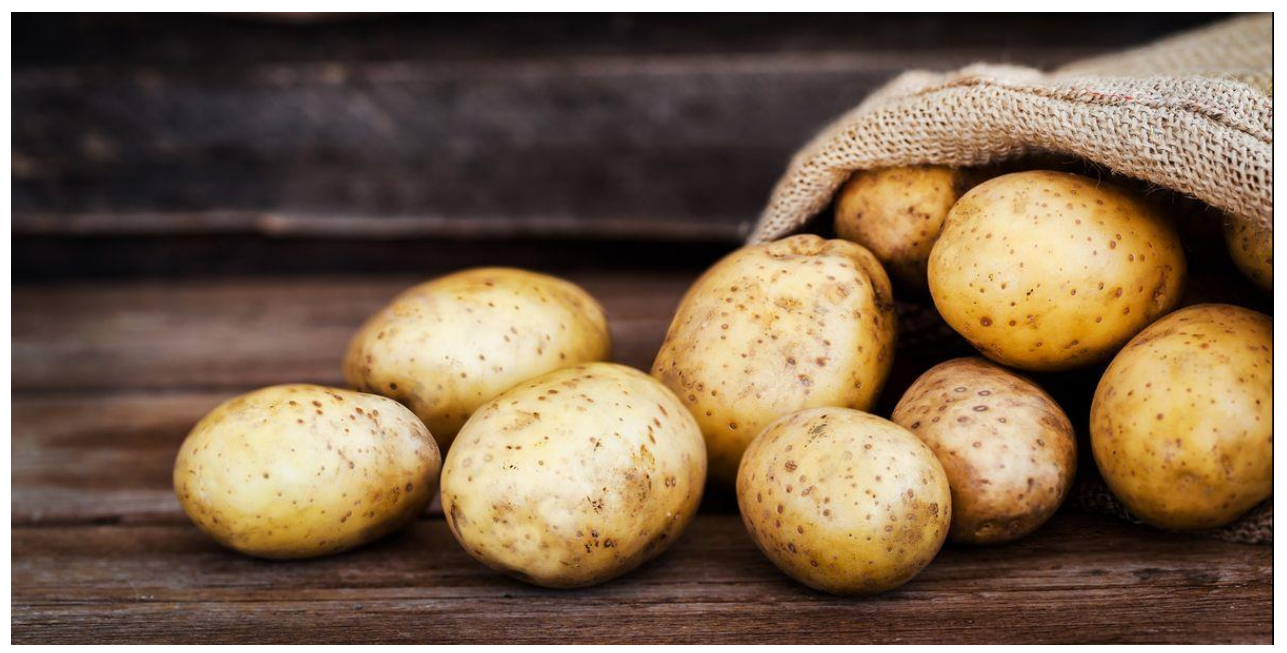




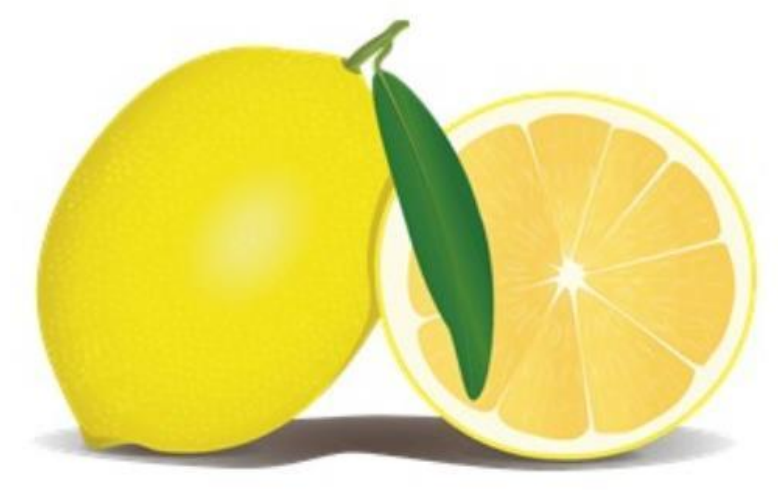

\section{LEMONS WORD SEARCH PUZZLE}

DESSERT

DRINK

FRESH

FRUIT

GROW

HARVEST

OIL

PEEL

RIND

RIPE

SCENT

SEED

SEGMENT

SQUEEZE

SOUR

VITAMINS

YELLOW

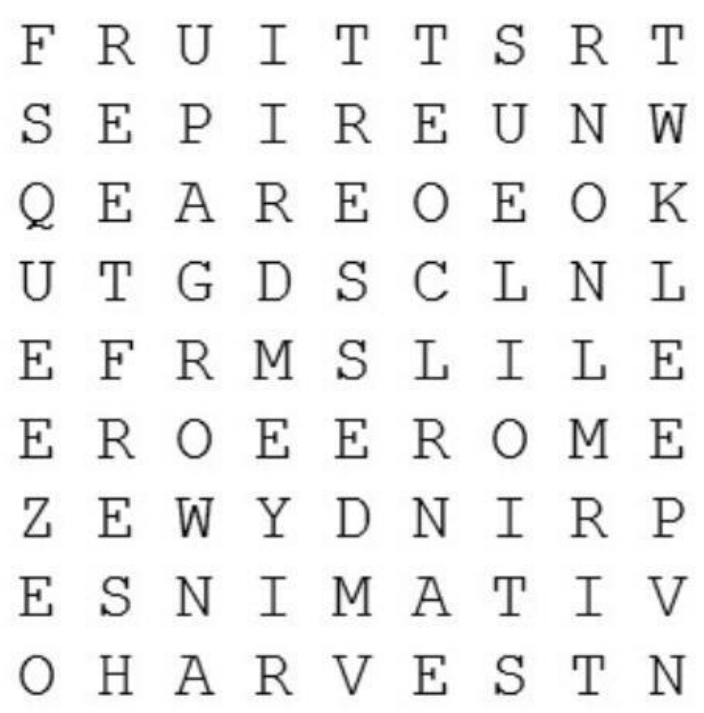

The words appear UP, DOWN, BACKWARDS, and DIAGONALLY. Find and circle each word. 


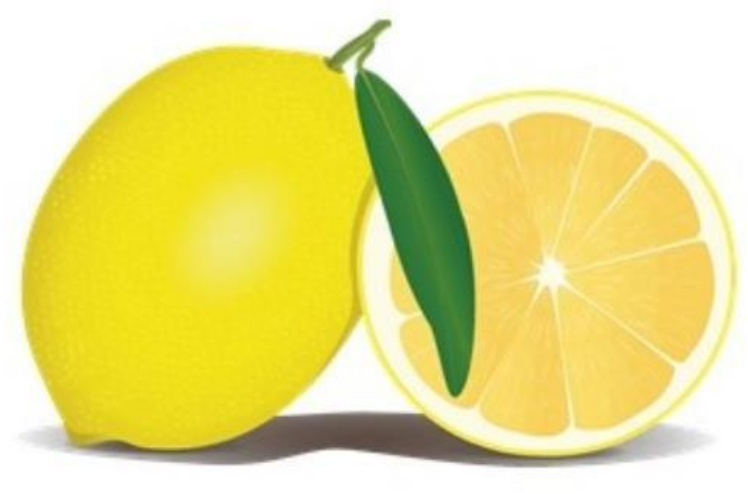

DESSERT *

DRINK .

FRESH

FRUIT

GROW

HARVEST

OIL

PEEL

RIND

RIPE

SCENT *

SEED .

SEGMENT

SQUEEZE

SOUR

VITAMINS

YELLOW

\section{LEMONS}

WORD SEARCH PUZZLE
The words appear UP, DOWN, BACKWARDS, and DIAGONALLY. Find and circle each word.

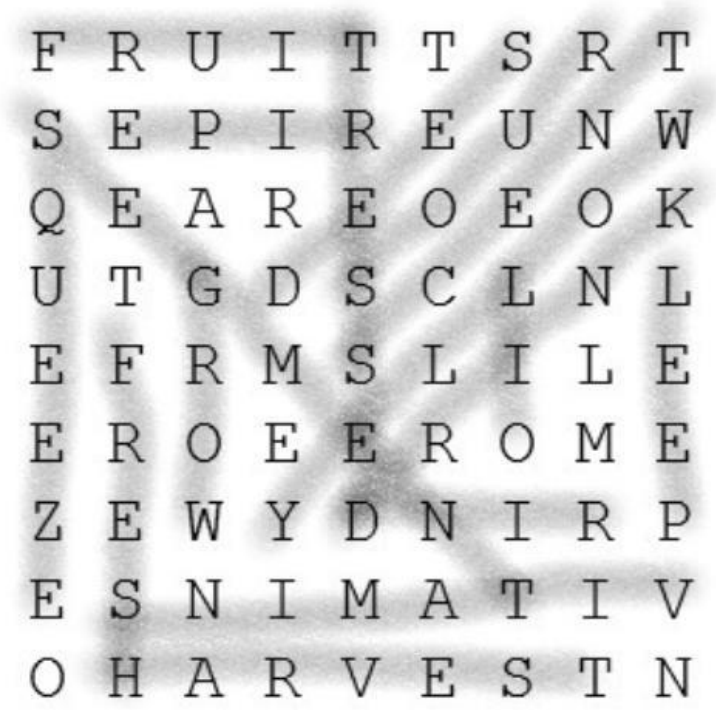




\section{The wonderful world of legumes}

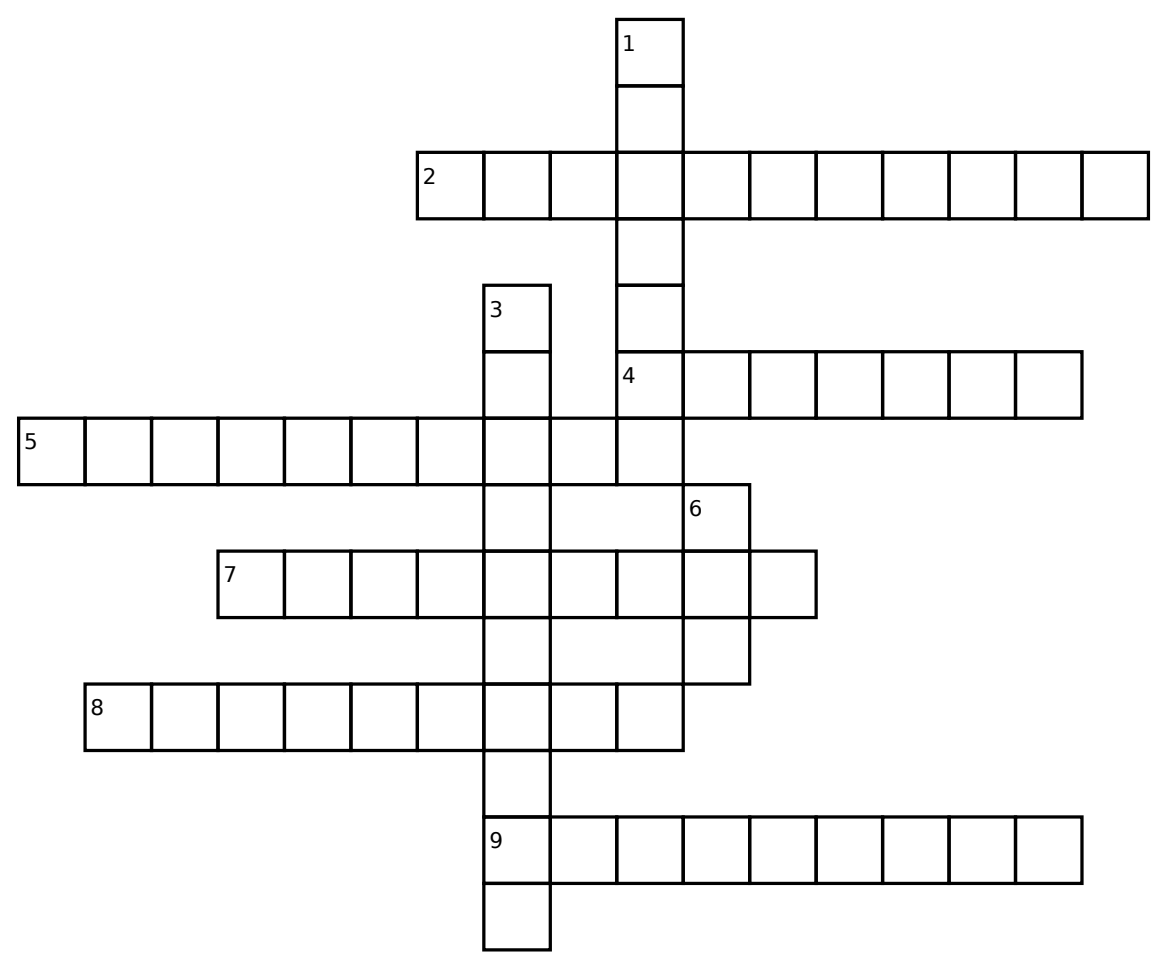

Down:

1. flat or lens-shaped legumes

3. dark-colored beans used in many dishes

6. a dish made of stewed lentils or split peas
Across:

2. a variety of beans which are named because of their kidney-like appearance

4. any name for a plant that produces pods with seeds inside

5. brown speckled beans used in refried beans

7. used in making hummus and falafels

8. peas that have been dried and split in half

9. used to make Boston Baked Beans 


\section{The wonderful world of legumes}

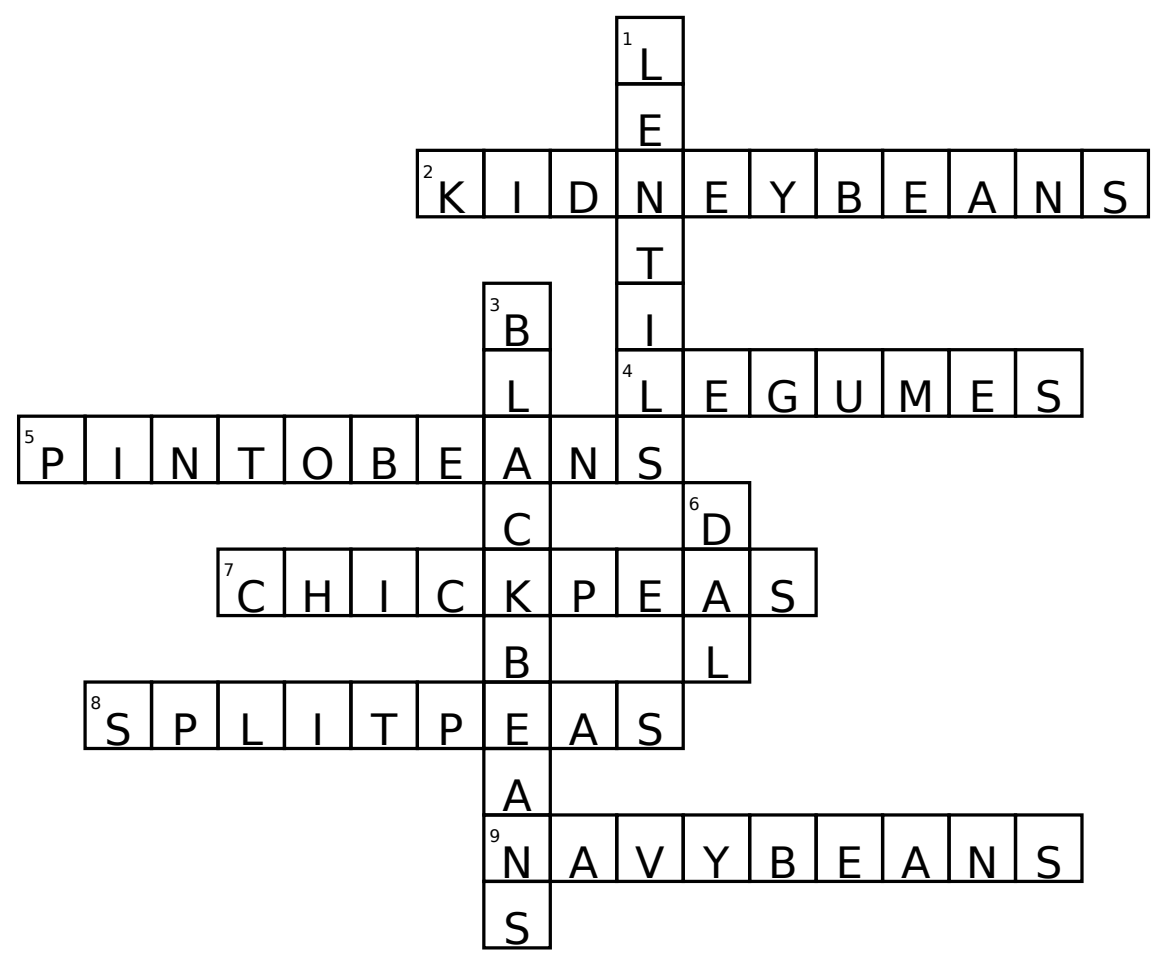

Down:

1. flat or lens-shaped legumes

3. dark-colored beans used in many dishes

6. a dish made of stewed lentils or split peas
Across:

2. a variety of beans which are named because of their kidney-like appearance

4. any name for a plant that produces pods with seeds inside

5. brown speckled beans used in refried beans

7. used in making hummus and falafels

8. peas that have been dried and split in half

9. used to make Boston Baked Beans 


\section{MyPlate Crossword Puzzle}

Use the words from MyPlate to help you complete this puzzle.

\section{Across}

1. Use the My as a guide.

2. Apples, oranges, and bananas fit into this food group.

5. This sweet, smooth food comes in many different flavors and is a great way to get calcium for your bones.

7. are an orange vegetable.

8. Try fat-free or low foods when you can.

9. Use whole-grain for your sandwiches.

11. Cheddar, swiss, mozzarella, monterey jack are examples.

14. Fits into the grains group of MyPlate. Goes great with stir-fry.

15. MyPlate is a to help you eat a variety of foods for a healthy body.

17. Spaghetti is a type of

\section{Down}

1. Chicken and turkey are examples of

2. Eat a variety of from all of the groups.

3. Broccoli and green beans are examples of a

4. These are a great source of protein and can be mixed with cereal and dried fruit for an "on-the-go" snack.

6. Pinto, kidney, black, refried - there are lots of different kinds and they can be eaten lots of different ways.

10. Vegetable or olive are part of a healthful diet.

11. This makes a quick and easy "ready-to-eat" breakfast with fruit and milk.

12. You can hard-boil, scramble, fry, or poach these, or eat them as an omelet. How do you like your ?

13. Salmon and trout are examples of

16. Lean is an excellent source of protein, iron, and zinc.

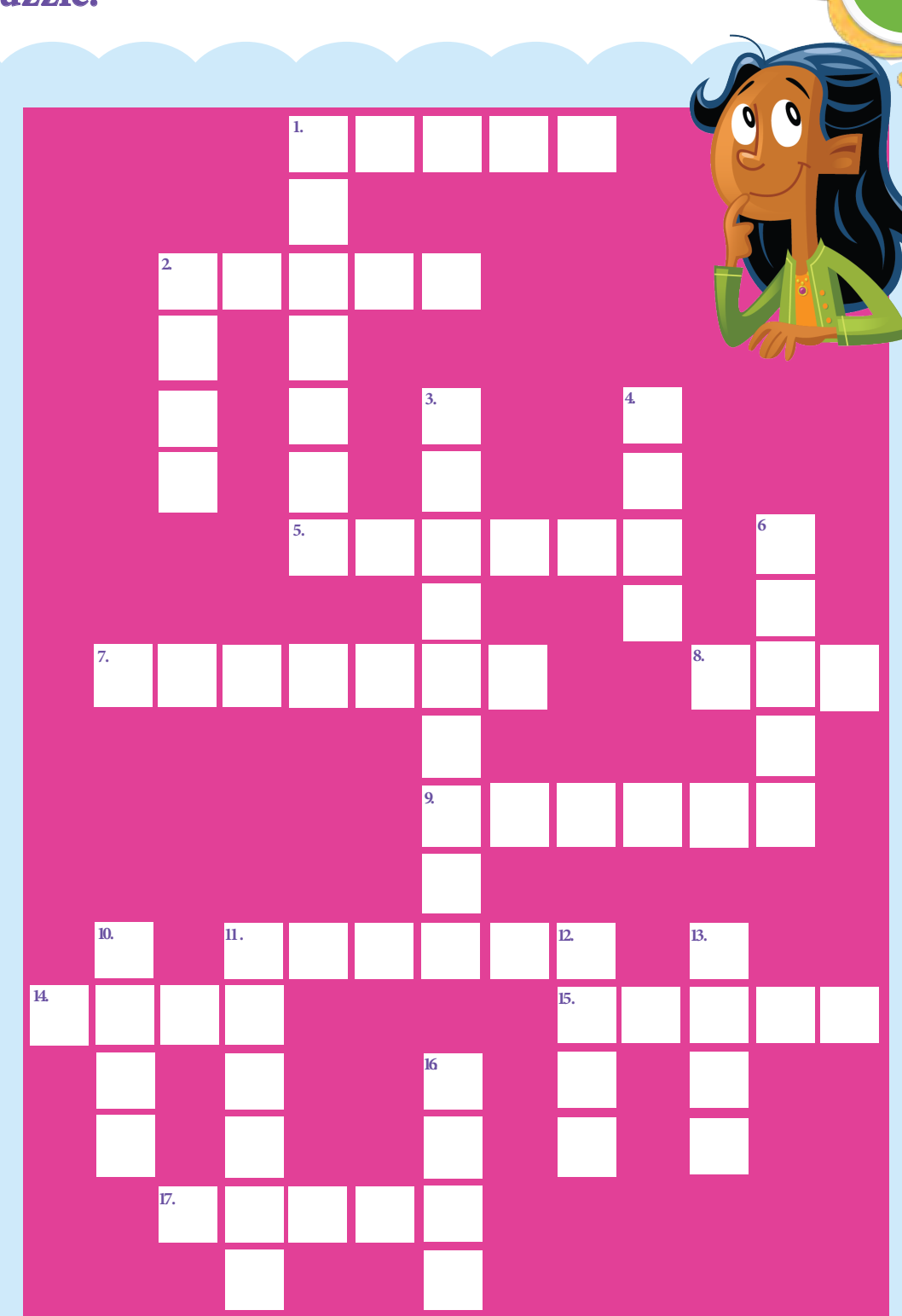




\section{MyPlate Crossword Puzzle}

Use the words from MyPlate to help you complete this puzzle.

\section{Across}

1. Use the My

as a guide.

2. Apples, oranges, and bananas fit into this food group.

5. This sweet, smooth food comes in many different flavors and is a great way to get calcium for your bones.

7. are an orange vegetable.

8. Try fat-free or low foods when you can.

9. Use whole-grain__ for your sandwiches.

11. Cheddar, swiss, mozzarella, monterey jack are examples.

14. Fits into the grains group of MyPlate. Goes great with stir-fry.

15. MyPlate is a to help you eat a variety of foods for a healthy body.

17. Spaghetti is a type of

\section{Down}

1. Chicken and turkey are examples of

2. Eat a variety of from all of the groups.

3. Broccoli and green beans are examples of a

4. These are a great source of protein and can be mixed with cereal and dried fruit for an "on-the-go" snack.

6. Pinto, kidney, black, refried - there are lots of different kinds and they can be eaten lots of different ways.

10. Vegetable or olive are often used for cooking and are part of a healthful diet.

11. This makes a quick and easy "ready-to-eat" breakfast with fruit and milk.

12. You can hard-boil, scramble, fry, or poach these, or eat them as an omelet. How do you like your

13. Salmon and trout are examples of

16. Lean is an excellent source of protein, iron, and zinc.

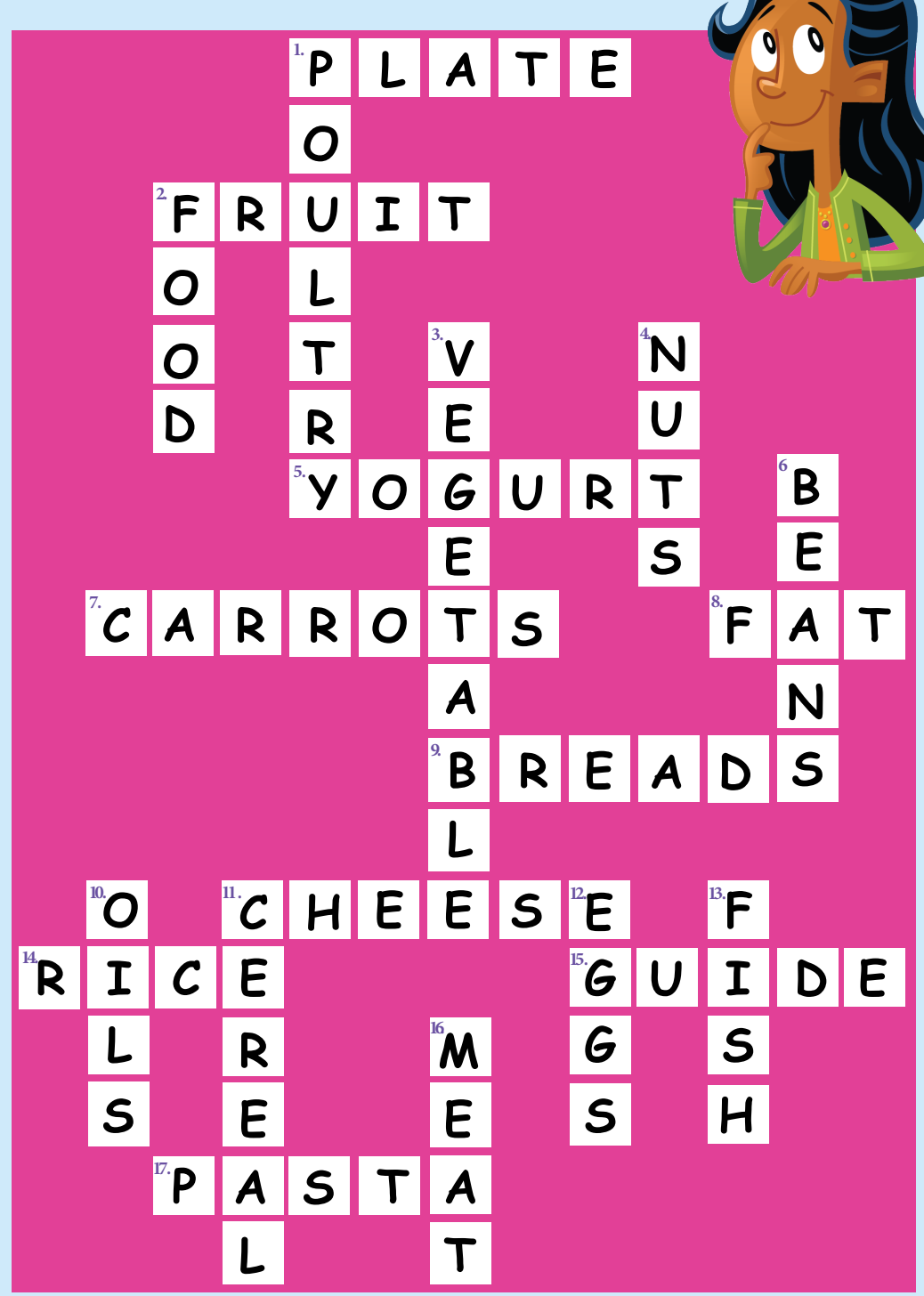




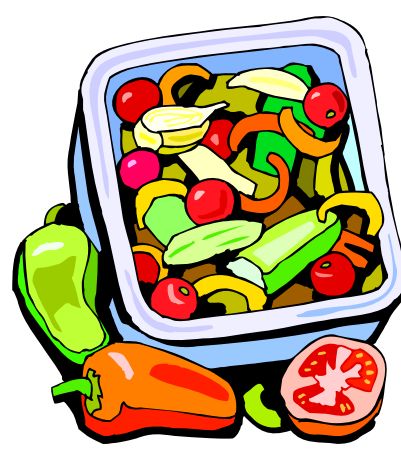

\section{Food Facts Hi ghl i ght s: Make Ahead Freezer Meals}

During the cold winter months, it can be fun to be in a warm kitchen, preparing food head for those busy spring weeks when there is yard work and gardening to do in addition to the normal chores. The following are some tips on preparing, and freezing, food ahead.

- Don't overcook food items that are intended for the freezer, and be particularly careful to slightly undercook pasta, rice, and vegetables. [Note: baked goods, however, should be fully cooked.]

- Cool all foods completely by setting meals in the refrigerator for at least an hour before freezing.

- Package items for the freezer in moisture-proof, airtight and odorless containers. Examples include zip-top plastic freezer bags (not food storage bags); rigid plastic or glass containers with wide mouths and tight-fitting lids; or heavy duty aluminum foil.

- Plan ahead for those foods that will go from the freezer to the oven. Package casseroles and other items that you will cook from the frozen state in aluminum trays or Pyrex cookware; cover with heavy-duty aluminum foil.

- Make certain all freezer containers are sealed completely and that you've removed excess air before sealing. [Air trapped in a container can react with the food, destroying nutrients and producing off flavors during extended storage.]

- Don't forget to label each package (try a permanent ink marker) with reheating instructions before freezing. Include the name of the meal, date frozen, number of servings, temperature and length of time it bakes, and any other necessary information. You can add any personal notes such as marking extra stars for your favorites.

\section{Check list for high quality make-ahead frozen food:}

$\square$ Food is packaged in small portions.

$\square$ Food is packaged in shallow containers.

$\square$ Container or packaging fits the shape and size of the food to be frozen.

$\checkmark$ Food is packed tightly to eliminate as much air space as possible.

$\square$ Container or packaging is almost full, leaving only a little space for the food to expand as it freezes.

Excess air is pressed from freezer bags.

$\square$ Container or bag is tightly sealed.

$\checkmark$ Contents of freezer are organized so wrappings don't become loose or pierced.

$\square$ Packages are labeled with a freezer marker indicating the contents, number of servings, and date of storage.

$\square$ Food is placed in a single layer on freezer shelves until frozen.

$\triangle$ Freezer is set to and maintains $0^{\circ} \mathrm{F}$ degrees or below

$\square$ Freezer is not freezing too much food at a time.

$\square$ An inventory identifying each food in the freezer and its "use by" date is posted on the outside of the freezer and is updated each time an item is removed.

$\square$ Food is thawed in refrigerator unless otherwise directed.

More ideas can be found on these web sites:

- Make ahead and freeze http://lancaster.unl.edu/food/ftnvdc99.htm

- Cook once, eat twice http://lancaster.unl.edu/food/cigf.htm

- Freezing cooked foods http://lancaster.unl.edu/food/ciq-freezing-techniques.htm

- Freezing prepared foods http://www.uga.edu/nchfp/publications/uga/FreezingPreparedFoods.pdf

A freezer storage list is found online http://www.oznet.k-state.edu/humannutrition/hrap/storage/stochart.htm January 2006. 


\section{Reading Food Labels}

Nutrition Facts food labels have information to help us to make choices about the foods we eat. Here are some tips on how to read them and what to look for.

\section{Limil these}

Saturated fat, trans fat, cholesterol, sodium and sugars.

\section{Get enough of} these

Fiber, vitamins A \& C, iron and calcium.

\begin{tabular}{|c|c|c|c|}
\hline \multicolumn{4}{|c|}{$\begin{array}{l}\text { Serving Size } 1 \text { cup }(228 \mathrm{~g}) \\
\text { Servings Per Container } 2 \\
\text { Amount Per Serving }\end{array}$} \\
\hline \multirow{2}{*}{ Calories 250} & \multicolumn{3}{|c|}{ Calories from Fat 11} \\
\hline & \multicolumn{3}{|c|}{$\%$ Daily Value } \\
\hline \multicolumn{3}{|l|}{ Total Fat $12 \mathrm{~g}$} & $18 \%$ \\
\hline \multicolumn{3}{|c|}{ Saturated Fat $3 g$} & $15 \%$ \\
\hline \multicolumn{4}{|c|}{ Trans Fat $3 \mathrm{~g}$} \\
\hline \multicolumn{3}{|c|}{ Cholesterol $30 \mathrm{mg}$} & $10 \%$ \\
\hline \multicolumn{3}{|c|}{ Sodium $470 \mathrm{mg}$} & $20 \%$ \\
\hline \multicolumn{3}{|c|}{ Total Carbohydrate $31 \mathrm{~g}$} & $10 \%$ \\
\hline \multicolumn{3}{|c|}{ Dietary Fiber 0g } & $0 \%$ \\
\hline \multicolumn{4}{|c|}{ Sugars $5 \mathrm{~g}$} \\
\hline \multicolumn{4}{|l|}{ Protein $5 \mathrm{~g}$} \\
\hline \multicolumn{3}{|l|}{ Vitamin A } & $4 \%$ \\
\hline \multicolumn{3}{|l|}{ Vitamin C } & $2 \%$ \\
\hline \multicolumn{3}{|l|}{ Calcium } & $20 \%$ \\
\hline \multicolumn{3}{|c|}{ Iron } & $4 \%$ \\
\hline \multicolumn{4}{|c|}{$\begin{array}{l}\text { * Percent Daily Values are based on a } 2,000 \text { calorie die } \\
\text { Your Daily Values may be higher or lower depending o } \\
\text { your calorie needs. }\end{array}$} \\
\hline & Calories: & 2,000 & 2,500 \\
\hline Total Fat & Less than & $65 g$ & $80 \mathrm{~g}$ \\
\hline Sat Fat & Less than & $20 \mathrm{~g}$ & $25 \mathrm{~g}$ \\
\hline Cholesterol & Less than & $300 \mathrm{mg}$ & $300 \mathrm{mg}$ \\
\hline Sodium & Less than & $2,400 \mathrm{mg}$ & $2,400 \mathrm{mg}$ \\
\hline Total Carbohydrate & & $300 \mathrm{~g}$ & $375 \mathrm{~g}$ \\
\hline Dietary Fiber & & $25 \mathrm{~g}$ & $30 \mathrm{~g}$ \\
\hline
\end{tabular}

Source: FDA

http://www.fda.gov/Food/LabelingNutrition/

ConsumerInformation/ucm078889.htm

\section{Serving Size}

Remember that one package may contain more than one serving. This is important because the amount of calories and nutrients is based on the serving size.

\section{Calories}

When comparing foods, keep in mind that 400 or more calories per serving is high, and try to keep track of the calories you eat throughout the day. The food label is based on a 2,000 calorie diet, but your calorie needs might be different. Check MyPyramid (www.mypyramid.gov) to find out how many calories you should eat.

\section{\% Daily Value (\%DV)}

This is the percentage on the right side of the label. At the bottom of the label you will see that the percentage is based on a 2,000 calorie diet; however, some people need more or less. You can use this to compare foods, just remember that 5\% DV is low and $20 \%$ DV is high.

Jessica Linnell, Doctoral Student, 2010 Sheri Zidenberg-Cherr, PhD Marilyn Briggs, PhD, RD 


\section{Directions:}

Circle as many healthy snacks as you can! Then fill in the missing letters for the healthy snacks listed on the next page to make your "All Star Snack List." Add some of your own favorite snacks to your list!

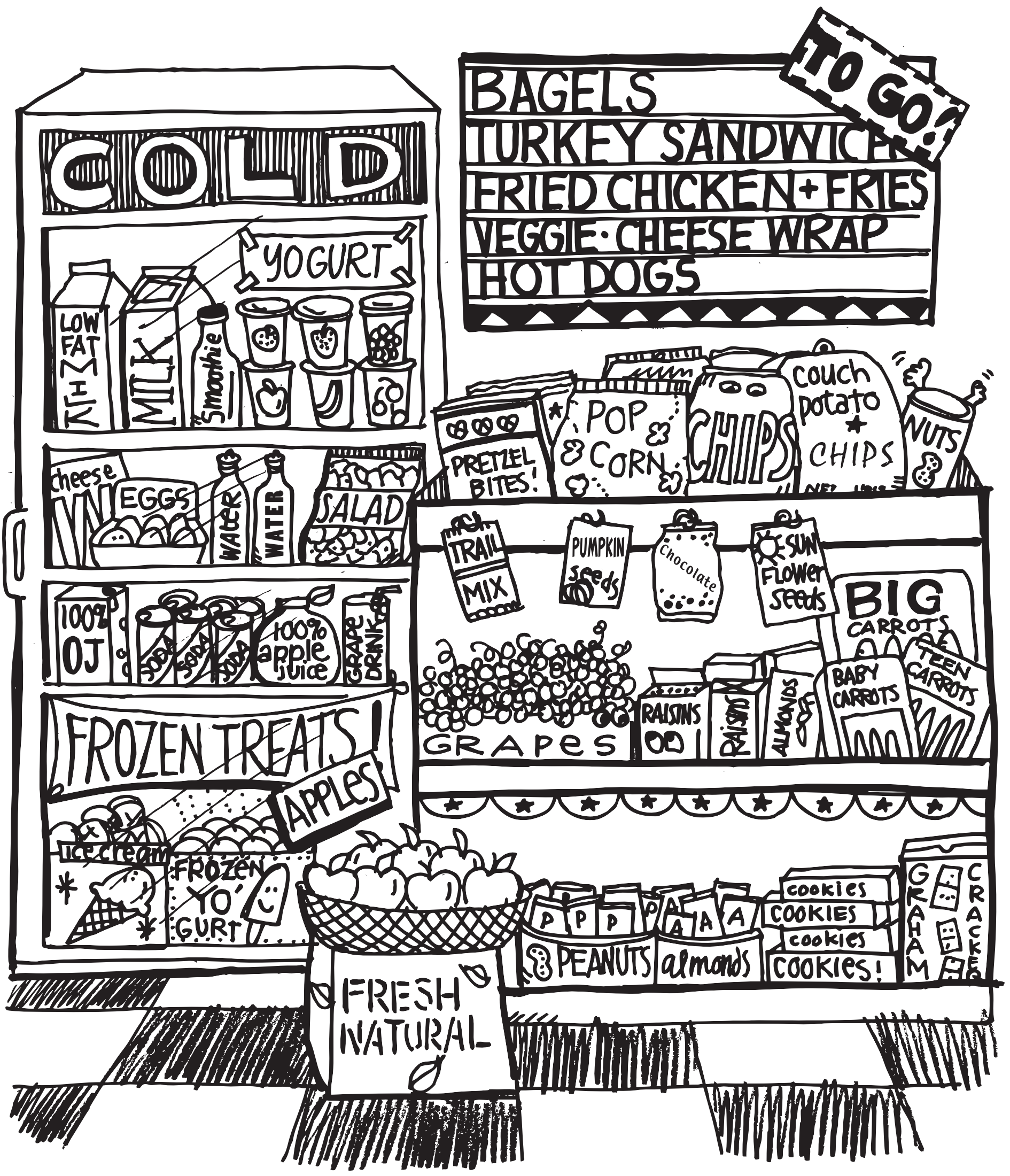




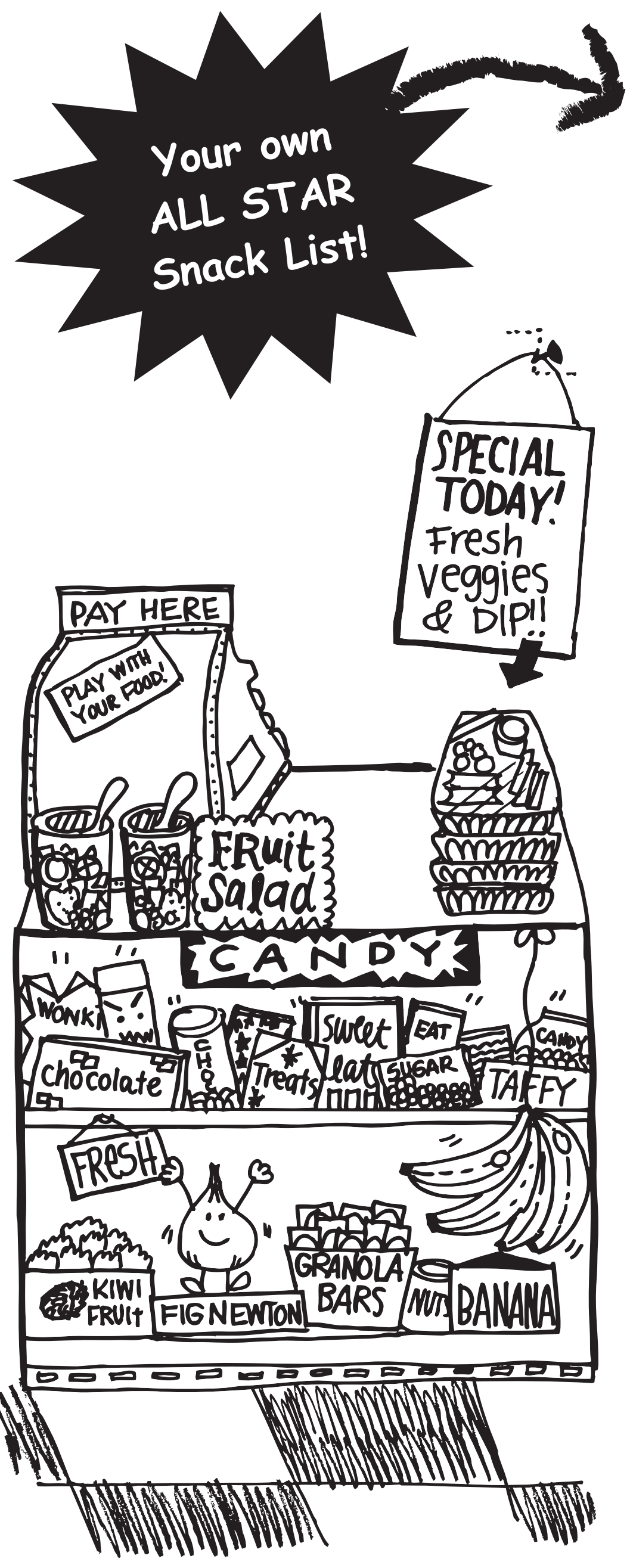

ALL STAR Snack List!

$$
\begin{aligned}
& \text { YOPLE } \\
& \text { YOGUR } \\
& \text { SA_AD } \\
& \text { ERCORN } \\
& \text { RAISIN } \\
& \text { ARROTS }
\end{aligned}
$$$$
A L M O N \_S
$$$$
\text { ATER }
$$

Now add your own favorite snacks!

For more fun food ideas, visit us at in www. foodplay.com is $x_{1}^{1}$

Cut this out and put on your fridge! 
Name:

Date:

Def Find and circle each of the words from the list below. Words may appear horizontally or vertically, but forwards only.

$\begin{array}{lllllllllllll}N & C & P & U & E & X & R & A & A & U & N & F\end{array}$

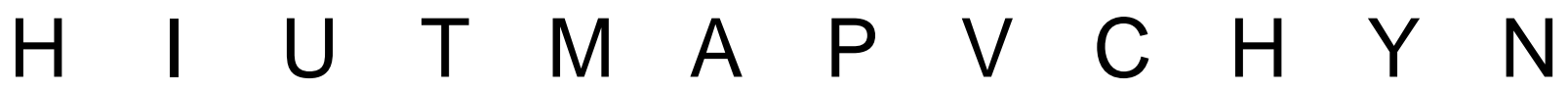

$\begin{array}{llllllllllll}T & \text { I } & B & R & O & C & C & O & L & \text { I } & \text { A } & P\end{array}$

$\begin{array}{llllllllllllllllllll}P & E & P & P & E & R & S & C & C & \text { I } & W & E\end{array}$

$\begin{array}{lllllllllllll}B & A & S & \text { I } & L & N & W & A & A & L & E & A\end{array}$

$\begin{array}{lllllllllllll}B & E & E & T & R & A & J & D & R & U & U & S\end{array}$

$\begin{array}{llllllllllll}C & O & R & N & M & Z & G & O & R & J & N & D\end{array}$

$\begin{array}{llllllllllll} & \mathrm{U} & A & \mathrm{~T} & \mathrm{O} & \mathrm{M} & \mathrm{A} & \mathrm{T} & \mathrm{O} & \mathrm{E} & \mathrm{S} & \mathrm{U}\end{array}$

$\begin{array}{lllllllllllll} & \mathrm{O} & \mathrm{N} & \mathrm{I} & \mathrm{O} & \mathrm{N} & \mathrm{A} & \mathrm{I} & \mathrm{D} & \mathrm{T} & \mathrm{L} & \mathrm{P} & \mathrm{D}\end{array}$

$\begin{array}{llllllllllll}N & Y & G & I & C & U & C & U & M & B & E & R\end{array}$

peppers carrot broccoli onion

tomatoes cucumber avocado

corn basil Beet peas 


\section{Fresh Veggies A N S W ER KE Y}

Def Find and circle each of the words from the list below. Words may appear horizontally or vertically, but forwards only.

$\begin{array}{llllllllllllll}N & C & P & U & E & X & R & A & A & U & N & F\end{array}$

\begin{tabular}{lllllll|lllll}
$H$ & $I$ & $U$ & $T$ & $M$ & $A$ & $P$ & $V$ & $C$ & $H$ & $Y$ & $N$
\end{tabular}

\begin{tabular}{lllllll|llllll}
$T$ & $I$ & $B$ & $R$ & $O$ & $C$ & $C$ & $O$ & $L$ & I A & $P$ \\
\hline
\end{tabular}

\begin{tabular}{|lllllll|l|l|llll}
$P$ & $E$ & $P$ & $P$ & $E$ & $R$ & $S$ & $C$ & $C$ & I & $W$ & $E$ \\
$B$ & $A$ & $S$ & I & L & N & W & $A$ & $A$ & $L$ & $E$ & $A$
\end{tabular}

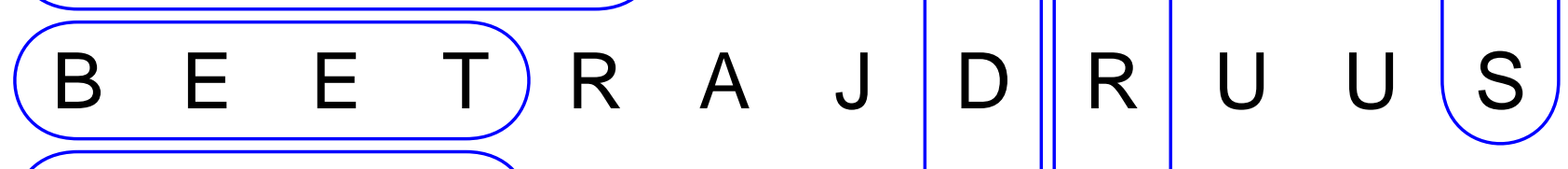

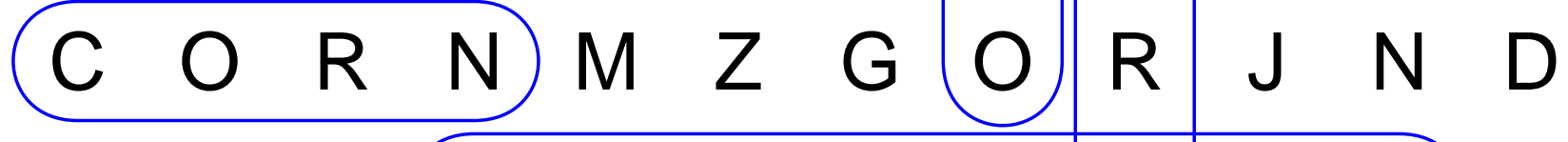

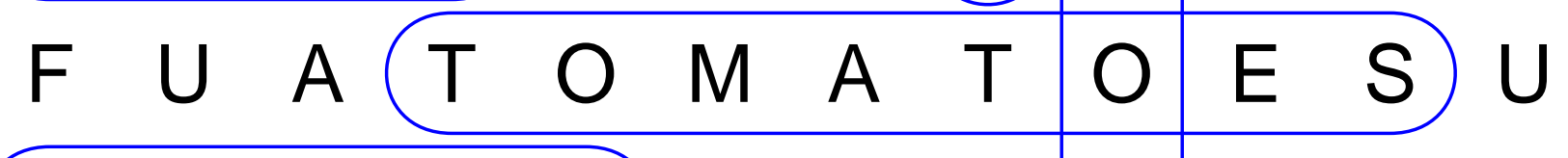

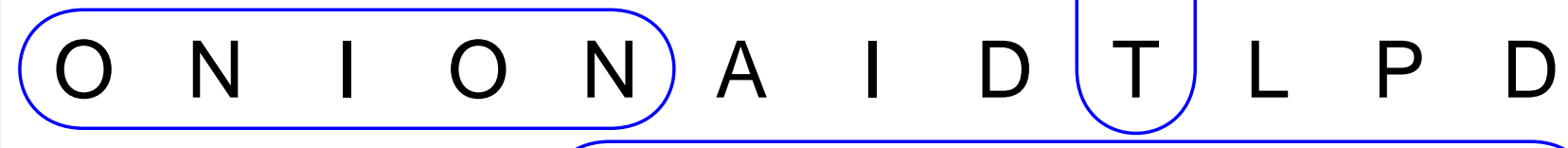

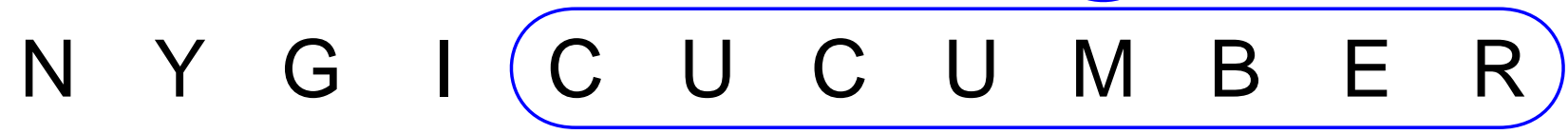

peppers carrot broccoli onion

tomatoes cucumber avocado

corn basil Beet peas 


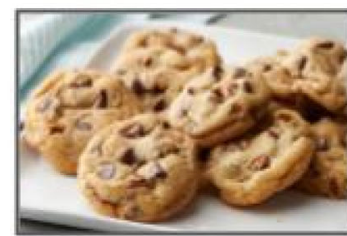

(C)

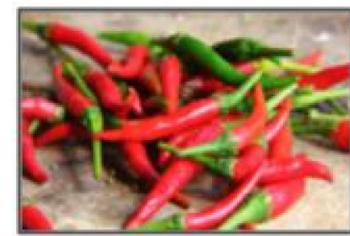

(C)
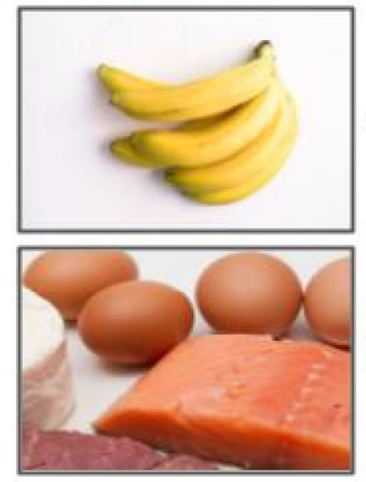

(C)

(C)
Draw a line to match the types of food!
(อ)

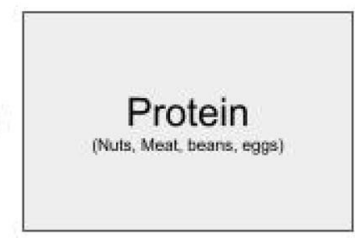

(Q)

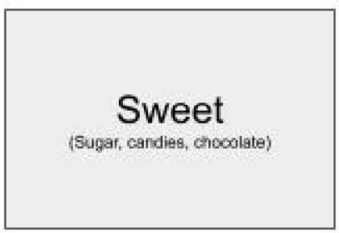

(O)

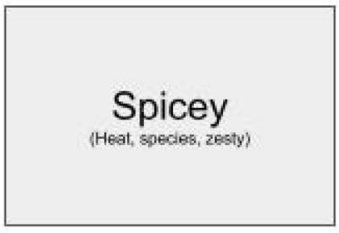

(Q)

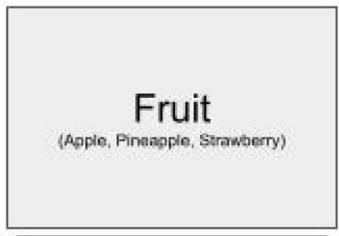

Made by Brendan Rollin 


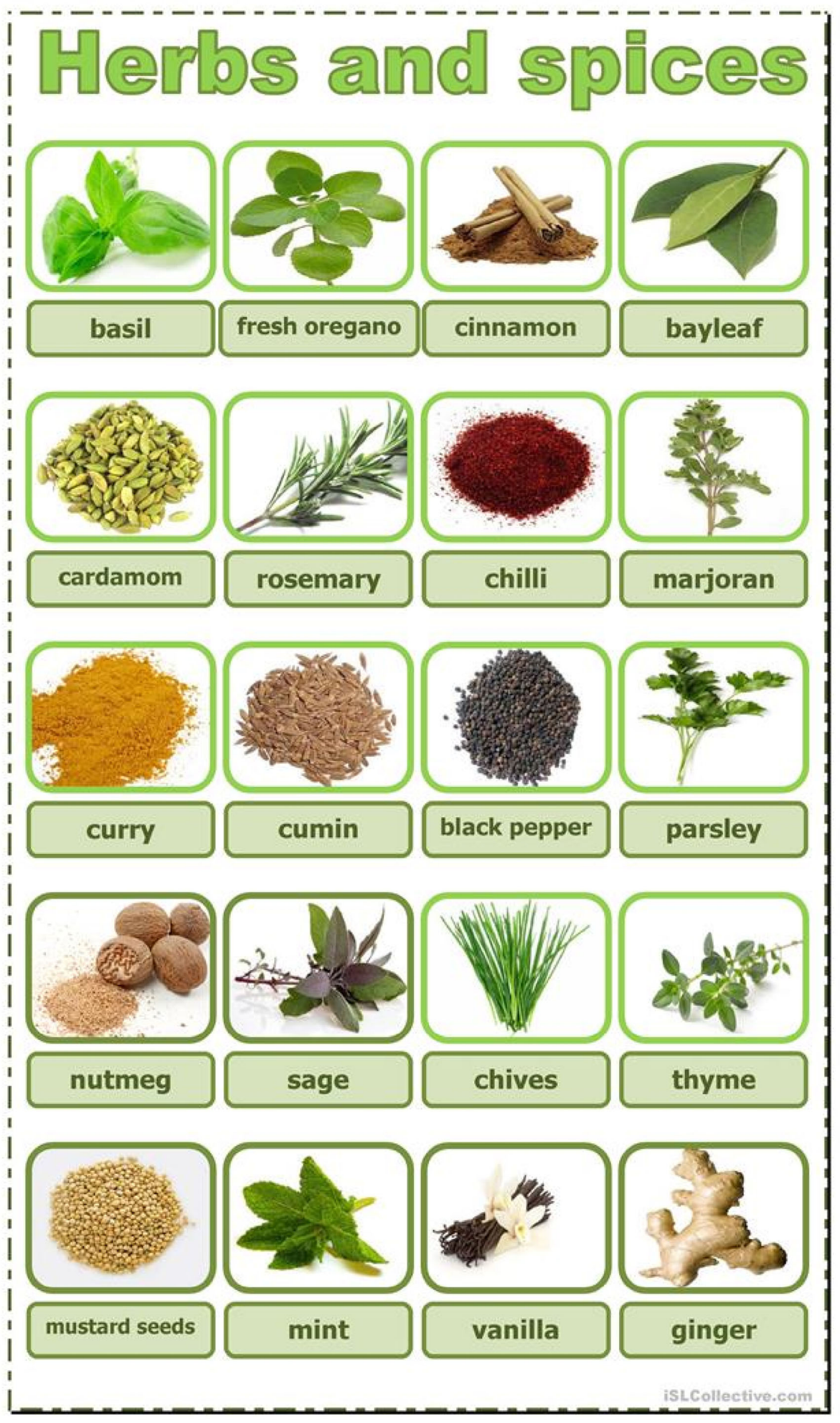




\section{Basic Nutrition Crossword}

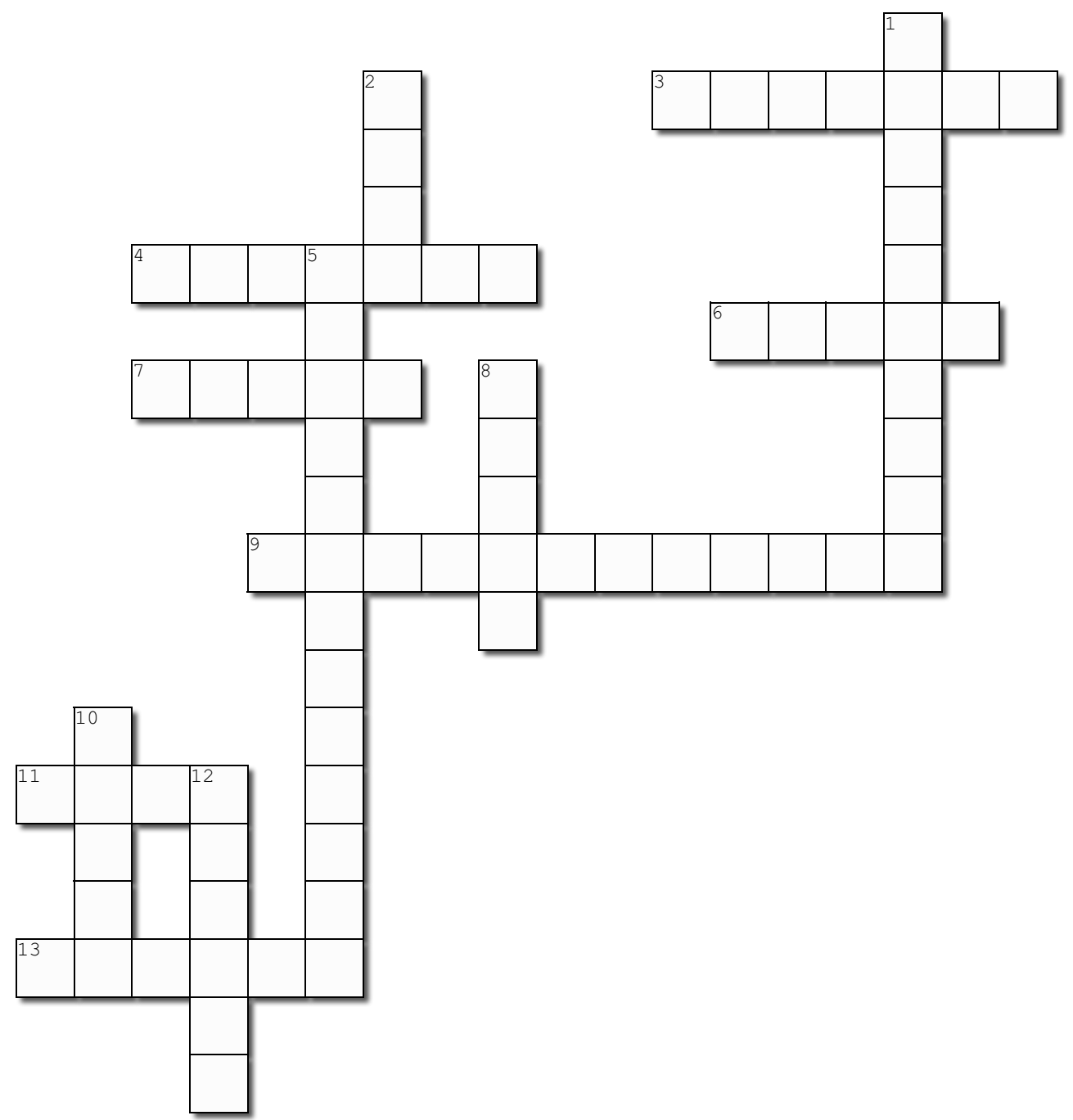

\section{Across}

3. This macronutrient helps build and repair muscles among many other functions

4. A good source of lean protein (type of poultry) 6. , Beverages with should be limited and should only drink occasionally

7. Cheese and milk fall into this food group

9. These grains are the grains you should consume most of the time

11. This macronutrient is at the top of the food pyramid ( should consume the least amount of this food group)

13. These foods are usually bright in color and provide a lot of vitamins and minerals along with natural sugars

\section{Down}

Created using the Crossword Maker on TheTeachersCorner.net

1. These foods come out of the ground most of the time and are full of fiber and vitamins and minerals 2. This drink holds a lot of calcium and vitamin D (good for bone health)

5. This macronutrient is our body's main source of fuel (large quantities in pasta, rice, bread)

8. , Recommended amount of meals one should consume daily

10. A drink you should drink every day

12. Another word for salt (should not exceed RDA if you can help it 


\section{Basic Nutrition Crossword}

Name:

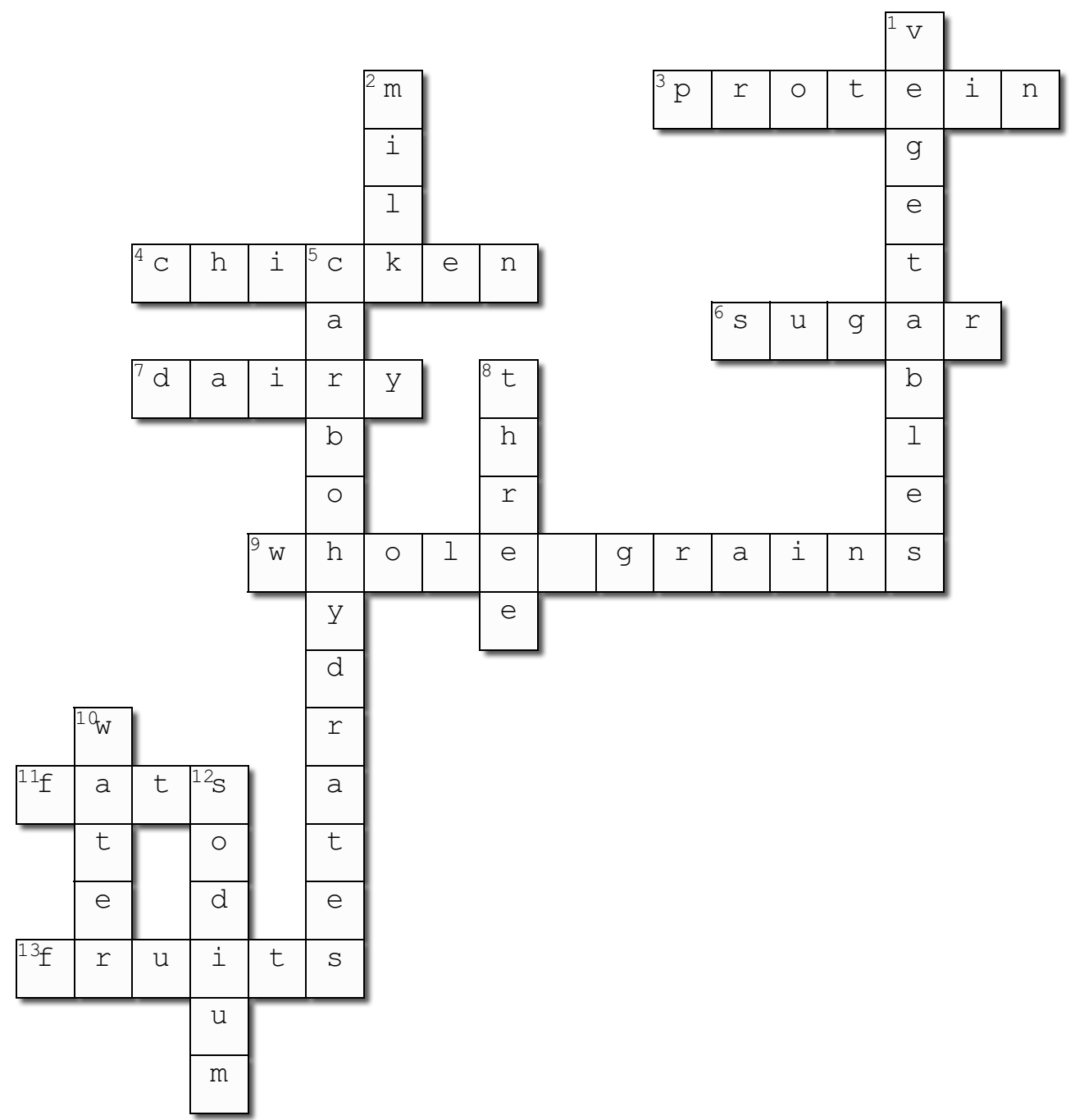

\section{Across}

3. This macronutrient helps build and repair muscles among many other functions (protein)

4. A good source of lean protein (type of poultry) (chicken)

6. , Beverages with should be limited and should only drink occasionally (sugar)

7. Cheese and milk fall into this food group (dairy) 9. These grains are the grains you should consume most of the time (whole grains)

11. This macronutrient is at the top of the food pyramid ( should consume the least amount of this food group) (fats)

13. These foods are usually bright in color and provide a lot of vitamins and minerals along with natural sugars (fruits)

\section{Down}

Created using the Crossword Maker on TheTeachersCorner.net

1. These foods come out of the ground most of the time and are full of fiber and vitamins and minerals (vegetables)

2. This drink holds a lot of calcium and vitamin $D$ (good for bone health) (milk)

5. This macronutrient is our body's main source of fuel (large quantities in pasta, rice, bread)

(carbohydrates)

8. , Recommended amount of meals one should consume daily (three)

10. A drink you should drink every day (water)

12. Another word for salt (should not exceed RDA if you can help it (sodium) 